Review Article

\title{
Organocatalysis: Key Trends in Green Synthetic Chemistry, Challenges, Scope towards Heterogenization, and Importance from Research and Industrial Point of View
}

\author{
Isak Rajjak Shaikh ${ }^{1,2,3}$ \\ ${ }^{1}$ Department of Chemistry, Shri Jagdishprasad Jhabarmal Tibrewala University, Vidyanagari, Jhunjhunu-Churu Road, \\ Chudela, Jhunjhunu District, Rajasthan 333001, India \\ ${ }^{2}$ Razak Institution of Skills, Education and Research (RISER), Shrinagar, Near Rafaiya Masjid and Hanuman Mandir, \\ Nanded, Maharashtra State 431 605, India \\ ${ }^{3}$ Post Graduate and Research Centre, Department of Chemistry, Poona College of Arts, Science and Commerce, Camp Area, \\ Pune 411 001, Maharashtra State, India
}

Correspondence should be addressed to Isak Rajjak Shaikh; isak@india.com

Received 26 September 2013; Revised 17 December 2013; Accepted 23 December 2013; Published 26 March 2014

Academic Editor: Sankaranarayana Pillai Shylesh

Copyright (C) 2014 Isak Rajjak Shaikh. This is an open access article distributed under the Creative Commons Attribution License, which permits unrestricted use, distribution, and reproduction in any medium, provided the original work is properly cited.

This paper purports to review catalysis, particularly the organocatalysis and its origin, key trends, challenges, examples, scope, and importance. The definition of organocatalyst corresponds to a low molecular weight organic molecule which in stoichiometric amounts catalyzes a chemical reaction. In this review, the use of the term heterogenized organocatalyst will be exclusively confined to a catalytic system containing an organic molecule immobilized onto some sort of support material and is responsible for accelerating a chemical reaction. Firstly, a brief description of the field is provided putting it in a green and sustainable perspective of chemistry. Next, research findings on the use of organocatalysts on various inorganic supports including nano(porous)materials, nanoparticles, silica, and zeolite/zeolitic materials are scrutinized in brief. Then future scope, research directions, and academic and industrial applications will be outlined. A succinct account will summarize some of the research and developments in the field. This review tries to bring many outstanding researches together and shows the vitality of the organocatalysis through several aspects.

\section{Introduction}

In 1987, the United Nations Commission on Environment and Development (Brundtland Commission) [1] defined "sustainable development" as the development that meets the needs of the present without compromising the ability of future generations to meet their own needs. Two of the key aspects of sustainable development from an energy and chemical perspective are to develop more renewable forms of energy and to reduce pollution. Chemistry during the twentieth century changed the living standard of human beings. Among the greatest achievements of chemistry are petrochemical and pharmaceutical industries. But these industries are often blamed for polluting environment. The challenge for the present-day chemical industry is to continue providing applications and socioeconomic benefits in an environmentally friendly manner.

Over the last few decades, green chemistry has been recognized as a culture and methodology for achieving sustainable development [2]. Green chemistry is chemistry able to promote innovative technologies that reduce or eliminate the use or generation of hazardous substances. Anastas and Warner defined the 12 principles of green chemistry (Figure 1) [3]. Catalysis (including enzyme catalysis, heterogeneous catalysis, and organocatalysis, in particular) is identified to be at the heart of greening of chemistry [4] because this branch of science is found to reduce the environmental impact of chemical processes [5]. 


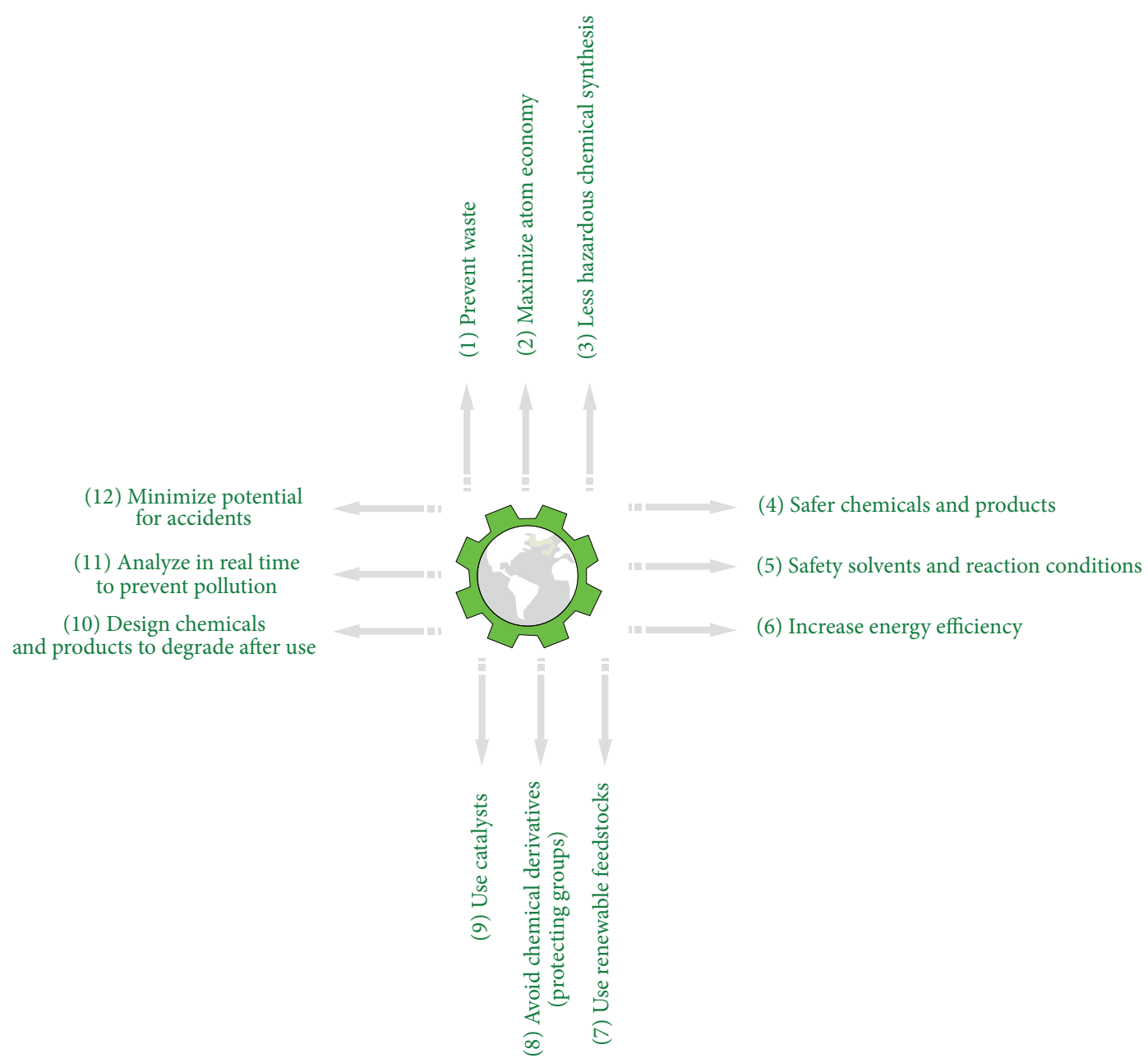

FIGURE 1: Inspired by the 12 principles of green chemistry, from [3].

\section{Catalysis: A Multidisciplinary Area of Chemistry}

Catalyst is one of the few conceptual words that have carried over broadly outside scientific language. Catalysis is a significant multidisciplinary area of chemistry. The term "catalysis" was first introduced in 1836 by Berzelius who tried to explain special powers of some chemical substances capable of influencing various decomposition and chemical transformations.

According to Ostwald [6], "a catalyst accelerates a chemical reaction without affecting the position of the equilibrium." A catalyst works by interacting with reactants, generating intermediates that react to give products. It affects the rate of approach to equilibrium of a reaction but not the position of the equilibrium (Figure 2). Most of the times, it also provides subtle control of chemical conversions, increasing the rate of a desired reaction pathway but not the rates of undesired side reactions (i.e., the selectivity of a chemical process).

Catalysts are usually classified according to structure, composition, area of application, or state of aggregation.

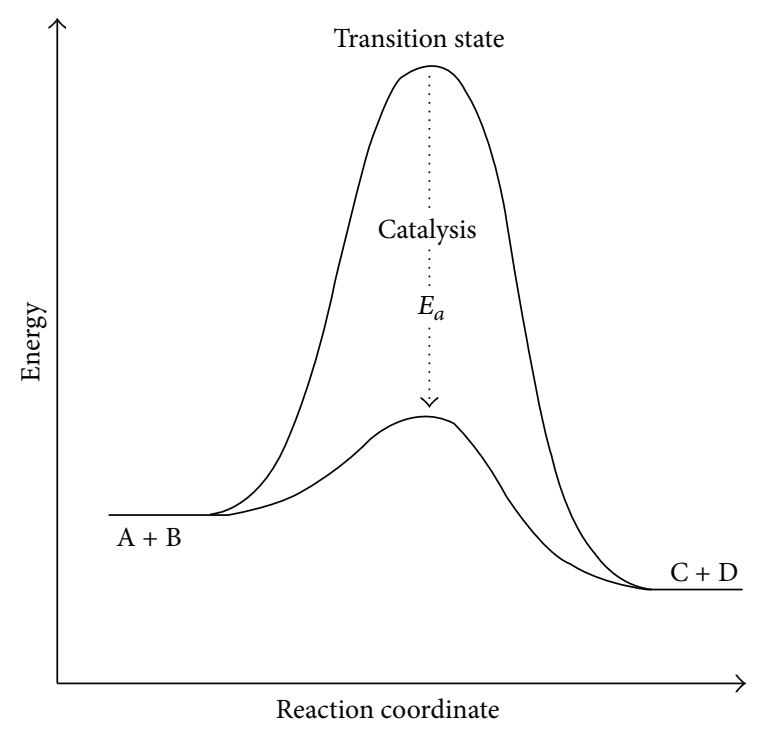

FIGURE 2: Schematic illustration of the effect of a catalyst on the transformation of $\mathrm{A}+\mathrm{B}$ into $\mathrm{C}+\mathrm{D}$. 
According to the state of aggregation in which the catalysts act, there are two main groups: homogeneous catalysts and heterogeneous catalysts. Homogeneous catalysts are welldefined chemical compounds or coordination complexes, which, together with the reactants, are molecularly dispersed in the reaction medium and carry out processes in a uniform gas or liquid phase. Heterogeneous catalysis takes place between different phases. Generally the catalyst is in solid state, and the reactants are gases or liquids. The immobilized catalysts obtained by attaching homogeneous catalysts to solid are in between. In supported catalysts the catalytically active substance is applied to a support material that has a large surface area and is usually porous. Arguments for and against shall always be made while discussing the merits and limitations of individual groups of catalysts for their respective applications in industries.

\section{Application of Catalysis}

Catalysis has played a pivotal role in the success of the chemistry industry in the twentieth century. More than $90 \%$ of chemical manufacturing processes in the world utilize catalysts $[7,8]$. Historically, the first industrially applied catalytic process was for the hydrogenation of oils and fats to produce margarine using finely divided nickel as catalyst. Thus, heterogeneous catalysis was applied first industrially. The issue of metal leaching and the avoidance of trace catalyst residues are very important from environmental health point of view. All the basic raw materials or building blocks for chemicals are manufactured by very important set of heterogeneous catalytic reactions (Table 1) [8]. Although catalysts are not consumed by the reaction itself, they may be inhibited, deactivated, or destroyed by secondary processes. The solid-state catalytic materials are the most important type of catalysts.

Implementation of "clean" and "green" chemical technology in industries may help address the problem of environmental degradation besides producing useful chemicals [9-12]. Some catalysts also present important technology in the prevention of emissions, for example, catalytic converter for automobiles. Keeping in mind the fragile ecosystem and the importance of preserving the environment, the heterogeneous catalysts are tested in the pollution abatement [13, 14 ] and to remove aqueous organic wastes, volatile organic compound, and vehicular primary emissions such as $\mathrm{CO}$, unburned hydrocarbon, NOx, and soot.

Heterogeneous catalysis which takes place between different phases has now grown into an important branch of science $[8-12,15]$. Exciting new opportunities are emerging in this field based on nanotechnology approaches. Hence, research efforts are being directed to develop chemistry of nanomaterials and their applications in catalysis for developing cost-effective, selective, energy sufficient, ecofriendly, and environmentally benign synthetic processes for industries. Though this involves a great scientific, economic, and technological challenge, it is essential to a sustainable and healthy way of life.

The petroleum and fine chemical and pharmaceutical industries mostly rely on catalysts to produce everything from natural gas/fuels to various commodities $[15,16]$. There are a variety of new challenges in creating alternative fuels, reducing harmful by-products in manufacturing, cleaning up the environment and preventing future pollution, dealing with the causes of global warming, and creating safe chemicals and pharmaceuticals. Thus, catalysts are needed to meet these challenges of health, safety, and environmental, energy-related, and economic issues, but their complexity and diversity demand an insight on the way catalysts are studied, designed, and used. This could come into reality only through the application of an interdisciplinary approach involving new methods for synthesizing and characterizing molecular and material systems. Research in heterogeneous catalysis demands the cooperation of scientists from analytical chemistry, solid-state chemistry, (nano)materials chemistry, physical chemistry, surface science, computational and theoretical chemistry, reaction kinetics and mechanisms, reaction engineering, and so forth. Opportunities to understand and predict how catalysts work at the atomic scale are now appearing, made possible by breakthroughs in the last decade in computation, measurement techniques, characterization, spectroscopy, and imaging and especially by new developments in surface-reactivity studies, model catalyst design, and evaluation [16, 17]. Surface science and spectroscopy has its prominent role in analysing surface reaction chemistry on the catalyst $[18,19]$.

Fermentation of sugar to ethanol and the conversion of ethanol to acetic acid catalyzed by enzymes were an example of catalysis in antiquity. Off late, enzymatic catalysis is considered as a separate branch of (biological) catalysis. It is the most recent branch widely included in many commercial applications [20,21]. Enzymes are also highly active under mild conditions such as temperature, pressure, and $\mathrm{pH}$, which make them easier to work with on a small scale, but are also more appealing on an industrial scale on a cost and efficiency basis. Another benefit is that reactions are preferentially carried out in aqueous media therefore providing a "greener" route. Not to forget, the development of water based organic transformations is also an area of rapidly growing importance in chemistry [22, 23].

The homogeneous catalysis prior to the recognition of the effects of heterogeneous catalysts started with the action of nitrous oxides in the lead chamber process. Although the fundamental processes for refining petroleum and its conversion to basic building blocks are based on heterogeneous catalysts, many important value-added products are manufactured by homogeneous catalytic processes (Table 2) [12]. Homogeneous catalysts have been well researched, since their catalytic centers can be relatively easily defined and understood, but difficulties in separation and catalyst regeneration prevent their wider use [12, 24-28]. The most widely used homogeneous catalysts are simple acids or bases which catalyze well-known reactions such as ester and amide hydrolysis or esterification. The market share of homogeneous catalysts is estimated to be only ca. $10-15 \%$. Many of the benefits of homogeneous catalysts, especially high selectivity, arise from tailored made catalysts involving transition metals (or lanthanides) and appropriate ligands. Such catalysts are inexpensive enough that they can be 
TABLE 1: List of some of the industrially applied reactions and catalysts.

\begin{tabular}{|c|c|c|}
\hline Reaction & Catalyst & Inventor (Year) \\
\hline Sulphuric acid (lead-chamber process) & $\mathrm{NO}_{x}$ & Clement, Desormes (1806) \\
\hline Chlorine production by $\mathrm{HCl}$ oxidation & $\mathrm{CuSO}_{4}$ & Deacon (1867) \\
\hline Nitric acid by $\mathrm{NH}_{3}$ oxidation & Pt, Rh nets & Ostwald (1906) \\
\hline Fat hardening & $\mathrm{Ni}$ & Normann (1907) \\
\hline Ammonia synthesis $\left(\mathrm{H}_{2}+\mathrm{N}_{2}\right)$ & $\mathrm{Fe}$ & $\begin{array}{c}\text { Mittach, Haber, Bosch (1908); } \\
\text { Production } 1913 \text { BASF }\end{array}$ \\
\hline Hydrogenation of coal to hydrocarbons & $\mathrm{Fe}, \mathrm{Mo}, \mathrm{Sn}$ & Bergius (1913); Pier (1927) \\
\hline Methanol synthesis from $\mathrm{Co} / \mathrm{H}_{2}$ & $\mathrm{Zno} / \mathrm{Cr}_{2} \mathrm{O}_{3}$ & Mittach (1923) \\
\hline Hydrocarbons from $\mathrm{CO} / \mathrm{H}_{2}$ (motor fuels) & $\mathrm{Fe}, \mathrm{Co}, \mathrm{Ni}$ & Fischer, Tropsch (1925) \\
\hline Alkylation of olefins to gasoline & $\mathrm{AlCl}_{3}$ & Pines (1932) \\
\hline Cracking of hydrocarbons & $\mathrm{Al}_{2} \mathrm{O}_{3} / \mathrm{SiO}_{2}$ & Houdry (1937) \\
\hline Cracking in a fluidized bed & Aluminosilicates & Lewis, Gilliland (1939) \\
\hline Ethylene polymerization at low pressure & Ti compounds & Ziegler, Natta (1954) \\
\hline Hydrogenation, isomerization, hydroformylation & Rh-, Ru complexes & Wilkinson (1964) \\
\hline \multirow{3}{*}{ Methanol carbonylation to acetic acid } & Co/iodide & BASF (1960); \\
\hline & Rh/iodide & Monsanto Co. (1966); \\
\hline & Iridium & BP Chemicals Ltd. (2000) \\
\hline Asymmetric hydrogenation & $\mathrm{Rh} /$ chiral phosphine & Knowles (1974) \\
\hline Three-way catalyst & $\mathrm{Pt}$, Rh/monolith & General Motors (1974) \\
\hline Methanol conversion to hydrocarbons & Zeolites & Mobil Chemical Co. (1975) \\
\hline Alpha-olefins from ethylene & $\mathrm{Ni} /$ chelate phosphine & Shell company (1977) \\
\hline Sharpless (epi) oxidation & TI/ROOH/Tartarate & May, Baker, Upjohn, ARCO (1981) \\
\hline Selective oxidations with $\mathrm{H}_{2} \mathrm{O}_{2}$ & TS-1 (titanium silicate) & Enichem (1983) \\
\hline Hydroformylation & Rh/phosphine & Rhone-Poulene-Ruhrchemie (1984) \\
\hline Polymerization of olefins & Zirconocene/MAO & Sinn, Kaminsky (1985) \\
\hline Selective catalytic reduction (SCR) & V, W, Ti oxides/monolith & 1986 \\
\hline
\end{tabular}

TABLE 2: Differences between homogeneous catalysts and heterogeneous catalysts.

\begin{tabular}{lc}
\hline Homogeneous catalysts & Heterogeneous catalysts \\
\hline Same phase as reaction medium & Solid phase \\
Difficult separation & Easily separable \\
No recyclability & Recyclability and regeneration \\
Often high rates of reaction & Low rates of reaction \\
No diffusion control & Diffusion control \\
Robust to poisoning & Poisoning, deactivation \\
High selectivity & Low selectivity \\
Short life & Long catalytic life \\
Mild conditions & Energy-consuming process \\
Well understood mechanism & Poor mechanistic understanding \\
\hline
\end{tabular}

neutralized, easily separated from organic materials, and disposed of. This contributes to the huge quantity of aqueous salt waste generated by industry. Organometallic catalysts are currently widely used in industry, but the search for improved efficiencies, enantioselectivities, or recycling is still a matter of intense researches [29-33]. It is true that homogeneously catalyzed processes such as hydroformylation, carbonylation, oxidation, hydrogenation, metathesis, and hydrocyanation contribute with millions of tons to the bulk chemicals, but on the other hand the progress of homogeneous catalysis is also going on with fine chemicals $[25,33]$. In spirit of that, the beginning of this century saw the renaissance of organocatalysis presenting an environmental advantage over metal based catalysts for stereoselective or asymmetric synthetic methodologies. The absence of metal in organocatalyst brings an undeniable advantage considering the principles of "green chemistry" and the economic point of view (Tables 3 and 4).

Understanding catalytic systems involve study of structure, state, and composition of catalysts and the phase in which they perform. And, for this, one needs to understand chemistry of molecules and materials useful as catalysts and or catalyst carriers.

\section{Materials for Catalysis}

The diversity of research field connected to the chemistry of materials is significant for their applications in many areas including adsorption, catalysis, electrochemistry, and surface science. Nanoparticles [34], metal oxide, and mixed metal oxides [35-38] prepared by simple methods are useful catalysts. Research involving metal-organic frameworks [39, 40], mesoporous silica [41-43], microporous or open-framework inorganic [44-46], and/or mesopore modified [47] materials 
TABLE 3: Comparison among organometallic catalysts, enzyme catalysts, and organocatalysts.

\begin{tabular}{lcc}
\hline Organometallic catalyst & Enzyme catalyst & Organocatalyst \\
\hline $\begin{array}{l}\text { Wide substrate scope; high catalytic } \\
\text { activity; involving tedious process; } \\
\text { potential heavy metal pollution }\end{array}$ & $\begin{array}{c}\text { Limited substrate scope; high } \\
\text { selectivity and catalytic activity; } \\
\text { usually single enantiomer }\end{array}$ & $\begin{array}{c}\text { Robust; inexpensive; readily available; nontoxic; inert toward } \\
\text { moisture and oxygen; method especially attractive for the } \\
\text { preparation of compound that do not tolerate metal contamination } \\
\text { (pharmaceutical products) }\end{array}$ \\
\hline
\end{tabular}

TABLE 4: Advantages and disadvantages of organocatalysts.

\begin{tabular}{lc}
\hline Advantages & \multicolumn{1}{c}{ Disadvantages } \\
\hline $\begin{array}{l}\text { Easy preparation or availability } \\
\text { Easy handling; inert towards moisture }\end{array}$ & High catalyst loading \\
(water) and air (oxygen) & Relatively premature field \\
Easy scale-up & \\
No metal contamination & \\
Easy screening & \\
Useful in complex (steric) reactions & \\
\hline
\end{tabular}

has steadily increased following the widespread utility of aluminosilicate zeolites [48-51], titanosilicates [52, 53], and aluminium phosphates $[54,55]$.

In industries, research endeavours are mainly devoted towards the study and development of zeolites or zeolitic materials with several attractive features such as catalytic active site(s), large surface area, zeolitic pore walls, and pore size control. The synthesis and characterization of the crystalline aluminosilicate materials with tunable meso-/microporosity and their strong acidity have potentially important technological implications for shapeselective catalytic reactions, ion exchange, and adsorption of organic compounds [56-58]. The pore diameters can be finely chosen, tuned, and utilized for exhibiting shape-selective catalysis depending on the molecular shape/size of organic reactant and product. The widespread interest has been developed in the zeolitic science towards the development and discovery of zeolites with desired characteristics since conventional zeolites lack fine tuning of their properties to acid/base and redox or bifunctional or multifunctional properties. Organic functionalization adds new catalytic functions to zeolites [59].

Zeolites are microporous crystalline aluminosilicates with unique properties used for many processes. Zeolites possess acid sites that are associated with the tetrahedral aluminium atoms in their framework, and therefore, the amount of acidity depends on the aluminium content of the zeolite. Zeolite acid catalysts have wide application in industrial processes. The introduction of Y-zeolites to replace amorphous silica-alumina in fluidized catalytic cracking (FCC) and in hydrocracking processes in the early 1960's was a breakthrough application in acid catalysis. With the ever increasing research efforts in this area leading to discoveries of new structures and modification schemes by academic and industrial laboratories, the potential of solid acids has evolved tremendously. However, with the exception of the ZSM-5, Mordenite, and to some extent Beta zeolite, very few of these structures have been applied in industrial processes to any significant extent. Yet one can account for relatively few applications to the huge number of new materials introduced. Notable examples are the reported uses of SAPOs in lube dewaxing and in natural gas to olefin technologies and MCM-22 in aromatics alkylation. The zeolite structures with large-pore/bimodal porosity and tunable acidity can be a remarkable benefit for catalytic processes in industries. Within industrial catalysis, there are constant innovation and changing approaches to provision of selective, economically viable, and environmentally benign processes.

Recently, enormous growth in the chemical diversity of inorganic materials with transition-metal incorporation in new compositional domains has also been explored due to their potential application in adsorption and catalysis. Inorganic polymers, transition metal phosphates, and metalorganic frameworks $[39,40]$ with novel catalytic, electronic, magnetic, and unique structural properties are particularly promising candidates [60-64]. The mesoporous structure with strong acidity can be a remarkable benefit for catalytic reactions involving large organic molecules, in which diffusion constraints and/or adsorption of reactant molecules onto the strong acid sites are the main concern. A lot has been reported about the pathways to develop mesostructured silica [65]. In terms of surface functionalization, the performance of mesoporous silica has been polished by several methods such as metal incorporation [66], metal deposition [67], grafting by organic functional groups [68], and immobilizing metal complex [69]. New approaches to synthesis and characterization of bimodal, that is, micro-mesoporous and or meso-macroporous materials might assist us in understanding the phenomena of diffusion, confinement effects, selectivity, and so forth [47].

\section{Organocatalysis: A Novel Synthetic Philosophy}

The term "organocatalyst" is a concatenation of the words "organic" and "catalyst." The definition corresponds to a low molecular weight organic molecule which in substoichiometric amounts catalyzes a chemical reaction. The organocatalyst could be achiral or chiral and could be composed of $\mathrm{C}$, $\mathrm{H}, \mathrm{N}, \mathrm{S}$, and P. Organocatalysis has several advantages not only because of its synthetic range but also for the economic reasons. The absence of metal in organocatalyst brings an undeniable advantage considering both the principles of "green chemistry" and the economic point of view (Figure 3).

Nowadays organocatalysis is one of the hot research topics in advanced organic chemistry. It is a novel synthetic philosophy and mostly an alternative to the prevalent 


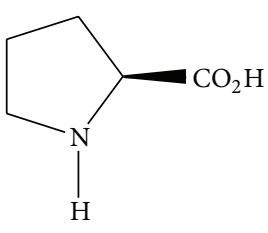

L-Proline<smiles>C[N+](C)c1ccncc1</smiles>

DMAP

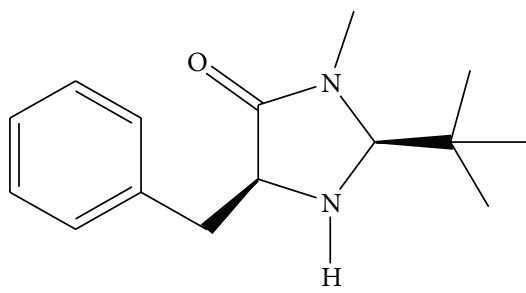

MacMillan's catalyst<smiles>Nc1ccc2c(c1-c1c(O)ccc3ccccc13)C[C@H]1C=C[C@H]2C=C1</smiles><smiles>COc1ccc2nccc([C@@H](O)C3C4C=CC3NCC4)c2c1</smiles>

FIgURE 3: Few famous examples of organocatalysts: L-proline, DMAP, quinine, and MacMillan's catalyst.

transition metal catalysis. Organocatalysts are often based on nontoxic organic compounds originating from biological materials. Organocatalysts can be Lewis bases, Lewis acids, Brønsted bases, and Brønsted acids. Most of the organocatalysis reported so far are explained by Lewis base mechanism. The Lewis base mechanism can be simplified as follows.

Step I: Lewis base, for example, cinchona alkaloid, initiates catalysis via a nucleophilic addition to, or deprotonation of, the substrate.

Step II: the chiral intermediate undergoes reaction.

Step III: separation of product(s) from the catalyst occurs.

Step IV: regeneration of the catalyst and its availability for a new catalytic cycle occurs.

There are many organocatalytic reactions that need a second mechanism to explain the catalytic cycle involved. This is called bifunctional organocatalysis in which the organocatalyst possesses not only a Lewis base (nitrogen or phosphorus atom) but also a Brønsted acidic site. There is a lot to be done in redox catalysis and in exploitation of the synergetic effect of different catalytic active sites within one organic compound or material.

Some advantages of organocatalysts include the following.

(i) Reactions performed by organocatalysts have potential application in large scale production in industries.

(ii) Scope: organic reactions occur which are not in practice and not possible by other forms of catalysts, for example, asymmetric synthetic processes. (iii) Price/Availability: Low cost; alkaloids, natural amino acids, L-proline, tartaric acid, and so forth are easily available and are economically attractive.

(iv) Recycling issues: immobilization of the catalyst is the simplest way to recover it.

(v) Some of the examples include bioderived and biodegradable organocatalysts.

(vi) Organocatalysts work at mild reaction conditions.

(vii) Sometimes the final products of reactions contain high levels of metal contamination derived from catalyst degradation phenomena, which pose a serious drawback if the metal is toxic for pharmaceutical and food industries. Absence of transition-metal brings organocatalysis at the heart of greening chemistry.

Organocatalysis can be categorized into our different types as follows.

Type-I: activation of the reaction based on the nucleophilic/electrophilic properties of the catalyst is done (Scheme 1).

Type-II: organic molecules form reactive intermediates. The chiral catalyst is consumed in the reaction and requires regeneration in parallel catalytic cycle as it is reported in Scheme 2.

Type-III: phase transfer reactions occur. The chiral catalyst forms a host-guest complex with the substrate and shuttles between the standard organic solvent and a second phase. 


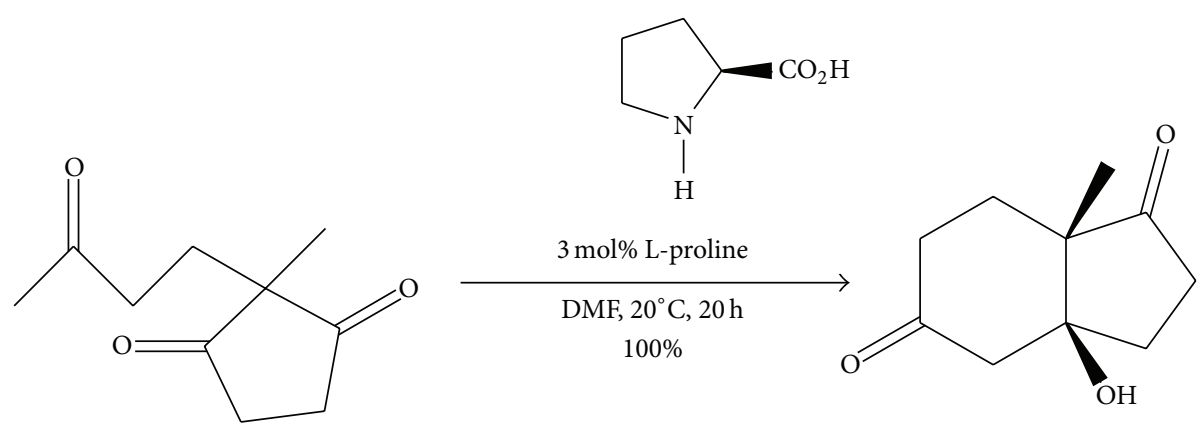

Scheme 1: Hajos and Parrish [70].

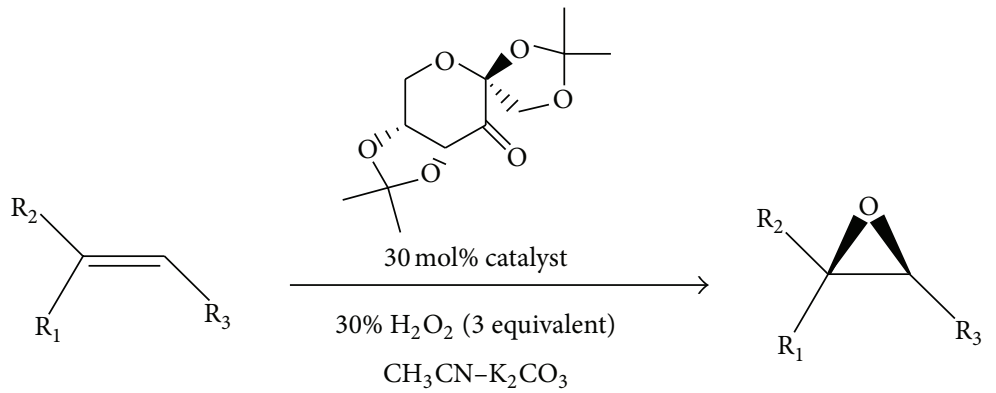

SCHEME 2: Shu and Shi [71].

Catalytic enantioselective enolate alkylation (Scheme 3) occurs

Type-IV: molecular-cavity-accelerated asymmetric transformations occur in which the catalyst may select from competing substrates, depending on size and structure criteria (Scheme 4).

\section{Discovery and the History of Organocatalysis}

Liebig's synthesis of oxamide from dicyan and water is the first organocatalytic reaction reported [74]. Acetaldehyde was further identified to behave as the then-named "ferment," now called as enzyme. Dakin in 1909 demonstrated that in a Knoevenagel type condensation between aldehydes and carboxylic acids or esters with active methylene groups, the amine catalysts could be mediated by amino acids [75]. Langenbeck is remembered for developing enamine type reactions and the application of simple amino acids and small oligopeptides as catalysts [76-78]. Natural products, in particular, strychnine, brucine, and cinchona alkaloids and amino acids (including short oligopeptides), were among the first organic catalysts tested $[79,80]$. Though the field of small-molecule catalysts seems very simple, there are evidences that prove their pivotal role in synthesis of building blocks for life. L-Alanine and L-isovaline capable of catalyzing certain $\mathrm{C}-\mathrm{C}$ bond formation reactions had been found on meteorites [81].

An asymmetric transformation with an organic molecule was published in 1912 by Bredig and Fiske [82]. Pracejus applied cinchona alkaloids in the asymmetric conversion of ketenes to (S)-methyl hydratropate [83, 84]. An initial research by Yamada \& Otani was important, too [85]. The seventies brought another milestone; Hajos and Parrish reported a L-proline catalyzed Robinson annulation in excellent enantioselectivities [70, 86, 87]. Eder et al. reported organocatalytic aldol reactions in good enantioselectivities [88]. To summarize, in 1970s, Hajos and Parrish and, independently, Eder, Sauer, and Wiechert published a series of papers and patents involving such organocatalytic transformations. The asymmetric synthesis of enediones, useful building blocks in natural product total syntheses, was achieved. (S)-Proline induced the formation of (S)-enediones.

Two mechanisms [89] were proposed: (1) involving the formation of a carbinolamine intermediate, followed by the displacement of the proline moiety by nucleophilic attack of the enol from the side chain ketone; (2) involving an enaminium intermediate acting as a nucleophile in the $\mathrm{C}-\mathrm{C}$ bond formation with concomitant $\mathrm{NH}$... O hydrogen transfer. Wynberg firstly published various 1,2 and 1,4 additions catalyzed by cinchona bifunctional organocatalysis [90-92]. 


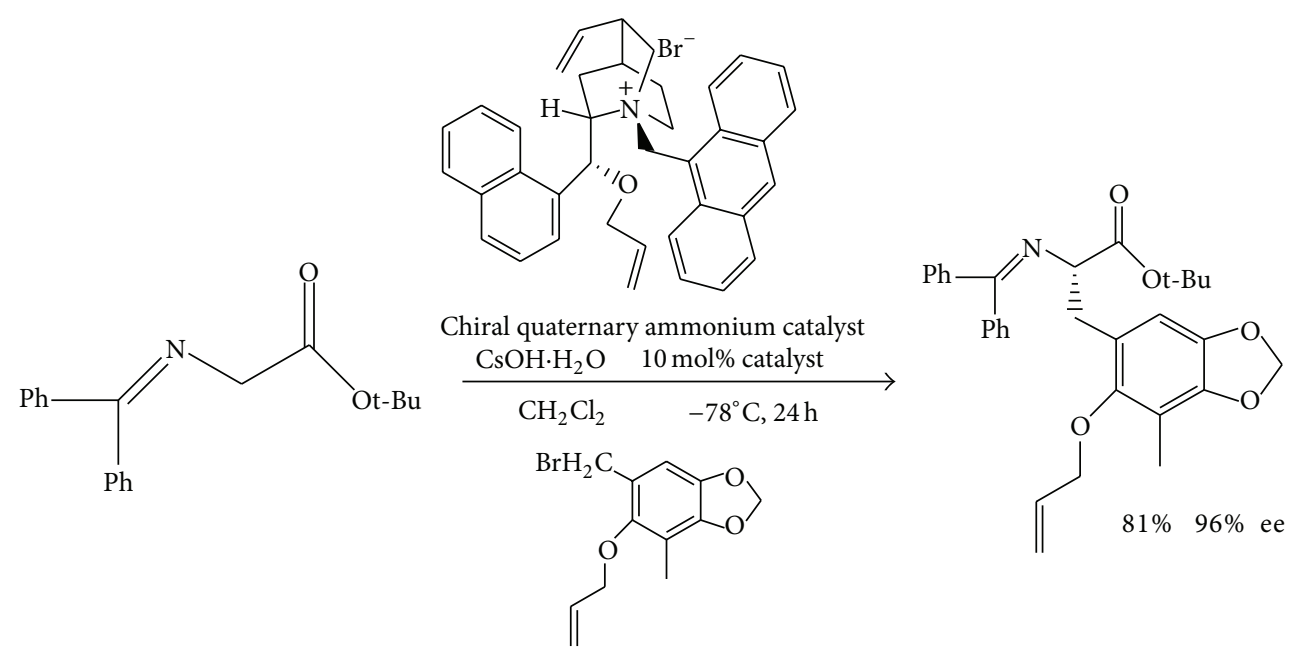

Scheme 3: Corey et al. [72].

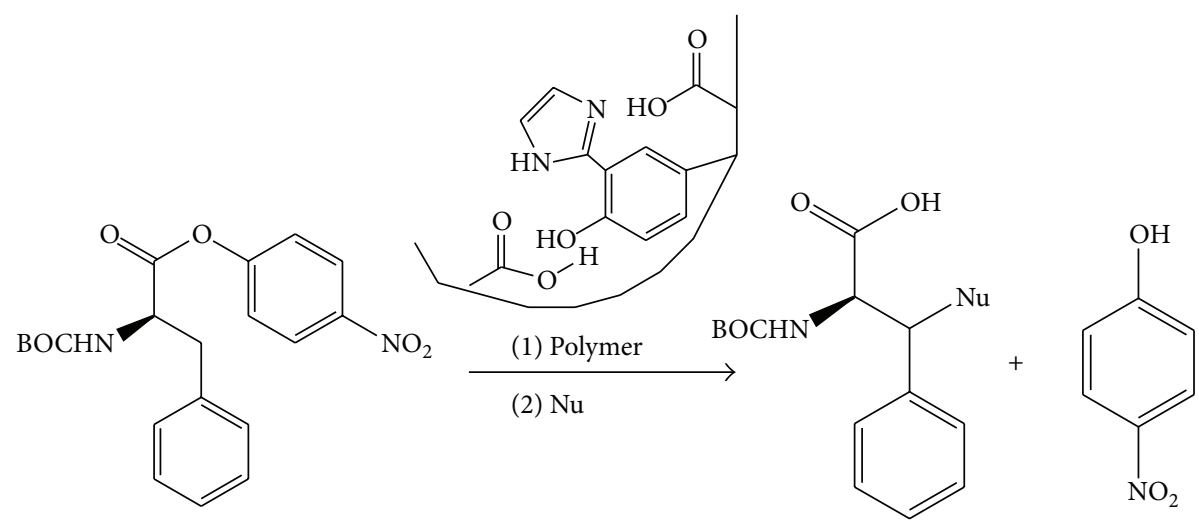

Scheme 4: Sellergren et al. [73].

All these research endeavours were not carefully looked into till List et al. reported in 2000 proline catalyzed aldol reaction in good enantiomeric excesses $[93,94]$.

Asymmetric catalysis constitutes one of the most important subjects in synthetic organic chemistry. Asymmetric synthesis achieving atom economy is a challenge for organic synthesis and homogeneous catalysis using metal complexes leads the way. But the application of such methodologies in chemical industry is rather limited due to the high cost of chiral ligands and noble metals used in such transformations. Moreover, the pharmaceutical entities and food industry products do not tolerate a contamination, of even traces, of any such metals for that matter. Synthesis of chiral drugs has a major financial impact in pharmaceutical industries on a global scale. Different enantiomers or diastereomers of a molecule often have different biological activity. Most of the drugs might be soon sold as single enantiomers in the coming years. There is a huge demand for organocatalysts leading to $100 \%$ yield, $100 \%$ ee, of the desired product. The need from chemical industry, especially pharmaceutical, for reliable asymmetric transformations of molecular skeletons is higher than ever. Therefore, asymmetric organocatalysis is in a process of attaining maturity into a very powerful, practical, and broadly applicable methodological approach in the catalytic asymmetric synthesis.

\section{Some Examples and Developments in Catalyst Structural Variants}

Following are the famous examples of organocatalysts.

7.1. Proline and Derivatives. The proline catalyzed Robinson annulation was one of the earliest examples of an enantioselective reaction using an organic catalyst [85]. This amino acid contains both a nucleophilic secondary amino group and a carboxylic acid moiety functioning as a Brønsted acid. The availability of proline in both enantiomeric forms brings advantages over enzymatic methods. Arguably, the first example of proline catalyzed asymmetric aldol reaction is reported by Hajos and Parrish [70, 86, 87]. The WielandMiescher ketone is a useful synthetic building block for which a classical asymmetric procedure using ( $\mathrm{S}$ )-proline was published forty years ago [88]. It is quite significant that the first efficient organocatalyzed asymmetric reactions were described by Hajos \& Parrish [86, 87] and by Eder et al. [88], 
both teams from pharmaceutical companies (Hoffmannla-Roche and Schering). The asymmetric synthesis of the Wieland-Miescher ketone is also based on proline and another early application was one of the transformations in the total synthesis of erythromycin by Woodward et al. [95]. Proline is recognized as a versatile organocatalyst of these times (Scheme 5).

In fact, the renewal of proline catalyzed transformations in early 2000 by D. W. C. MacMillan, Carlos F. Barbas III, and Benjamin List saw the renaissance of the concept and it was the starting point of the word "organocatalysis." Professor Ahrendt group reported the first enantioselective organocatalytic Diels-Alder reaction [96]. Proline was identified as an effective organocatalyst for asymmetric aldol reaction [97]. The catalytic asymmetric $\alpha$-alkylation of aldehydes was reported by Vignola and List [98]. This transformation had been accomplished with the help of covalently attached auxiliaries. $\alpha$-Methyl L-proline exhibits higher enantioselectivities and improved reaction rates when compared to Lproline. In recent years, proline, especially L-proline, has been used to catalyze essential transformations used in the fine chemical and pharmaceutical industries, such as the direct asymmetric aldol reactions [99-107], Diels-Alder reactions, Michael reactions [108-115], Mannich reaction [116122], Multicomponent reactions [123, 124], and $\alpha$-amination [125], $\alpha$-aminoxylation [126-128], $\alpha$-oxyaldehyde dimerization [100], $\alpha$-functionalization of carbonyl compounds [129], and $\alpha$-alkylation of aldehydes [130]. Organocatalytic cyclopropanation reactions were typically performed using catalyst-bound ylides. However, Kunz and MacMillan demonstrated that activation of olefin substrates using catalytic $(S)-(-)$-indoline-2-carboxylic acid is a viable route for the formation of highly enantioenriched cyclopropanes [131].

Prof. K. A. Jørgensen has made an important breakthrough in asymmetric synthesis by developing $(R)$ and (S)- $\alpha, \alpha$-bis[3,5-bis(trifluoromethyl)phenyl]-2-pyrrolidinemethanol trimethylsilyl ether as excellent chiral organocatalysts in the direct organocatalytic $\alpha$-functionalization of aldehydes. Diarylprolinol silyl ether reagents were found to catalyze $\mathrm{C}-\mathrm{C}, \mathrm{C}-\mathrm{N}, \mathrm{C}-\mathrm{O}, \mathrm{C}-\mathrm{S}$, and $\mathrm{C}-\mathrm{Hal}$ bond forming reactions [132-138]. Cascade or domino reactions swiftly construct complex biologically important compounds and minimize waste and also the laboratory operations [139]. Enders' group developed proline derived organocatalyst for a chemo-, diastereo-, and enantioselective three-component domino reaction to yield tetrasubstituted cyclohexene carbaldehydes [140]. The four stereogenic centers are generated in three consecutive $\mathrm{C}-\mathrm{C}$ bond formations, that is, Michael/Michael/aldol condensation with high diastereoand complete enantiocontrol. The synthesis of polyfunctional cyclohexene building blocks involving proline catalytic steps is reported in this domino reaction.

Though this segment of our review is dedicated to proline as an important class of organocatalysts, it would also be a good place to acknowledge the research contributions from professor Ahrendt et al. to the field of organocatalysis $[96,99$, $100,103,127,131,141-150]$.
Heterogenized Proline. An explosion of research articles in the area of homogeneous organocatalysis occurred within the last decade or so. In addition to the initial proline catalyzed reactions, the word "organocatalysis" covers nowadays many other well-known organocatalysts and organic reactions. Proline immobilized onto some sort of inorganic support paves the way towards heterogenization of other organocatalysts [151-153]. A simple and efficient synthesis of polystyrenesupported proline and prolinamide is reported. Polystyrenesupported proline catalyzes the asymmetric aldol reaction between cyclohexanone and substituted benzaldehydes in water. High yields, diastereoselectivities, and ee values have been observed. The versatility of this resin was also confirmed by selenenylation of aldehydes. Both proline and prolinamide resins gave high yields. Recycling studies showed that the proline resin performs as better heterogeneous organocatalyst as compared to the prolinamide resin [153]. An aldol reaction catalyzed by proline functionalized silica gel was investigated in continuous flow microreactors by reactionprogress kinetic analysis and nonlinear chromatography [154].

Though the research community advocates asymmetric synthesis for industrial application, organocatalysts have been seldom applied in industry, due to insufficient efficiency and the difficulties in catalyst separation and recycling [155-161]. The concept of heterogenizing organocatalyst on supports combines the advantages of both homogeneous organocatalysis and heterogeneous recycling. Though this might seem simple and present opportunities in industrial chemical processes, the research in heterogeneous organocatalysis demands a multidisciplinary approach by identifying catalytic activity upon bonding organocatalyst covalently to the support; understanding noncovalent interaction as structure-reactivity and conformation deciding factor; taking into consideration the characteristic properties of the supports, confinement effects, if any, and so forth. Some recent examples will be described on the applications of supported proline as organocatalysts for their preindustrialization study. The latter half of this review, in general, irons out the detailed discussion on key trends with examples, scope, challenges, and "green" applications of heterogeneous organocatalysts.

7.2. Other Amino Acids. Barbas and coworkers found the proteinogenic amino acid tryptophan (Figure 4) to be an excellent organocatalyst for the Mannich reaction of hydroxyacetone with a variety of imines performed in DMF leading the desired anti-amino alcohols in excellent diastereoselectivities (up to $>19: 1$ ) and enantioselectivities (90-98\% ee). Similarly, $t$-butyl protected threonine catalyzed the aldol reaction of hydroxyacetone and various aldehydes in NMP to give the corresponding syn-aldol adducts in high yields and good to excellent enantio- and diastereoselectivities [162]. Zhao et al. reported [163] the development of an amino acid based small molecule capable of promoting asymmetric monosilylation of meso-1,2-diols. Furthermore, the catalyst can be recycled with equal efficiency. Three-component reaction involving condensation of aldehyde, 1,3-carbonyl 


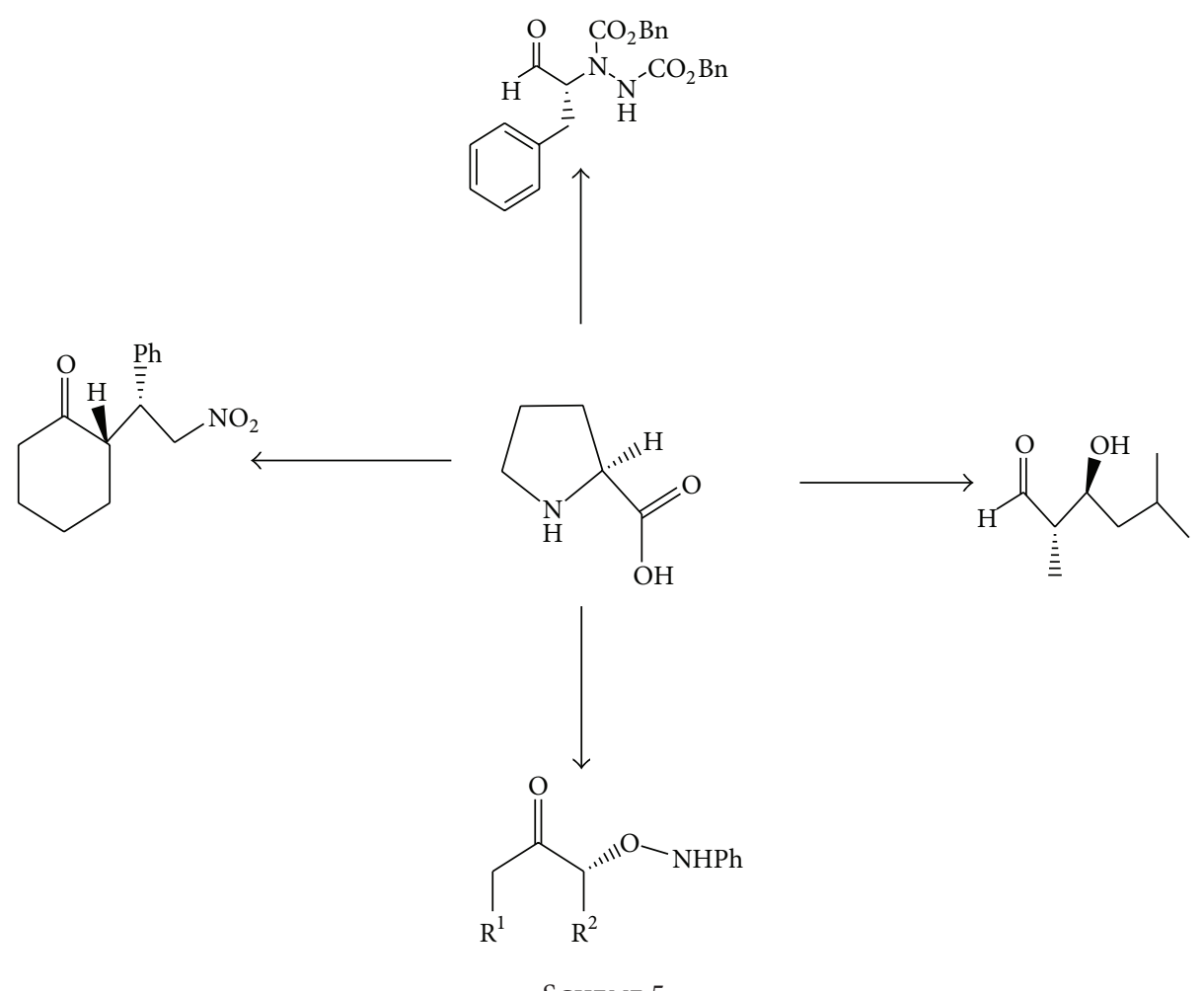

SCHEME 5<smiles>N[C@@H](Cc1c[nH]c2ccccc12)C(=O)O</smiles>

FIGURE 4: L-Tryptophan.

compound, and (thio)urea is known as Biginelli reaction. Various organocatalysts such as tartaric acid, oxalic acid, citric acid, and lactic acid were found effective in producing Biginelli products [164-172].

Because of the "privileged" green nature of this field, it has become an obligation for scientific community and academic institutions to be mindful and teach this branch of catalysis to students and also keep it as a driving force in the generation and dissemination of knowledge in pursuit of efficient synthetic methodologies and processes using organocatalysts. The synthesis of new chiral building blocks or complex molecular structures involving organocatalytic $\operatorname{step}(\mathrm{s})$ is being reported almost every day in scientific literature. As it is not possible here to discuss all the catalysts individually in detail, the author decides to present salient developments in organocatalysis and allied research areas.

Synthesis of prochiral cyclohexanones by amine catalyzed self-Diels-Alder reactions of $\alpha, \beta$-unsaturated ketones in water brought coupled the concept of green chemistry with catalysis. Useful asymmetric heterodomino reactions for the highly diastereoselective synthesis of symmetrical and nonsymmetrical synthons of benzoannelated centropolyquinanes were reported $[173,174]$.

In recent years, trials are being made by using amino acids, especially L-proline, to catalyze essential transformations in the fine chemical and pharmaceutical industries. The interest in this field has thus increased spectacularly in the last few years. However, organocatalytic methods often require catalyst loadings as high as $30 \mathrm{~mol} \%$ for the achievement of high conversions in reasonable reaction times [175]. Some critics suggest that low turnover numbers might limit the potential uses of organocatalysis for industrial applications. Process development and scale-up are being tested for several organocatalytic reactions confirming organocatalysis as a valuable tool for industrial scale solutions. Scientists are reporting novel organocatalytic systems in various reputed international research journals and those catalysts exhibit various valuable functions derived from a variety of structural, ionic/electronic, and chemical properties. Broad variety of efficient syntheses will contribute to an increasing number of organocatalytic large scale reactions in the future. The organocatalysts shall be used in various fields, especially in asymmetric organic synthesis.

7.3. Amine and Chiral Vicinal Diamines. Proline and pyrrolidine derivatives, commonly known as Hayashi-Jørgensen catalysts, in the form of ferrocenyl pyrrolidine, are applied as organocatalyst wherein the ferrocene moiety controls the conformational space and a simple alkyl group effectively covers a face of the derived enamine (Figure 5) [180]. 


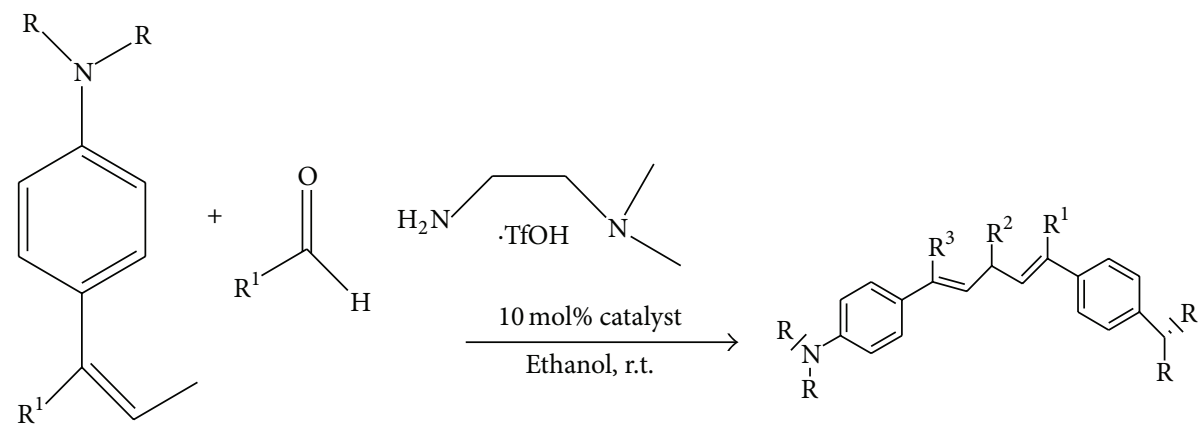

SCHEME 6

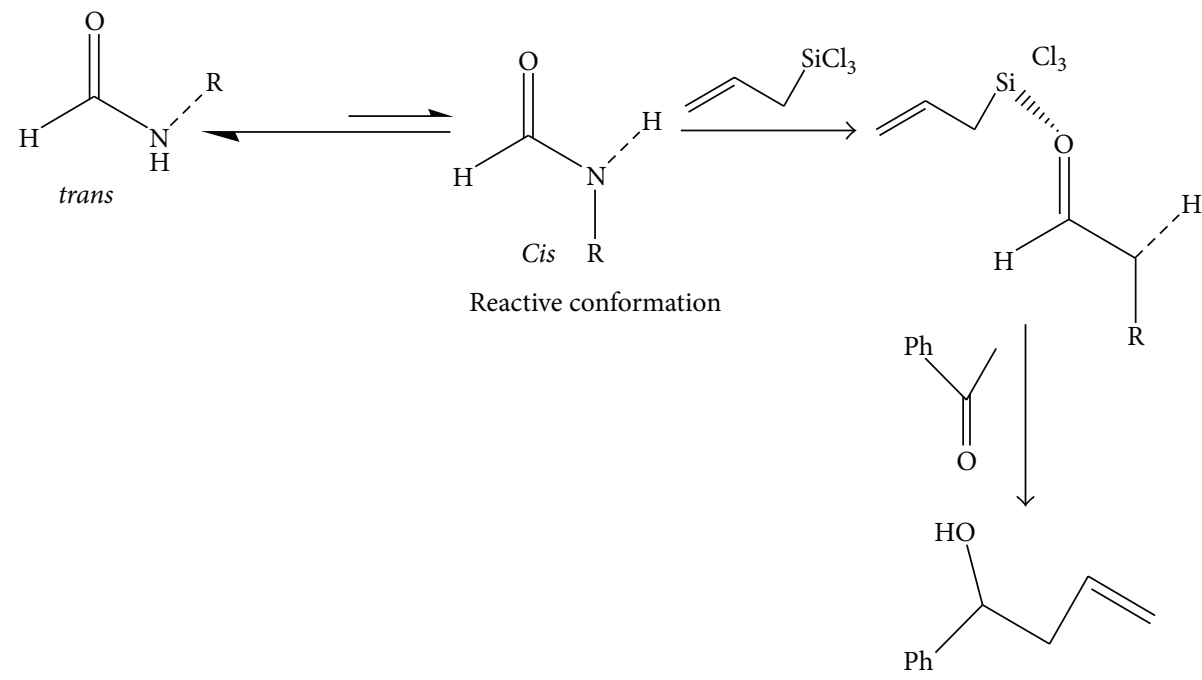

SCHEMe 7

Sulzer-Mossé and Alexakis reported chiral amines catalyzing asymmetric conjugate addition to nitroolefins and vinyl sulfones via enamine activation [181].

A bifunctional $\mathrm{H}$-bond directing aminocatalytic system is found to achieve high stereo- and regiocontrol over dienamine mediated hetero-Diels-Alder reaction [183].

Though amine catalysis is constructing a wide variety of chiral scaffolds in asymmetric synthesis, organocatalysis with amines for nonasymmetric transformations is also developing very fast $[184,185]$. The $[2+2]$ cycloaddition of enals with nitroalkenes is catalyzed by a chiral secondary amine in the presence of an achiral thiourea for the enantioand diastereoselective synthesis of highly functionalized cyclobutanes. Mechanistically, two consecutive Michael reactions proceed through an unprecedented combination of dienamine/iminium activation mode [186]. The reaction engineering of dienamine catalysis for single-step syntheses of highly functionalized molecules such as natural products or bioactive compounds is reviewed in literature [187].

Chin and coworkers have recently reported some preliminary theoretical and experimental studies for converting a parent diamine into other chiral vicinal diamines. These diamines can be handy as ligands for chiral catalysts or they can make chiral heterocyclic rings and betalactams [188-190].
There are some $\mathrm{C}-\mathrm{C}$ bonds forming reactions catalyzed by such diamine organocatalysts (Scheme 6) [191].

7.4. Amides. Recently, the synthesis of multifunctional organocatalysts, easily obtained by the condensation of $(S)$ proline with 2-aminopyridine, 2,6-diaminopyridine, or 2aminoimidazole, is reported. These chiral prolinamides promoted the aldol condensation between cyclohexanone and different aromatic aldehydes (up to $98 \%$ ee) and also catalyzed Diels-Alder and Michael reactions [192, 193].

Rationally designed pyrazole amides function as Michael donors in urea catalyzed asymmetric Michael reactions with excellent chemical and optical yields [194].

A structure-activity relationship with regard to formamides as organocatalysts is explored. This study highlights that the cis-conformation of secondary formamides is the reactive conformation in the allylation of aldehydes with allyltrichlorosilane (Scheme 7) [195].

7.5. Imidazolidinones. A certain class of imidazolidinone compounds (also called MacMillan imidazolidinone organocatalysts) function as catalysts for many asymmetric organic transformations such as asymmetric Diels-Alder reactions. 


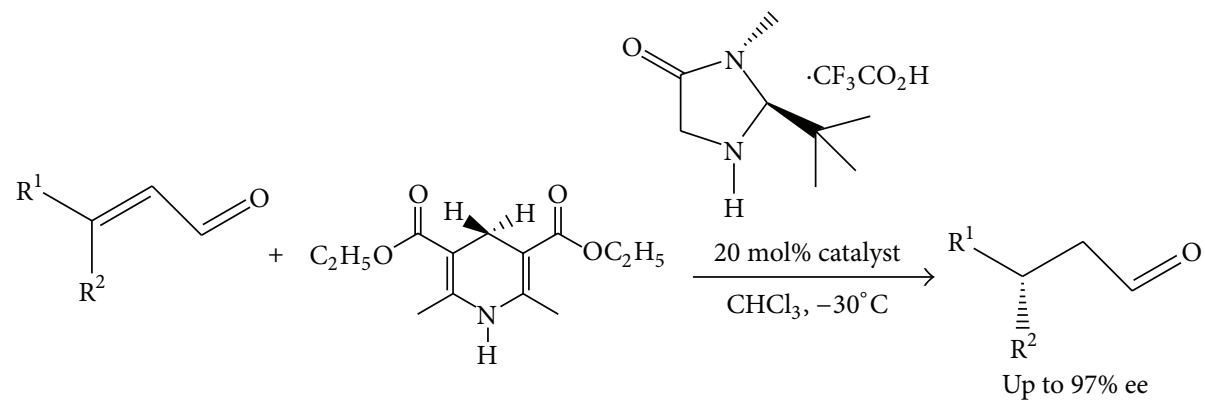

Scheme 8: Ouellet et al. [202].

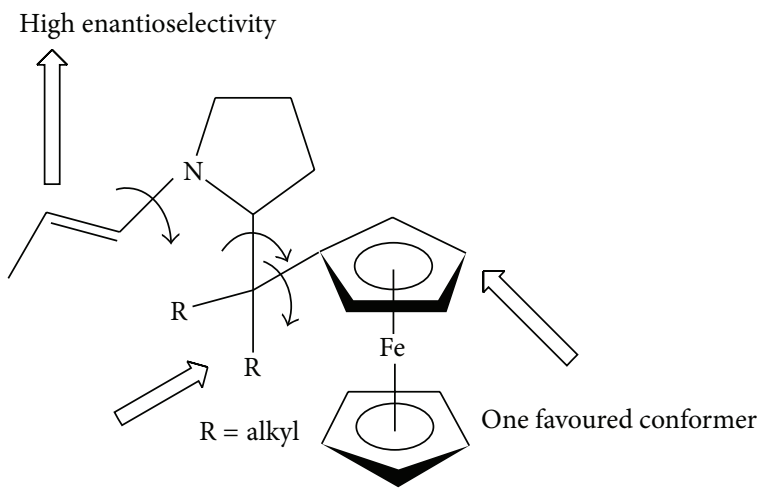

FIGURE 5

The original such compound was derived from the chiral biomolecule phenylalanine [196, 197]. The first highly enantioselective organocatalytic Diels-Alder reaction using a chiral organocatalyst was reported in MacMillan's pioneering work where the activated iminium ion, formed through condensation of the imidazolidinone and an $\alpha, \beta$ unsaturated aldehyde, reacted with various dienes to give $[4+2]$ cycloadducts in excellent yields and enantioselectivities. Ahrendt et al. reported many other asymmetric reactions such as the 1,3-dipolar cycloadditions, Friedel-Crafts alkylations, $\alpha$-chlorinations, $\alpha$-fluorinations, and intramolecular Michael reactions using MacMillan's organocatalysts [96, 150, 198-201].

Ouellet et al. also reported the combination of imidazolidinone organocatalyst and Hantzsch ester to facilitate the first enantioselective organocatalytic hydride reduction of $\alpha, \beta$-unsaturated aldehydes (Scheme 8) [202, 203]. This imitated nature's stereoselective enzymatic transfer hydrogenation with NADH cofactor.

Noncovalent interaction is a structure-reactivity and conformation deciding factor which requires immediate attention for understanding organocatalysis [204]. Of special interest would be the identifying and understanding of other noncovalent interactions such as charge transfer [205], pp stacking immobilization [206], and adsorption or entrapment of organocatalysts in nanomaterials [207].
Homogeneous and Heterogenized MacMillan's Organocatalyst. An asymmetric Diels-Alder reaction was catalyzed with high efficiency and recyclability by a soluble, "self-supported" chiral organosilica polymer with embedded imidazolidinone catalytic moieties [208].

7.6. Chiral Phosphoric Acids. BINOL derived phosphoric acids catalyze nucleophilic addition reactions to imine substrates. A direct Pictet-Spengler reaction was reported using a geminally disubstituted tryptamine organocatalyst to form isoquinolines in excellent yield and enantiomeric excess [209]. Phosphoric acid catalyzing the reduction of an imine with a Hantzsch ester in good enantiomeric excess was firstly reported by Rueping et al. Hoffmann et al. reported an improvement to this methodology [210, 211].

Storer research group reported a one-pot reductive amination of a range of methyl ketones and aryl amines [212]. Reductive amination of 2-butanone over silylated phosphoric acid MacMillan TiPSY catalyst was obtained with good enantiomeric excess.

Zhou and List published on the use of chiral Brønsted acid (R)-TRIP for highly enantioselective synthesis of pharmaceutically relevant 3 -substituted cyclohexylamines from 2,6-diketones wherein the achiral amine substrate accelerates the cascade reaction before getting incorporated into the final product (Scheme 9) [213].

Rowland et al. reported VAPOL derived phosphoric acid catalyzed addition of sulfonamides to BOC protected aryl imines and protected aminals in excellent enantioselectivities [214].

The (R)-TRIP catalyzed the aza-Diels-Alder reaction of aldimines with Danishefsky's diene to yield piperidinone derivatives with high enantioselectivity. Addition of acetic acid was found to improve both reactivity and enantioselectivity [215]. Six chemical bonds, five stereogenic centers, and three cycles were formed in one-pot four-component Ugi type reaction catalyzed by a chiral BINOL derived phosphoric acid [216]. BINAP is one of the earliy commercially applied ligands in industrial catalysis [217]. A microporous recyclable heterogeneous catalyst, offering excellent enantioselectivity, was made from a $1,1^{\prime}$-binaphthalene-2,2' -diol (binol) derived phosphoric acid chloride and was found as active as the corresponding homogeneous catalyst [218]. 


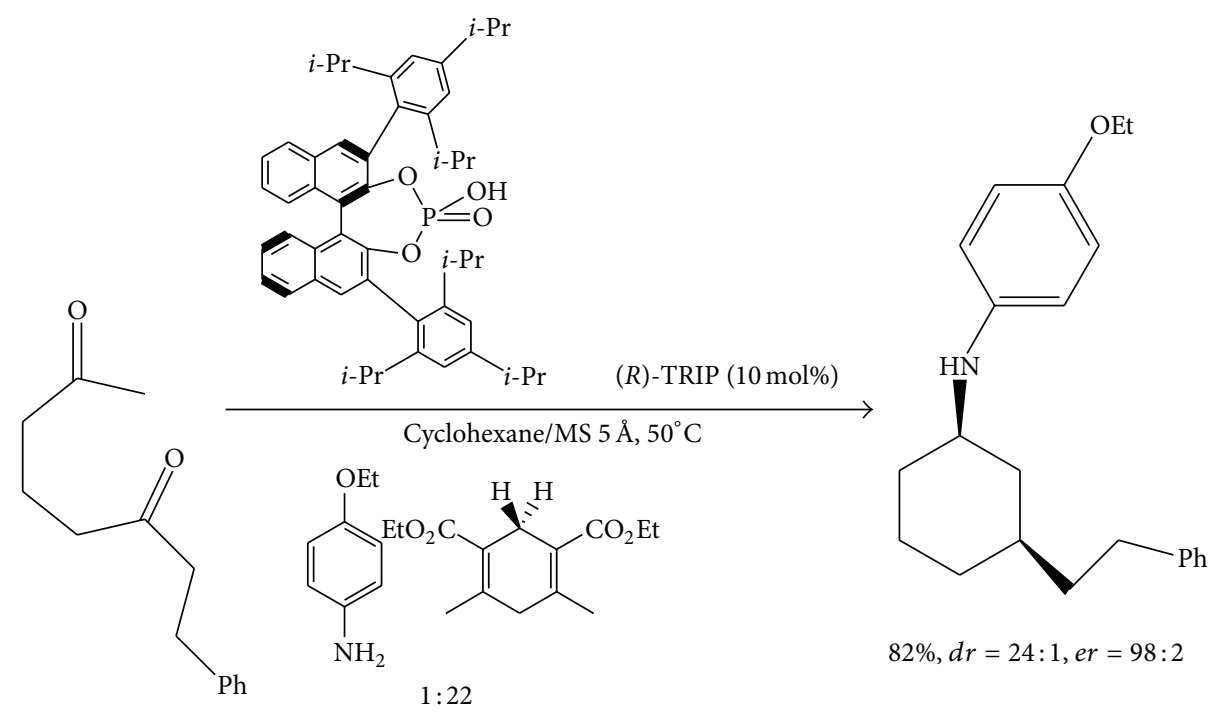

Scheme 9: Zhou and List [213].

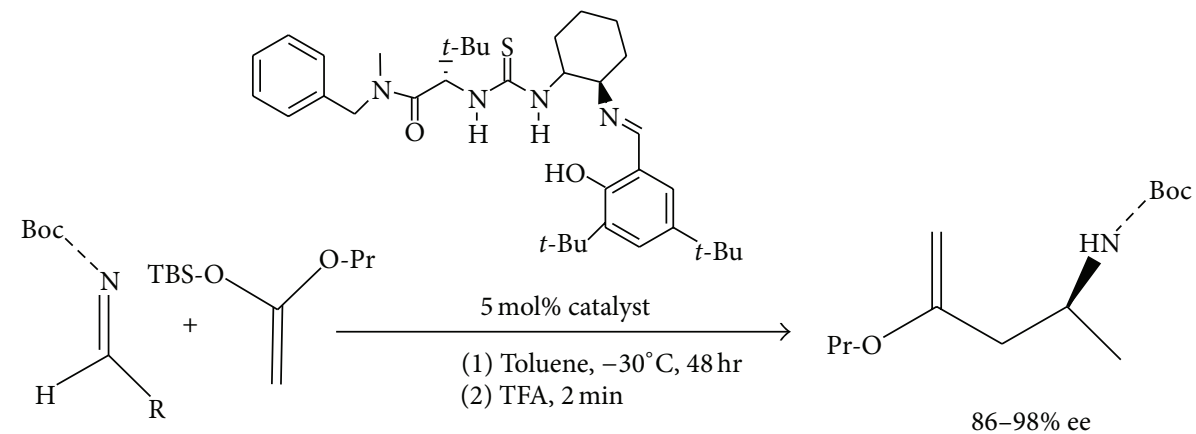

SCHEME 10<smiles>CC1(C)O[C@@H](C(O)(c2cccc3ccccc23)c2cccc3ccccc23)[C@H](C(O)(c2cccc3ccccc23)C(O)(c2cccc3ccccc23)c2cccc3ccccc23)O1</smiles>

Figure 6

7.7. Chiral Diols. Huang et al. reported on use of TADDOLs (Figure 6) as Brønsted acid organocatalysts in highly stereoselective hetero-Diels-Alder reactions [219].

The $\alpha$-amination of carbonyl compounds has also been accomplished by using the 1-naphthyl TADDOL derivative as a Brønsted acid organocatalyst [220]. McDougal and Schaus reported asymmetric Morita-Baylis-Hillman reaction, that is, the addition of cyclohexenone to different aldehydes catalyzed by octahydro-BINOL derived Brønsted acid [221].

7.8. Jacobsen Thioureas. Professors Vachal and Jacobsen identified chiral thioureas (Figure 7) as versatile and effective organocatalysts. $1 \mathrm{~mol} \%$ of the thiourea was reported to have catalytic activity in the hydrocyanation (Strecker reaction) of both aldimines and ketoimines with very high enantioselectivities [222].

Imine hydrophosphonylation, particularly effective with electron-withdrawing ester substituents on the phosphate, took place in the presence of $10 \mathrm{~mol} \%$ of the catalyst [223]. Mannich reactions of BOC protected imines have also been reported (Scheme 10) [224] with excellent yields and enantioselectivities and show heterocyclic substrate tolerance.

A variant of thiourea organocatalyst was found to catalyze the cyanosilylation of ketones and aldehydes in high yields and enantiomeric excesses [225]. Thiourea organocatalyst was put to use in the acyl-Pictet-Spengler reaction to form tetrahydro- $\beta$-carbolines [226]. The acyl-Mannich reaction, providing a route to enantioenriched heterocycles from 


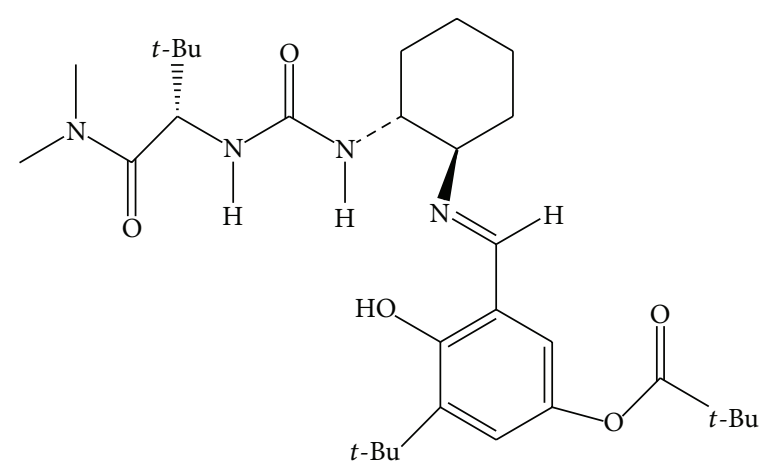

Figure 7

aromatic starting materials and trichloroethyl chloroformate (TrocCl), is also catalyzed by the thiourea organocatalyst [227]. Bifunctional thiourea-base catalyzed double-Michael addition of benzofuran-2-ones to dienones is reported for the synthesis of optically enriched spirocyclic benzofuran-2ones [228]. In another interesting example, benzoylthioureapyrrolidine catalyst was synthesized and used in the asymmetric Michael addition of ketones to nitroalkenes [229].

Primary amine-thioureas were improvised to catalyze difficult Michael reactions synthesizing (S)-baclofen, $(R)$ baclofen, and (S)-phenibut [230].

7.9. Cinchona Alkaloids. The cinchona alkaloids catalyze many useful processes with high enantioselectivities. Asymmetric phase transfer catalysis (PTC) presents a "green" alternative to homogeneous synthetic organic chemistry methodologies. Cinchona alkaloids are synthetically modified for their usage in asymmetric PTC. O-Alkyl $\mathrm{N}$-aryl methyl derivatives of cinchona alkaloid led highly enantioselective alkylation of glycine imines to generate $\alpha$-amino acid derivatives. And, for the same reaction, dimeric cinchona alkaloid obtained 97-99\% enantiomeric excess [231, 232]. Cinchona alkaloids deprotonate substrates with relatively acidic protons forming a contact ion pair between the resulting anion and protonated amine. This interaction generates a chiral pool around the anion and facilitates enantioselective reactions with electrophiles. The control over the formation of quaternary asymmetric centers is essential to obtain high enantiomeric excesses. The $\alpha$-functionalization of ketones (Scheme 11) by the addition of TMSCN to the corresponding cyanohydrin in excellent yield and enantiomeric excess is catalyzed by the (DHQD) ${ }_{2} \mathrm{AQN}$ catalyst [233].

Increasingly remote stereocenters are being targeted in asymmetric aminocatalysis. Organocatalytic allylic amination presents an alternative to the conventional palladium catalyzed methodology. Amination at the remote $\gamma$-position using (DHQ) ${ }_{2}$ PYR forms highly functionalized amine compounds [234].

Bella and Jørgensen's reported the first enantioselective conjugate addition of $\beta$-diketones to both aromatic and aliphatic alkynones using (DHQ) ${ }_{2}$ PHAL catalyst [235]. Cinchona based primary amine catalysis is found to offer high efficiency and reliability in the asymmetric functionalization of carbonyl compounds [236, 237]. Organocatalysts derived from cinchona alkaloids function as Lewis base catalyst in the cyclizations of allenoates with electron deficient olefins and imines and emerged as important synthetic tool in the preparation of biologically active and pharmaceutically interesting cyclic compounds, including natural products [238]. Recently, cinchona thioureas have been reported for the first time as catalysts in the area of asymmetric oxidations [239]. Cinchona and cinchonidine derived catalysts perform asymmetric direct aldol reaction of pyruvic aldehyde dimethyl acetal with isatin derivatives [240]. Likewise, there are various other examples reported where cinchona or its variants are used as organocatalysts for syntheses of various biologically important molecules [241-246].

7.10. Maruoka Phase Transfer Catalysts. The chiral catalyst forms a host-guest complex with the substrate and shuttles between the standard organic solvent and a second phase, example, catalytic enantioselective enolate alkylation [72]. As we know, chiral quaternary ammonium catalysts can be useful in asymmetric synthesis. Kitamura et al. reported C2symmetric ammonium salts catalyzing monoalkylation of glycine derived Schiff bases with alkyl halides to synthesize $\alpha$ alkyl- $\alpha$-amino acids under remarkably low catalyst loadings [247-249].

Utilizing the solubility of aqueous quaternary ammonium salts into organic solvents, professor Maruoka developed spirotype chiral ammonium salt with two binaphthyl rings as a novel chiral phase transfer catalyst. Figure 8 depicts the organocatalyst for direct asymmetric aldol reaction of $\beta$ hydroxy- $\alpha$-amino acid derivative.

7.11. Oxazaborolidines. Chiral oxazaborolidines (known as CBS oxazaborolidines after Corey, Bakshi, and Shibata) catalyze the reduction of prochiral ketones, imines, and oximes to produce chiral alcohols, amines, and amino alcohols, respectively, in high yields and excellent enantiomeric excesses. The chiral Lewis acid generated from $o$-tolyl-CBSoxazaborolidine after protonation with trifluoromethanesulfonimide is very useful in the enantioselective Diels-Alder reaction (Scheme 12) [250-256]. 


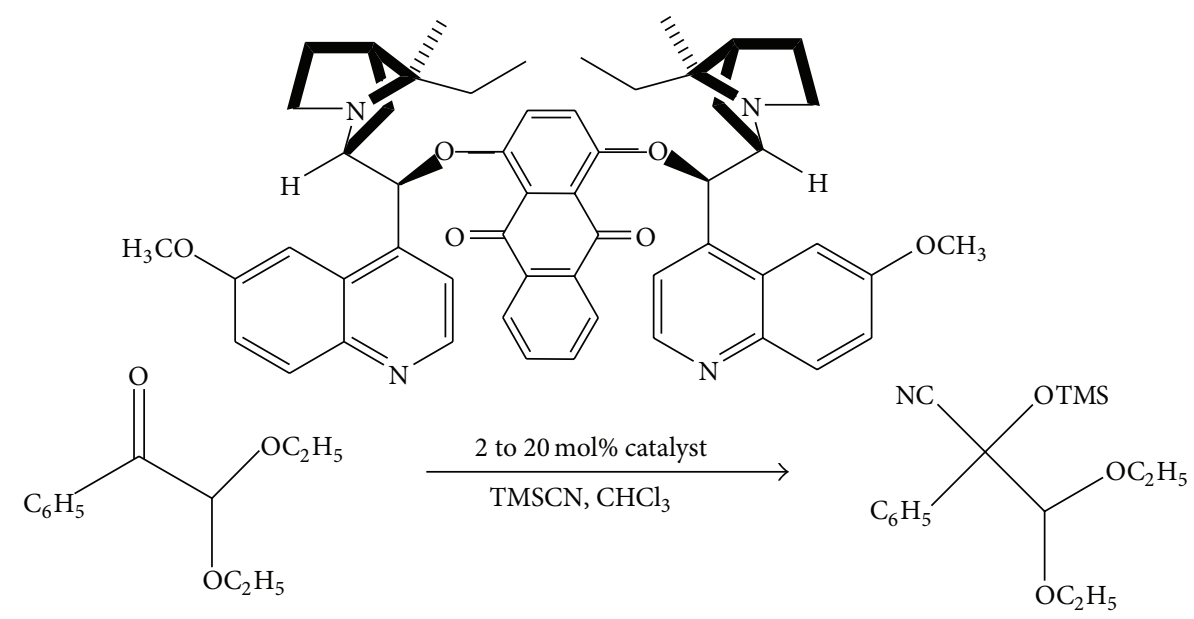

Scheme 11: Tian et al. [233].

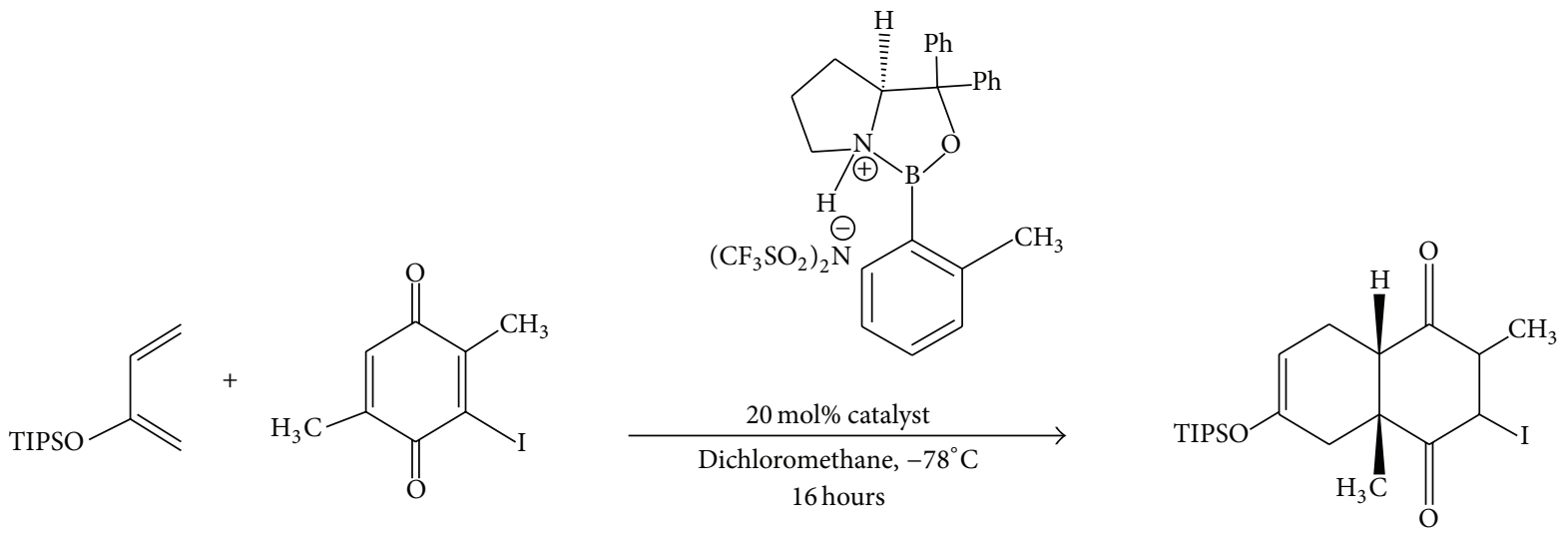

SCHEMe 12: See [250-256].

7.12. Shi Epoxidation Catalyst. Tu et al. reported a fructose derived ketone in efficient asymmetric epoxidation of transolefins (Scheme 13) [257]. Epoxidation catalyst is able to epoxidize trans-alkenes and certain cis-alkenes with good to excellent yields and selectivities [258, 259]. Marigo et al's group reported an asymmetric organocatalytic epoxidation of $\alpha, \beta$-unsaturated aldehydes with environmentally friendly oxidant hydrogen peroxide [260].

\subsection{N-Heterocyclic Carbene (NHC) as Organocatalysts}

7.13.1. Rovis Catalyst. The conjugate addition of an aldehyde to an $\alpha, \beta$-unsaturated compound (Stetter reaction) is a practical methodology for the construction of 1,4-dicarbonyl compounds bearing quaternary stereocenters. Triazolium salt in the presence of a base functions as an N-heterocyclic carbene organocatalyst (Figure 9) in highly enantioselective intramolecular Stetter reactions [261, 262].

7.13.2. Bode Catalyst. Bode's studies on NHCs (Figure 10) mainly involve catalytic generation of reactive species such as enolates, homoenolates, and activated carboxylates.
N-Mesityl substituent on an imidazolium or triazolium NHC precursor generates highly enantioselective annulations from simple starting materials under mild reaction conditions $[263,264]$. In an interesting example, the catalysts facilitate highly enantioselective cyclopentene forming annulations of simple enals and activated enones [265]. Redox esterifications and amidations of $\alpha$-functionalized aldehydes using achiral catalyst are also reported [266]. Uniting unique activation modes of N-heterocyclic carbene (NHC) catalysts with the concept of domino reactions, a new fast-growing field came into the spotlight in last couple of years or so [267-269].

Domino Michael/aldol reaction between 2-mercaptoquinoline-3-carbaldehydes and enals was catalyzed by diphenylprolinol silyl ether producing $2 H$-thiopyrano[2,3-b]quinolines in excellent yields and enantioselectivities [270]. Zhao et al. reported studies on "cooperative NHC and rutheniun redox catalysis" in the oxidative esterification of aldehydes [271]. Blanc et al. reported NHC mediated organocatalytic one-pot allylstannation to generate syn-diols [272]. With enals as starting aldehydes, elegant cascade processes have been developed using oxidative carbene catalysis [273-276]. Over the last few years, there are examples reported in literature where various organocatalysts rally 


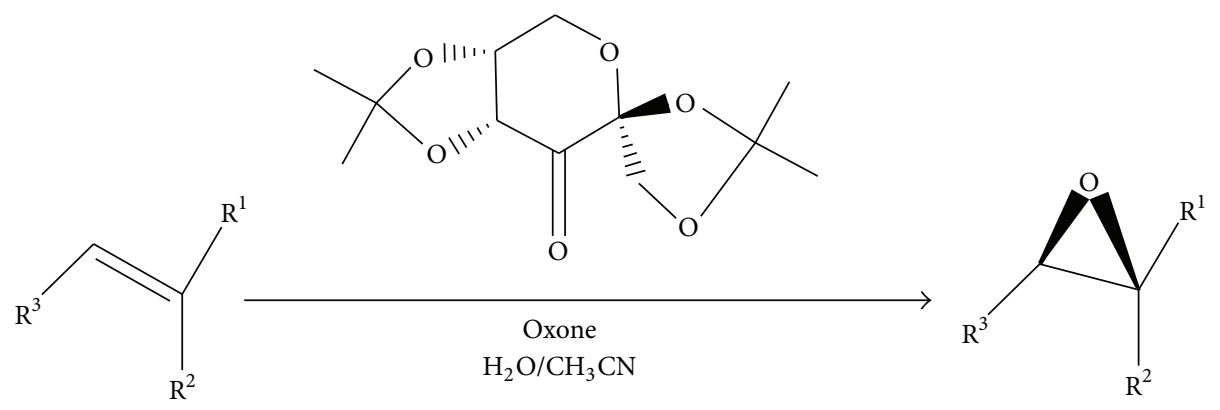

SCHEME 13

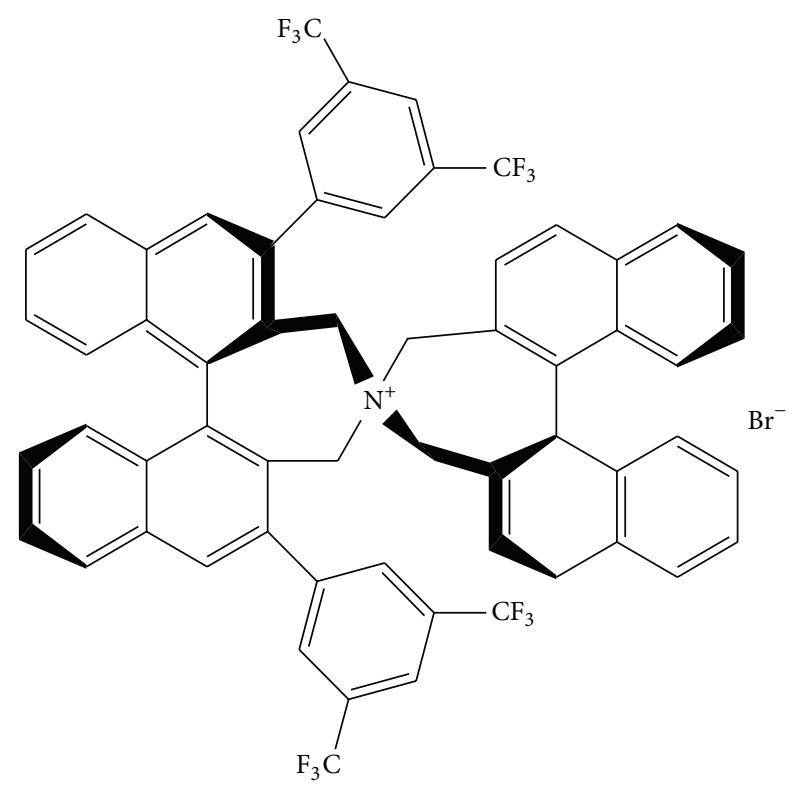

FIGURE 8: See [176].<smiles></smiles>

Figure 9

domino reactions and attract their application in organic processes in industries $[174,175,180,181,183]$.

Apart from the aforementioned organocatalysts, there are other organic systems which upon appropriate activation function as catalysts in useful asymmetric syntheses [155-157]. 1,2-Dicarbonyl compounds, because of their adjacent multiple reactive centers, upon activation, act as efficient pronucleophiles in asymmetric organocatalyzed

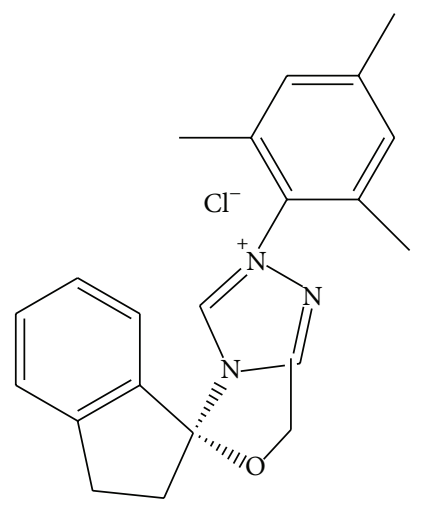

FIGURE 10 sequential or domino transformations including $\mathrm{C}-\mathrm{C}$ or $\mathrm{C}-$ $\mathrm{N}$ bond formation [277]. Cyclopropenone catalyzed conversion of aldoximes and primary amides into nitriles in a one-pot mild reaction widens the scope of the utilization of cyclopropenones in organic synthesis [278]. The first asymmetric organocatalytic synthesis by phosphine catalyzed [3+2] cycloaddition of allenoates onto fullerene is reported to yield enantiomerically pure carbocyclic fullerene derivatives under mild conditions [279]. A new $[3+2]$ cycloaddition/cycloreversion strategy for organocatalytic and thermally allowed carbonyl-olefin metathesis is reported [280]. Recently, a strong evidence for halogen bond based organocatalysis is reported for the reaction of 1-chloroisochroman with ketene silyl acetals [281]. Acid catalyzed asymmetric acetalizations of aldehydes are also described [282]. beta-Isocupreidine catalyzed the enantioselective Morita-Baylis-Hillman reaction of maleimides with isatin derivatives to form 3-substituted 3-hydroxyoxindole derivatives [283, 284].

Recent advances in asymmetric catalysis resulted in utilizing the less discussed electrophilic properties of iminium type intermediates in complex annulations of indoles [285, $286]$ and also pyridines [287, 288]. Shibatomi and Narayama discussed the catalytic enantioselective $\alpha$-chlorination of carbonyl compounds and stereospecific substitution reactions of the resulting optically active alkyl chlorides [289].

Though there is no relation between the development of two different fields of organocatalysis and gold catalysis, 
an interesting synthetic utility and merger of both catalytic systems in the same reaction flask is explored [290].

Following Are the Synthetic Methodologies Reported on Mannich Reactions Using Various Organocatalytic Systems. Asymmetric three-component Mannich reaction and antiMannich reactions were reported by organocatalysts [122, 175]. The title reaction provides facile access to enantioenriched 3,4-dihydroquinazolin-2(1H)-ones containing a quaternary stereogenic center in high yields with excellent enantioselectivities. Subsequent transformations lead to the convenient preparation of the anti-HIV drug DPC 083 and $\mathrm{N}$-fused polycyclic compounds without loss of enantiomeric excess [291].

An asymmetric catalytic, desulfonylative Mannich reaction of keto imines with aldehydes, as catalyzed by diarylprolinol silyl ether, was developed. It gave the Mannich product in good yield with excellent anti- and enantioselectivity [292]. New chiral bis(betaine)s, containing two catalytically active centers, have been designed and have proven to be promising organocatalysts for the direct Mannich type reaction of azlactones with a broad spectrum of aliphatic imines [293]. Hong and Wang reviewed advances in asymmetric organocatalytic construction of $3,3^{\prime}$-spirocyclic oxindoles [294]. And the applications of organocatalysts in total synthesis and natural product synthesis include enantioselective synthesis of Amaryllidaceaealkaloids (+)-vittatine, (+)-epi-vittatine, and (+)-buphanisine [295, 296].

\section{Heterogeneous Organocatalysis: New Direction in Research and Development}

8.1. Making of Heterogenous Catalyst from Homogeneous Catalyst: The Concept and Methodologies. With the knowledge of heterogeneous catalysis and chemistry of materials at hand, several modified and different systems are made these days and are tested for their catalytic applications in various organic transformations. Following are the most common and well-known methods for the heterogenization of homogeneous catalysts:

(i) impregnation,

(ii) occlusion in porous materials (ship-in-a-bottle),

(iii) grafting or tethering (through covalent bond).

Impregnation is the immobilisation of catalytic element via electrostatic interactions with a solid support. One of the famous examples includes $\mathrm{Rh}$-diphosphine cationic complexes impregnated on anionic resins via ion-pair formation [297]. Similarly, organocatalysts supported on solid could be envisioned to yield a recyclable catalyst.

Heterogenisation via catalyst entrapment is a typical method that is applied to zeolite supports and termed as "ship-in-bottle" catalysis. A famous example includes in situ synthesis of the transition metal complex in support cages $[298,299]$. The great practical advantages of "ship-in-bottle" single-site heterogeneous catalysts were well illustrated by Zsigmond et al's research [300]. Similar approach, retaining steric factors, could be applicable as another methodology for heterogenization of organocatalysts.

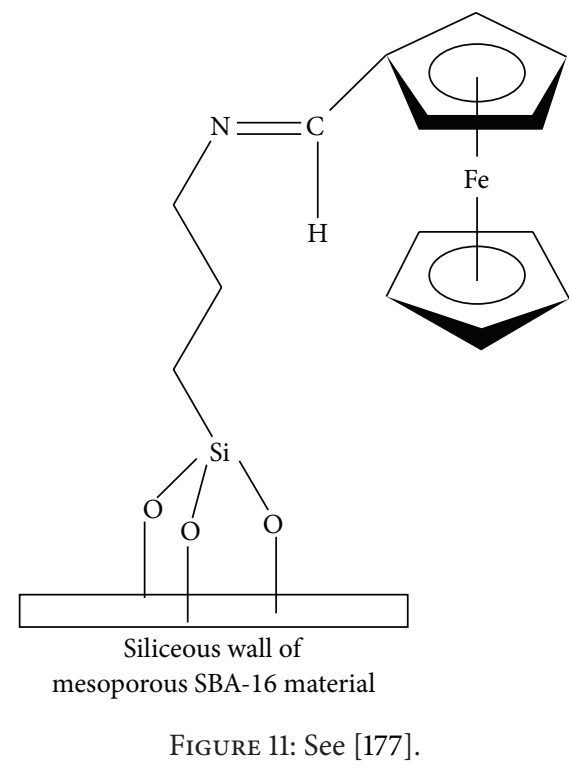

While in grafting, the catalytic active site is directly anchored on the support. This procedure is previously used for supporting organometallic complexes (Figure 11) [177, 301-304]. The tethering technique involves a spacer that is introduced between the catalyst and the support. The characteristic chemical nature and the structure of the spacer should be chosen to avoid the steric hindrance, if any. Though structurally different, catalytic activity can be expected to be similar to catalyst in homogeneous state.

Catalyst immobilization has been widely explored with asymmetric transition metal catalysts and enzymes aiming to improve their applicability and practicability. Similarly, the immobilization strategy has also been frequently attempted for organocatalysis even before its renaissance. The preparation of supported or immobilized catalysts involve either organic polymers such as linear, non-cross-linked, or crosslinked polymers as supports or porous inorganic solids such as alumina, silica, zirconia, clays, zeolites, MCM, and SBA type mesoporous materials. Many inorganic supports have robust composition and offer large surface areas due to the presence of internal pores. Different routes to immobilisation of (homogeneous) catalyst can alter the nature of the catalytic active site. When the anchoring of catalytic moieties on silica is concerned, the key aspect is the functionalization of silanol groups on the surface. The pretreatment temperature of the parent silica determines the nature of the hydroxy groups (isolated, geminal, or hydrogen bound), their location, and reactivity. In nanostructured mesoporous silica of the MCM-41 type, the reactivity of the siloxanes is considered to be sufficient for covalent linking with a tether [305]. Subsequent silylation with trimethylchlorosilane neutralizes residual hydroxyl groups and increases the hydrophobicity. Various aluminosilicates and mesoporous silicas could be envisioned as suitable hosts for encapsulating and anchoring organocatalysts. 
Organocatalysis has drawn a lot of interest in both academia and industry. The fact is that the asymmetric version of organocatalysis is the fastest growing field of synthetic organic chemistry. Few applications in industries include (i) epoxidation of chalcones and (ii) alkylation of cyclic ketones. Along with a commentary on very recent research endeavors in organocatalysis, the scope of heterogeneous organocatalysis in asymmetric synthesis, other important organic reactions, green chemistry, and scope for industrial applications are presented in this review.

Organic functionalization of nanostructured, nanoporous, and other nanomaterials widens the range of their applications and allows for the manipulation of the surface properties that control the interaction with various organic and inorganic guest species and thereby adds new catalytic functions to the materials. One of the basic premises behind the preparation of these kinds of materials is aiming at the development of heterogeneous and supported catalysis for their practical purposes that would have distinct advantages over widely investigated homogeneous catalysts and organometallic compounds that are vulnerable to decomposition due to oxidation of the ligand bound to the metal center.

Using a rationale, similar to that reported earlier for the immobilisation of transition-metal amino acid complexes [306-310], amino acids with functional side chains that can react with tethering silanes such as lysine, arginine, glutamic acid, cysteine, or amino acid derived organocatalysts could be covalently anchored to the inner walls of porous silica and other relevant inorganic structures. These materials have therefore been identified as promising supports for making organocatalysts heterogeneous for industrial significant reactions. This field is therefore well poised for their potential large scale applications in industry.

An organocatalyst attached to some sort of support/material is called heterogenized organocatalyst and this, as the term implies, makes the organocatalyst heterogeneous and thereby brings in all the advantages of heterogeneous catalysis to the system without losing the intrinsic catalytic activity of the organocatalyst. When used in heterogeneous system, one ensures no leaching of catalyst entity into the reaction medium and simple workup or easy separation of catalyst from the products. Such catalyst can be reused. In order to obtain heterogeneous organocatalyst, many approaches have been explored, including impregnation to layered material [311], covalent grafting to solid support $[312,313]$, electrostatic interaction between organocatalyst and the support [314], encapsulation to porous material $[309,310]$, and adsorptive method [315]. Several solid supports have been introduced for heterogenizing of organocatalysts in terms of covalent grafting such as polymer matrix, zeolites, amorphous silica, and mesoporous silica [316-319]. Due to the strong covalent bond with silica surface, the covalently anchored organic moieties are supposed to be more resistant toward leaching during the catalytic reactions. Typically, the immobilization of organocatalysts has been achieved via covalent attachment onto solid supports such as polystyrene [319-323], poly(ethylene glycol) [324, 325], and dendrimers
[326]. However, most of these supported organocatalysts demonstrated reduced activity and selectivity comparing with their small molecular parent catalysts. There has also been increasing examples of supported organocatalysts via noncovalent strategies starting to show their potentials in this field. There are major progresses regarding the development of noncovalently supported asymmetric organocatalysts, with a focus on the immobilization methods, their advantages, applications, and limitations. Noncovalent immobilization includes minimal modification of the parent catalyst, facile catalyst linkage, and combinatorial flexibility for the identification of an optimal-supported catalyst. Different modes of immobilization, such as acid-base, ion-pair, hydrophobic, biphasic, and self-assembled gel type, give different types of heterogeneous organocatalysts. The catalysts obtained by different methods have their advantages and disadvantages at the same time. There is a scope for developing new methodology for heterogenization of organocatalysts.

Immobilization is an effective methodology for heterogenizing an organic molecule onto inorganic material. The two principle mechanisms of organocatalysis are of both covalent and noncovalent nature which lead to (i) the formation of covalent adduct between catalyst and substrate, and (ii) the processes that rely on noncovalent interactions such as hydrogen bonding or within the catalytic cycle is the formation of ions pairs [327]. Owing to the application of organocatalysis in industrial setup, strategies for heterogenizing organocatalysts are being explored in fine chemical industries as well as pharmaceutical industries. Though the stability of an immobilised catalyst may vary in batch operation and continuous flow operation at higher reaction temperatures, such catalysts are expected to avail the advantages of heterogeneous catalysis. Heterogeneous organocatalysis is well poised for its potential industrial applications in industry with sustainable and energy efficient approaches. In order to implement the concepts of green chemistry and engineering in the pharmaceutical industry, one must develop large scale organocatalytic reactions processes that involve

(i) immobilization of organocatalysts (for recycling purposes);

(ii) no leaching problems due to covalent bonding with the support unlike metal complexes;

(iii) results superior to those obtained with free analogous;

(iv) solution phase catalysis.

The immobilisation of amino acid derived organocatalysts could be covalently anchored to the inner walls of porous silica and other relevant inorganic structures. These materials have shown promise as heterogeneous organocatalysts for industrial significant reactions, such as the Hajos-ParrishEder-Sauer-Wiechert reaction [88] and intramolecular [4+2] cycloadditions [328]. This approach has the potential to improve recoverability and recyclability, use far less mol\% of catalyst, and potentially give rise to significant improvements in activity and selectivity. Organocatalysts can be covalently anchored to mesoporous silica by building on current methodologies that are reported in the literature. Tethering 
is carried out through the side chain or a functionalized side chain of a derivatised amino acid, because the mechanism of catalysis relies on the amino and carboxylate groups to be free for substrate binding. Through spatial constraints, nature of the active site, and a precise balance of substrate-catalyst-pore wall interactions, the stereoselectivity of the catalytic reaction could also be suitably enhanced. Judiciously controlling the orientation of the channels and the pore diameter of the mesoporous support could facilitate enhancements in the desired stereochemical outcome, as observed earlier with anchored transition-metal amino acid complexes. The range of substrates and scope of reactions that can be catalyzed by heterogenised amino acids and their derivatives are ever expanding and immobilisation of these organic moieties could result in the design and development of more stable, highly active heterogeneous catalysts [329-331]. The potential for expanding the scope and industrial applicability of heterogenised organocatalysts demands a greater understanding of the synergistic effects, between the support and the organocatalyst; say, for example, amino acid, at a molecular level, which could provide valuable insights on structureproperty relationships and its mechanistic significance. The current organocatalysts development is more focused on solving practical asymmetric synthesis and processes [332]. Following are some interesting examples reported in the field.

Copolymer-supported heterogeneous organocatalyst is prepared and applied for asymmetric aldol addition in aqueous medium [333]. Aldol reaction between acetone and 4-nitrobenzaldehyde was catalyzed by covalently grafted lysine onto silica. The immobilisation technique was found to create well-defined and isolated catalytic sites offering improved activity and chemoselectivity when compared with the homogeneous system [331].

Enantiomerically pure iminium cations supported on zeolite Y, a microporous material, and on Al-MCM-41, a mesoporous material, were found effective for the epoxidation of aryl alkenes by using peroxymonosulfate as the stoichiometric oxidant. The catalytic reaction gave high conversions and enantioselectivities. The catalysts can be simply recycled by filtration and their activity and selectivity are found much higher than the homogeneous counterpart [334]. Chiral organocatalyst team up with heterogeneous inorganic semiconductors form $\mathrm{C}-\mathrm{C}$ bond through stereoselective photocatalysis [330]. Direct stereoselective alpha-functionalization of aldehydes forming $\mathrm{C}-$ $\mathrm{C}, \mathrm{C}-\mathrm{N}, \mathrm{C}-\mathrm{F}, \mathrm{C}-\mathrm{Br}$, and $\mathrm{C}-\mathrm{S}$ bonds is reported over organocatalysts [335]. Solvent-free noncovalent organocatalysis is reported on enantioselective addition of nitroalkanes to alkylideneindolenines [336]. DMAP-NCP, a new network nanoporous conjugated polymer containing 4-(N,Ndimethylamino)pyridine catalytic moieties, exhibits catalytic activity in the acylation of alcohols and phenols, even under neat and continuous flow conditions for practical applications on a large scale [337]. An asymmetric Diels-Alder reaction was catalyzed with high efficiency and recyclability by a soluble, "self-supported" chiral organosilica polymer with embedded imidazolidinone catalytic moieties [338]. The role of some ionic liquids as organocatalysts or cocatalysts requires further understanding and there is a scope for future

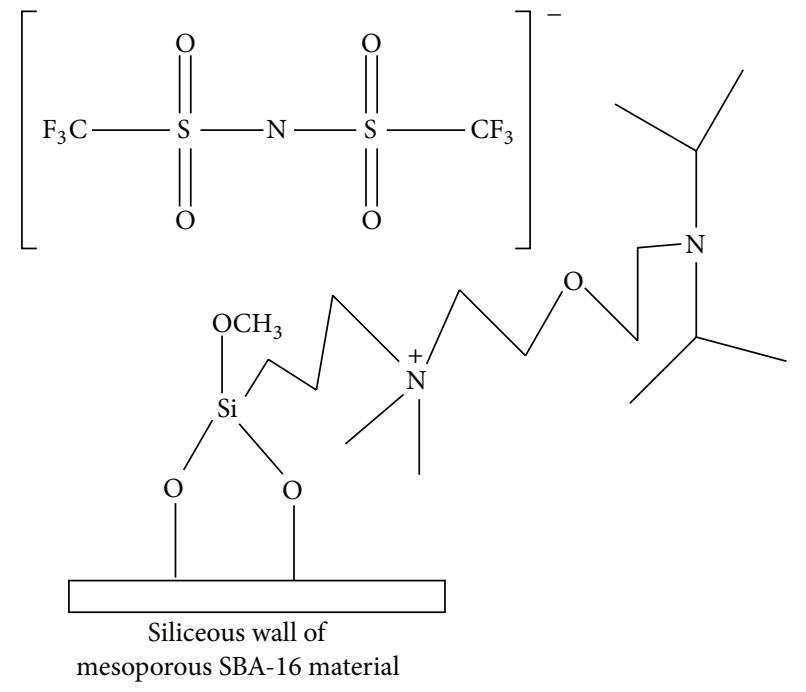

FIgURE 12: Heterogenization of a basic ionic liquid bearing $\mathrm{NTf}_{2}{ }^{-}$ anion on mesoporous SBA-16 silica $[178,179]$.

research in conceptualization of this field, its applications, and the context for heterogeneous organocatalysis (Figure 12) $[178,179,339]$.

8.2. Heterogeneous Organocatalysts from Renewable Resources. Kühbeck et al. reported a critical assessment of the efficiency of neutral $\mathrm{pH}$ chitosan biohydrogel beads as recyclable heterogeneous organocatalyst for a variety of C-C bond formation reactions (i.e., aldol reaction, Knoevenagel condensation, nitroaldol (Henry) reaction [340]. Researchers Françoise Quignard (France) and Luca Bernardi (Italy) undertake development of new heterogeneous organocatalysts based on polysaccharides (chitosan, alginate, or carrageenan). The polysaccharides are made available from renewable resources and exploited for their intrinsic catalytic activities. For example, chitosan is known to bring basic functions while alginate and carrageenan are acidic polymers. The variety of functional groups provides polysaccharides with a surface reactivity especially appealing for specific catalysis processes.

Verma et al. reported a cost effective, environmentally benign, easily accessible, biodegradable, recyclable, and highly efficient pyridinium based bifunctional organocatalyst (ES- $\mathrm{SO}_{3}-\mathrm{C}_{5} \mathrm{H}_{5} \mathrm{NH}^{+}$) grafted to the chemically modified expanded starch, a biomaterial, for the synthesis of b-amino carbonyls by aza-Michael reaction of amines to electron deficient alkenes under mild reaction conditions (Scheme 14) [341].

Heterogenized or supported organocatalysts, for example, grafted polyHDMS, offer engineering advantages and the final macromolecular properties strongly reflect the nature of the grafts. Off late, the use of polymethylhydrosiloxane PMHS anchored cinchona alkaloid derivatives has been reported [342]. 


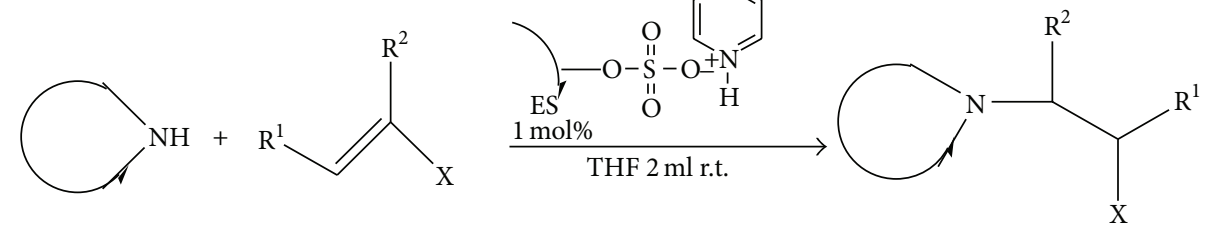

SCHeme 14

8.3. Heterogeneous Organocatalysts for Their Use under Continuous Flow Conditions. In the spirit of developing ecofriendly syntheses, researchers are interested in immobilization of various organocatalysts known to be efficient in aqueous media and in their use under continuous flow [320].

An interesting tether-free but immobilized bifunctional squaramide organocatalyst [343] has found potential application in batch and flow reactions (Scheme 15). A polystyrenesupported highly recyclable squaramide organocatalyst for the enantioselective Michael addition of 1,3 dicarbonyl compounds to $\beta$-nitrostyrenes has also found potential industrially utility [344].

Because of their stability and recyclability, solidsupported organocatalysts (Scheme 16) are therefore particularly suitable for continuous flow systems, [154, 345, 346] which allow large scale synthesis usually accompanied by higher turnover numbers. The miniaturised flow reactors allow improved control of mass and heat transfer and the inherently low reaction volume increases safety making them valuable tools for green chemistry. Reaction-progress kinetic analysis and nonlinear chromatography were applied to investigate a model aldol reaction performed in continuous flow microreactors packed with proline functionalized silica gel. The study facilitated by an online instrumental monitoring assessed optimal operation and feed variables [154].

Enantiomerically pure iminium cations, supported on microporous zeolite $\mathrm{Y}$ and on mesoporous Al-MCM-41, are effective asymmetric catalysts for the epoxidation of a range of aryl alkenes, giving high conversions quickly and with enantioselectivities (Schemes 17 and 18) [334].

Epoxides are versatile synthetic intermediate. A lot has been reported on ring opening methodologies of epoxides over metal alkoxids, amides, metal halides, metal triflates, and so forth. Organocatalysts are advantageous over such metal catalysts. Schreiner published the N,N'-bis[3,5bis(trifluoromethyl) phenyl]thiourea catalyzed ring opening of epoxides with different nucleophiles such as amines, phenols, and thiols in water with poor regioselectivity $(1: 1$ to $1: 4)$ [347, 348]. Bifunctional primary amine-thioureas catalyze usually difficult Michael reactions [349, 350]. Bidentate hydrogen bond donors, urea and thiourea, are found to be useful organocatalysts for the activation of carbonyl group. Hine and coworkers reported meta- and para-substituted phenols and biphenylenediols as double hydrogen bonding organocatalysts for addition of diethylamine to phenyl glycidyl ether [351, 352]. And, there are various examples of catalysts bearing multiple hydrogen bond donors [353, 354].

\section{Preindustrialization Organocatalysis}

In 2004, a special issue of the Advanced Synthesis and Catalysis research journal was dedicated to organocatalysis [355]. In year 2006, a special issue of the Advanced Synthesis and Catalysis research journal on Multiphase Catalysis, Green Solvents, and Immobilization was published by professor Cozzi describing in detail the immobilization of organic catalysts [356]. Several synthetic strategies are developed for the polymeric immobilization of chiral organocatalysts [357359]. Lu and Toy reviewed organic polymer supports for synthesis and for reagent and catalyst immobilization [360]. A lot has been done on supported or immobilized enamine and iminium derivatives for their applications as heterogeneous organocatalysts [361]. A heterogeneous catalyst (LPro LDHs) was developed using intercalation of L-proline in $\mathrm{Mg}-\mathrm{Al}$ layered double hydroxides (LDH). An investigation of the thermal stability and optical stability showed that the immobilization of the chiral catalytic centers in restricted galleries enhanced the enantiomeric stability against thermal treatment and light irradiation. Asymmetric aldol reaction of benzaldehyde and acetone was carried out using L-Pro LDHs as catalyst, resulting in a good yield (90\%) and a high enantiomeric excess (94\%) (Figure 13). Heterogenized Lproline catalyzed the asymmetric aldol reaction using anionic clays as intercalated support [182].

Calderón et al. researched [362] the aldol reaction of hydroxyacetone with different aldehydes using immobilized proline on a mesoporous support, assisted by heat and microwaves. It was found that heterogenized L-proline on MCM-41 catalyzed aldol reactions in both hydrophilic and hydrophobic solvents and provided stereoselectivities in some cases complementary to the homogeneous catalyst. The heterogeneous catalysts could be reused without significant loss of stereoselectivity. In a recent example, supramolecular assemblies of amphiphilic L-proline were regulated by compressed $\mathrm{CO}_{2}$ as a recyclable organocatalyst for the asymmetric aldol reaction [363]. Noncovalently supported heterogeneous chiral amine is used as catalyst for asymmetric direct aldol and Michael addition reactions [364]. An amine grafted on amorphous silica performs as an effective organocatalyst for microwave-promoted Michael reaction of 1,3-dicarbonyl compounds in water [365]. Silica immobilized N-hydroxyphthalimide was found to catalyze autoxidation [366]. Silica, identified as a useful support material for homogeneous catalysts, facilitates the catalyst recovery and reusability [367]. A heterogeneous organocatalyst for cyanosilylation is also reported lately [368]. 


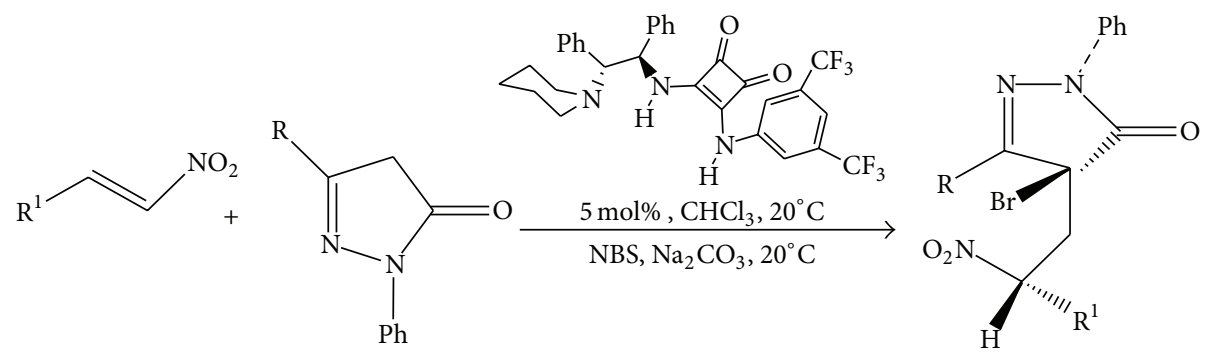

SCHEMe 15
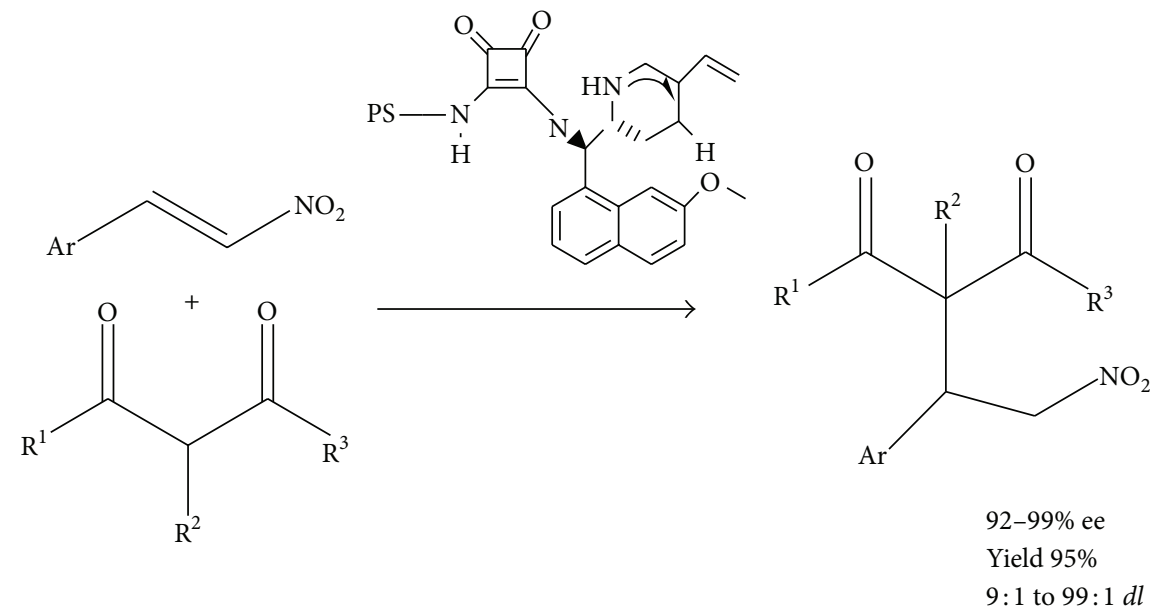

SCHEMe 16

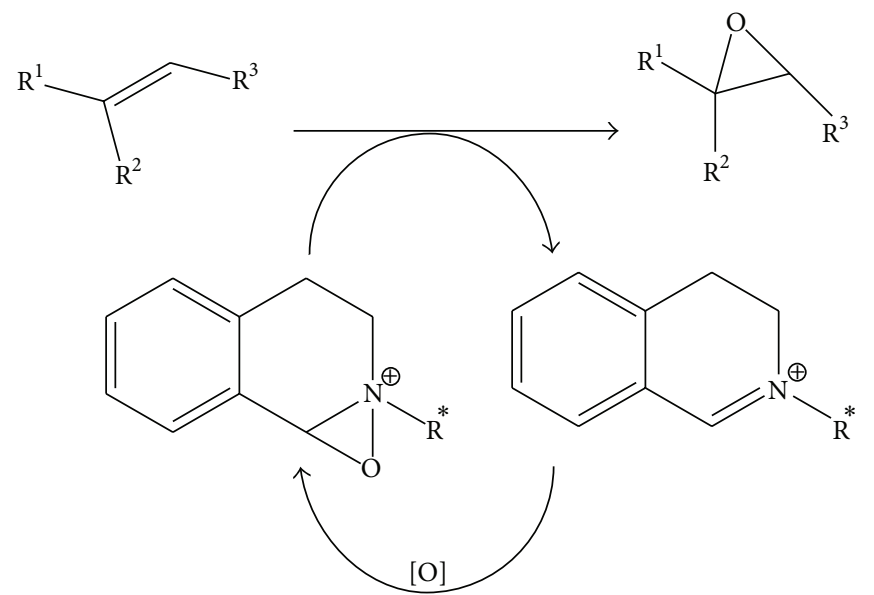

SCHEME 17: Mediation of alkene epoxidation by oxaziridinium cations [334].

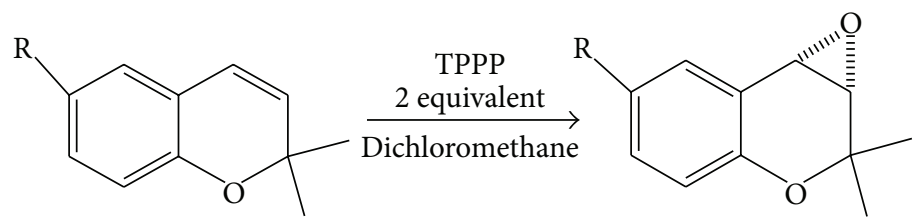

SCHEME 18: Epoxidation of chromenes by MCM catalyst [334]. 


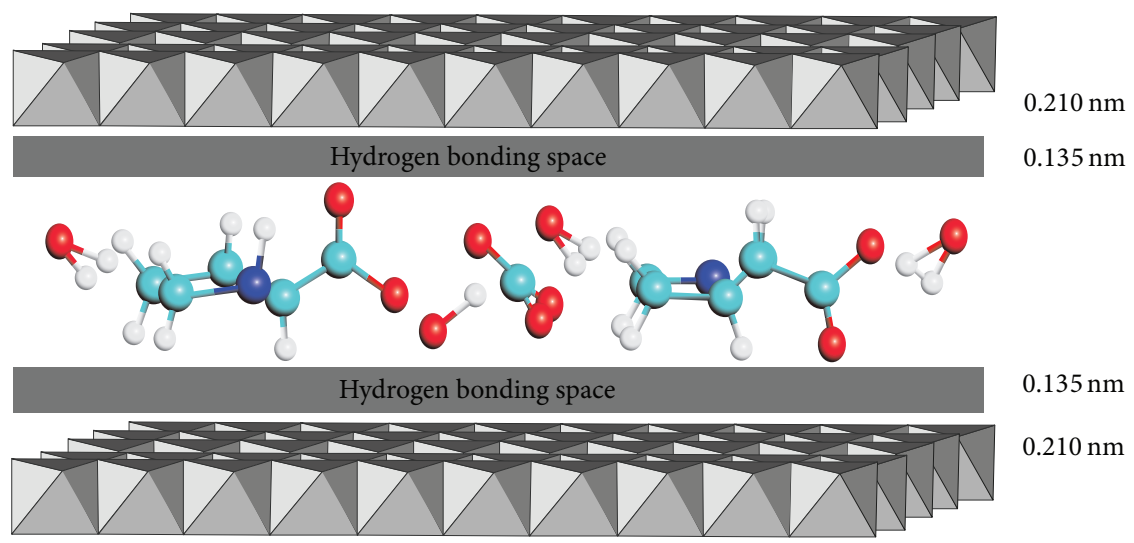

Figure 13: The schematic model of L-Pro LDHs (molar ratio of $\mathrm{Mg} / \mathrm{Al}=3: 1$, intercalated yield $=59 \%$ [182].

There are some interesting patents in the literature on usage of some organocatalysts in innovative chemical technologies with some industrial application. There is no need for metal based catalysis thus making a contribution to green chemistry. In this context, simple organic acids have been used as catalyst for the modification of cellulose in water on multi-ton scale [369]. In recent years, the emphasis has been on the variety of nano(porous)materials for that has found use in such catalytic systems: these include nanoparticles, dendrimers, metal oxides, inorganic polymers, and mesoporous materials such as MCM-n materials and SBA$n$ materials. In 2009, a patent related to the use of magnetic nanomaterial-supported glutathione and cysteine organocatalysts as "green" nanocatalysts for various reactions such as Paal-Knorr reactions, aza-Michael addition, and pyrazole synthesis was filed and later granted in year 2012 [370]. Sulfonamide based organocatalysts and method for their use are patented by inventors Rich Garrett Carter and Hua Yang. Proline sulfonamide organocatalysts performing various enantioselective or diastereoselective reactions such as the aldol reactions, conjugate additions, Michael additions, Robinson annulations, Mannich reactions, and alpha-aminooxylations, alpha-hydroxyaminations, alpha-aminations, and alkylation reactions. Among the various methodologies claimed, a sulfonamide derived catalyst was used for the construction of all carbon bicycles, such as [2.2.2]-bicycles [371].

Organocatalysts are blamed for not being recoverable after a reaction. There are interesting reports that study homogeneous or heterogeneous nanosupports for easy recovery of the organocatalysts. Caminade et al. identified perfectly defined hyperbranched polyphosphorhydrazone dendrimers, either neat or attached to siliceous solid material, as nanosupports for easy recycling of organocatalysts [326, 372374].

\section{Characterization Tools and Techniques}

In order for us to research catalysis and relevant aspects, we may require spectroscopic techniques, magnetic measurements, transport and thermal measurements, scattering techniques, microscopic techniques, thin-film deposition techniques, and so forth. The catalytic systems, especially the heterogenized organocatalysts, prepared can be characterized by X-ray diffraction (XRD), nitrogen sorption, scanning electron microscopy (SEM), transmission electron microscopy (TEM), FT-IR, UV-Visible, nuclear magnetic resonance (NMR), Raman, and so forth. In case of nanoporous materials, the pore diameters could be uniformly tailored. The NMR studies of organocatalysts in porous materials could also be of importance for understanding the structure and bonding within the organic and inorganic part of a catalytic system. There is always a scope for identifying and utilizing new characterization techniques for studying catalytic systems and properties, especially the surface behaviour, hydrophilic/hydrophobicity, interactions, molecular sorption, recognitions, and so forth.

\section{Future Scope of Heterogeneous Organocatalysts}

It is always a risk to predict what the future holds for any research area, but several aspects of modifications of existing catalysts and also heterogenisation of organocatalysts onto some sort of robust high surface area support including nanomaterials or nanoporous materials undoubtedly attract researchers' attention. Tremendous efforts should be directed towards the discovery and design of catalytic systems with better efficiency, new reactivity, and greater turnover numbers. Perhaps the most crucial area of research in the future will be the identification of important organic transformations at industries that are not available using other branches of catalysis. Given the huge growth and impact of organocatalysis in its present form, it will certainly be exciting to observe the development of the field upon heterogenization.

A variety of reactions such as reduction, oxidation, multicomponent, Mannich, alkylation, condensation, deprotection, cycloaddition, hydroxylation, dehydration, dehydrogenation, transesterification, reactions involving biomimetic oxygen-evolving catalysts, and other important $\mathrm{C}-\mathrm{C}$ bond 
forming reactions are well presented on the heterogenized organocatalysts under a variety of reaction conditions.

For any large scale catalytic process, the most salient considerations are cost and safety and so critic opinion on low turnover numbers limiting the potential usage might not discourage the industrial applications. Because organocatalysts are often cheaper than metal based catalysts, they can be used in larger quantities than metal based ones for the same price. Moreover, it is widely recognized in manufacturing that the removal of toxic catalyst related impurities from the waste stream can often have a larger financial impact than the turn over number of the catalyst. In the coming years, various approaches for immobilisation will be considered, with a focus on whether a novel methodology for the immobilisation of organocatalysts could be discovered. The benefits of heterogenisation will become apparent on evaluation of the catalytic potential. Apart from the nature of the support, the degree of catalyst loading and selection of reaction media or solvent tune the catalytic behaviour. Alternatively, immobilized organocatalysts can be prepared that are linked to the solvents like ionic liquids that allow the catalytic entity to be separate from the reaction medium by simple extraction or filtration. In another approach, the immobilized organocatalyst might permit us to perform the reactions in biphasic or different conditions. This catalytic system and reaction conditions could find industrial application. Scientific and technical tasks that researchers can undertake are the immobilization of the organocatalyst on solvent and or onto the walls of a reactor. Future catalysts development should be more oriented toward real problems in synthetic processes. It would be also interesting to see (i) the explorations of noncovalent interactions and entrapment in nanosized materials in developing supported organocatalysts; (ii) fine tuning of the screened catalysts and their thermal, mechanical, and catalytic stability; (iii) evaluation of catalyst deactivation and its rejuvenation mechanisms.

\section{Conclusions}

The literature survey and ideas jotted above do not fully claim to conceptualize all the aspects of this new field of heterogeneous organocatalysis. The aim of this review is to illustrate the significance of a variety of organic molecules as catalysts employed for a wide variety of organic transformations. The most highlighted fact is that these organocatalysts represent an interesting scope for heterogenization. In the review of literature, the basic concept of organocatalyst, strategies for heterogenization, preparation methods, and various applications of heterogeneous organocatalysts have been discussed. Like in other heterogeneous catalytic systems, the materials or supports could also play very important role in the total catalyst system used as both catalyst and catalyst carriers. The emphasis has been on the variety of nano(porous)materials that have found or could find use in such catalytic systems: these include nanoparticles, dendrimers, metal oxides, inorganic polymers, and mesoporous materials such as MCM$\mathrm{n}$ materials and SBA-n materials (this is an Open Access review under the terms of the Creative Commons Attribution License, which permits readers to use and distribute this e-review, provided that the original research work is properly cited. All rights are therefore reserved to the author and/or respective authors and researchers cited herein (2013)).

In this review, the author focused on applications of organocatalysts in asymmetric synthesis, synthesis of fine chemicals, and green chemistry. The preceding pages are an account of recent research and developments made in the use of organic molecules as catalysts. It is highlighted that organocatalysts are versatile which not only catalyze the most fundamental reactions in organic chemistry but also finds applications in processes of commercial importance in chemical industries. Several very useful applications of organocatalysts are in production of agrochemicals, clean energy, drugs, polymers, petrochemicals, and so forth. In view of the globally increasing interest towards energy efficient and environmentally friendly chemical technology for industries, research on the development of robust, recyclable, selective, metal-free, easy-to-scale up catalysts and their useful preparation methods are thus the need of the hour.

Great strides are still to be made in the synthesis and characterization of supported or immobilized organocatalysts in order to apply them as heterogeneous catalysts that emphasize applications in existing industrial processes. These catalysts are going to be modified in future and make their catalytic activities accessible in industrial setup for sustainable and environmentally benign technologies.

The author has also outlined recent progress in the use of heterogeneous organocatalysts by briefing the recent publications in scientific publications. Year 2012 saw thematic series, dedicated to showcase the current state of the art of organocatalysis, published by the Beilstein Journal of Organic Chemistry. For those readers who are expecting an update on the recent trends in organocatalysis, the author lists herein [375-383] excellent reviews published in year 2013 on some very specialized topics of organocatalysis.

To summarize, today, the growing need for the atom efficiency, energy efficiency, and environmental concerns stemming from the increase in chemical products demand necessitate the development of the "sustainable or environmentally benign" production methods. Asymmetric synthesis achieving atom economy is a challenge for organic synthesis and homogeneous catalysis using metal complexes leads the way. But the pharmaceutical entities and food industry products do not tolerate a contamination, of even traces, of any such metals for that matter. That why there is a huge demand for metal-free organocatalysts leading to $100 \%$ yield, $100 \%$ ee, of the desired product. The need from chemical industry, especially pharmaceutical, for reliable asymmetric transformations of molecular skeletons is higher than ever. Therefore, (asymmetric) organocatalysis is attracting widespread attention and has become an important field of research. And, moreover, heterogeneous organocatalysis is bringing in some important breakthroughs for industry, especially through flow chemistry.

This review encloses 376 useful references for providing readers with a well described state of the art. The studies to address the scope of this catalytic science are underway. The scientific discoveries and innovations involving organocatalysts are reported almost on a daily basis. Many 
researchers are joining this field, especially to understand the catalytic phenomena and develop heterogeneous catalysts for asymmetric synthetic methodologies for chemical industry. Let us catalyze the green chemistry revolution. As rightly said by Professor Benjamin List, "the research in organocatalysis constitutes the tip of the iceberg of a novel catalytic principle, of which the entire scope still remains to be fully uncovered."

\section{Conflict of Interests}

The author declares that there is no conflict of interests regarding the publication of this paper.

\section{Acknowledgment}

The author, Isak R. Shaikh, thanks National Chemical Laboratory (http://www.ncl-india.org/), Pune, India, for providing the library facilities.

\section{References}

[1] "Our Common Future: Report of the World Commission on Environment and Development, United Nations (UN) Commission on Environment and Development (Brundtland Commission), 1987," Published as Annex to General Assembly document A/42/427, Development and International Cooperation: Environment, August 1987.

[2] M. Lancaster, Green Chemistry: An Introductory Text, The Royal Society of Chemistry, Cambridge, UK, 2002.

[3] P. T. Anastas and J. C. Warner, Green Chemistry: Theory and Practice, Oxford University Press, New York, NY, USA, 1998.

[4] J. H. Clark, "Catalysis for green chemistry," Pure and Applied Chemistry, vol. 73, no. 1, pp. 103-111, 2001.

[5] J. H. Clark and C. N. Rhodes, Clean Synthesis Using Porous Inorganic Solid Catalysts, RSC Clean Technology Monographs, Cambridge, UK, 2000.

[6] W. Ostwald, "Die Überwindung des wissenschaftlichen Materialismus," in Verhandlungen der Gesellschaft Deutscher Naturforscher und $\ddot{A} r z t e$, pp. 155-168, 1895.

[7] R. A. Sheldon, "Consider the environmental quotient," Chemtech, vol. 25, pp. 38-47, 1994.

[8] R. A. Sheldon and H. van Bekkum, Eds., Fine Chemicals Through Heterogeneous Catalysis, Wiley-VCH, Weinheim, Germany, 2001.

[9] R. A. Sheldon and R. S. Downing, "Heterogeneous catalytic transformations for environmentally friendly production," Applied Catalysis A, vol. 189, no. 2, pp. 163-183, 1999.

[10] R. A. Sheldon, "The e factor: fifteen years on," Green Chemistry, vol. 9, no. 12, pp. 1273-1283, 2007.

[11] R. A. Sheldon, "E factors, green chemistry and catalysis: an odyssey," Chemical Communications, no. 29, pp. 3352-3365, 2008.

[12] R. A. Sheldon, "Selective catalytic synthesis of fine chemicals: opportunities and trends," Journal of Molecular Catalysis A, vol. 107, no. 1-3, pp. 75-83, 1996.

[13] R. A. Sheldon, "Catalysis and pollution prevention," Chemistry \& Industry, vol. 1, pp. 12-15, 1997.

[14] R. A. Sheldon, "Catalysis: the key to waste minimization," Journal of Chemical Technology and Biotechnology, vol. 68, pp. 381-388, 1997.
[15] G. Ertl, H. Knozinger, and J. Weitkamp, Eds., Handbook of Heterogeneous Catalysis, Wiley-Vch, Weinheim, Germany, 1997.

[16] R. A. van Santen, P. W. N. M. van Leeuwen, J. A. Moulijn, and B. A. Averill, Eds., Catalysis: An Intergrated Approach, Elsevier, Amsterdam, The Netherlands, 2nd edition, 1999.

[17] J. R. Anderson and K. C. Pratt, Introduction To Characterisation and Testing of Catalysts, Academic Press, Sydney, Australia, 1985.

[18] J. M. Walls and R. Smith, Eds., Surface Science Techniques, Pergamon, 1994.

[19] J. W. Niemantsverdriet, Spectroscopy in Catalysis, Wiley-Vch, Weinheim, Germany, 2007.

[20] J. J. Bozell and G. R. Petersen, "Technology development for the production of biobased products from biorefinery carbohydrates-the US Department of Energy's "top 10" revisited," Green Chemistry, vol. 12, no. 4, pp. 539-554, 2010.

[21] R. A. Gross, M. Ganesh, and W. Lu, "Enzyme-catalysis breathes new life into polyester condensation polymerizations," Trends in Biotechnology, vol. 28, no. 8, pp. 435-443, 2010.

[22] C. J. Li and T. H. Chan, Organic Reactions in Aqueous Media, Wiley-VCH, New York, NY, USA, 1997.

[23] P. A. Grieco, Organic Synthesis in Water, Kluwer Academic, Dordrecht, The Netherlands, 1997.

[24] B. M. Trost, "Atom economy - a challenge for organic synthesis: homogeneous catalysis leads the way," Angewandte Chemie International Edition, vol. 34, no. 3, pp. 259-281, 1995.

[25] B. Cornils and W. A. Herrmann, in Applied Homogeneous Catalysis with Organometallic Compounds, B. Cornils and W. A. Herrmann, Eds., Wiley-VCH, Weinheim, Germany, 2nd edition, 2002.

[26] B. Cornils and W. A. Herrmann, "Concepts in homogeneous catalysis: the industrial view," Journal of Catalysis, vol. 216, no. 1-2, pp. 23-31, 2003.

[27] S. Bhaduri and D. Mukesh, Homogeneous Catalysis, John Wiley \& Sons, 2002.

[28] G. W. Parshall and S. D. Ittel, Homogeneous Catalysis, John Wiley \& Sons, New York, NY, USA, 1992, Emphasis on Industrial Applications.

[29] B. Cornils and W. A. Herrmann, Eds., Applied Homogeneous Catalysis by Organometallic Complexes, Verlag Chemie, Weinheim, Germany, 1996.

[30] I. Ojima, Ed., Catalytic Asymmetric Synthesis, Verlag VCH, Weinheim, Germany, 1993.

[31] R. Noyori, Asymmetric Catalysis in Organic Synthesis, John Wiley \& Sons, New York, NY, USA, 1994.

[32] H.-U. Blaser, A. Indolese, and A. Schnyder, "Applied homogeneous catalysis by organometallic complexes," Current Science, vol. 78, no. 11, pp. 1336-1344, 2000.

[33] M. Beller and H.-U. Blaser, Eds., Organometallics as Catalysts in the Fine Chemical Industry, vol. 42 of Topics in Organometallic Chemistry, Springer, 2012.

[34] B. R. Cuenya, "Synthesis and catalytic properties of metal nanoparticles: size, shape, support, composition, and oxidation state effects," Thin Solid Films, vol. 518, no. 12, pp. 3127-3150, 2010.

[35] E. Victor Henrich and P. A. Cox, The Surface Science of Metal Oxides, Cambridge University Press, Cambridge, UK, 1994.

[36] H. H. Kung, "Transition metal oxides," in Surface Chemistry and Catalysis, Elsevier, Amsterdam, The Netherlands, 1989. 
[37] K. J. Klabunde, M. Fazlul Hoq, F. Mousah, and H. Matsuhashi, "Metal Oxides and their physico-chemical properties in Catalysis and Synthesis," in Preparative Chemistry Using Supported Reagents, Academic Press, London, UK, 1987.

[38] H. Schäfer, Chemiker-Zeitung, vol. 101, no. 7/8, p. 325, 1977.

[39] H.-C. Zhou, J. R. Long, and O. M. Yaghi, "Introduction to metalorganic frameworks," Chemical Reviews, vol. 112, no. 2, pp. 673674, 2012.

[40] D. Farrusseng, Ed., Metal-Organic Frameworks. Applications From Catalysis to Gas Storage, Wiley-VCH, Weinheim, Germany, 2011.

[41] N. Rahmat, A. Z. Abdullah, and A. R. Mohamed, "A review: mesoporous Santa Barbara amorphous-15, types, synthesis and its applications towards biorefinery production," American Journal of Applied Sciences, vol. 7, no. 12, pp. 1579-1586, 2010.

[42] S.-H. Wu, C.-Y. Mou, and H.-P. Lin, "Synthesis of mesoporous silica nanoparticles," Chemical Society Reviews, vol. 42, pp. 3862-3875, 2013.

[43] A. Bernardos and L. Kouřimská, "Applications of mesoporous silica materials in food: a review," Czech Journal of Food Sciences, vol. 31, no. 2, pp. 99-107, 2013.

[44] M. N. Timofeeva, V. N. Panchenko, Z. Hasan, and S.-H. Jhung, "Catalytic potential of the wonderful chameleons: nickel phosphate molecular sieves," Applied Catalysis A, vol. 455, pp. 71-85, 2013.

[45] I. R. Shaikh and S.-E. Park, "Microwave synthesis and catalytic applications of novel cobalt incorporated nickel phosphate," Diffusion and Defect Data Pt.B: Solid State Phenomena, vol. 119, pp. 279-282, 2007.

[46] I. R. Shaikh, Nanoporous nickel phosphate and silica materials for heterogeneous oxidation catalysis [Ph.D. thesis], Inha University, Inchon, Republic of Korea, 2007, Ph.D. thesis incomplete, unpublished and in conflict between S-E Park and Isak R. Shaikh.

[47] Y. Tao, H. Kanoh, L. Abrams, and K. Kaneko, "Mesoporemodified zeolites: preparation, characterization, and applications," Chemical Reviews, vol. 106, no. 3, pp. 896-910, 2006.

[48] M. E. Davis, "Ordered porous materials for emerging applications," Nature, vol. 417, no. 6891, pp. 813-821, 2002.

[49] K. Tsuji, C. W. Jones, and M. E. Davis, "Organic-functionalized molecular sieves (OFMSs): I. Synthesis and characterization of OFMSs with polar functional groups," Microporous and Mesoporous Materials, vol. 29, no. 3, pp. 339-349, 1999.

[50] C. W. Jones, K. Tsuji, and M. E. Davis, "Organic-functionalized molecular sieves as shape-selective catalysts," Nature, vol. 393, no. 6680, pp. 52-54, 1998.

[51] M. E. Davis, "The quest for extra-large pore, crystalline molecular sieves," Chemistry - A European Journal, vol. 3, pp. 17451750, 1997.

[52] B. Notori, "Microporous crystalline titanium silicates," Advances in Catalysis, vol. 41, pp. 253-334, 1996.

[53] R. J. Saxon, "Crystalline microporous titanium silicates," Topics in Catalysis, vol. 9, no. 1-2, pp. 43-57, 1999.

[54] J. M. Thomas and R. Raja, "Design of a "green" one-step catalytic production of $\varepsilon$-caprolactam (precursor of nylon-6)," Proceedings of the National Academy of Sciences of the United States of America, vol. 102, no. 39, pp. 13732-13736, 2005.

[55] M. Hartmann and L. Kevan, "Transition-metal ions in aluminophosphate and silicoaluminophosphate molecular sieves: location, interaction with adsorbates and catalytic properties," Chemical Reviews, vol. 99, no. 3, pp. 635-663, 1999.
[56] C. S. Cundy and P. A. Cox, "The hydrothermal synthesis of zeolites: history and development from the earliest days to the present time," Chemical Reviews, vol. 103, no. 3, pp. 663-701, 2003.

[57] A. Corma, "From microporous to mesoporous molecular sieve materials and their use in catalysis," Chemical Reviews, vol. 97, no. 6, pp. 2373-2419, 1997.

[58] G. De, M. Gusso, L. Tapfer et al., "Annealing behavior of silver, copper, and silver-copper nanoclusters in a silica matrix synthesized by the sol-gel technique," Journal of Applied Physics, vol. 80, no. 12, pp. 6734-6739, 1996.

[59] Y. Wan and D. Zhao, "On the controllable soft-templating approach to mesoporous silicates," Chemical Reviews, vol. 107, no. 7, pp. 2821-2860, 2007.

[60] A. K. Cheetham, G. Ferey, and T. Loiseau, Angewandte Chemie International Edition, vol. 38, p. 3298, 1999.

[61] G. Ferey, "Microporous solids: from organically templated inorganic skeletons to hybrid frameworks . . . ecumenism in chemistry," Chemistry of Materials, vol. 13, pp. 3084-3098, 2001.

[62] C. N. R. Rao, S. Natarajan, and R. Vaidhyanathan, "Metal carboxylates with open architectures," Angewandte Chemie International Edition, vol. 43, no. 12, pp. 1466-1496, 2004.

[63] F. Schüth and W. Schmidt, "Microporous and mesoporous materials," Advanced Materials, vol. 14, pp. 629-638, 2002.

[64] F. Schuth, K. Sing, and J. Weitkamp, Eds., Handbook of Porous Solids, vol. I-V, Wiley-VCH, Weinheim, Germany, 2002.

[65] Y. Wan and D. Y. Zhao, "On the controllable soft-templating approach to mesoporous silicates," Chemical Reviews, vol. 107, no. 7, pp. 2821-2860, 2007.

[66] V. Parvulescu, C. Anastasescu, and B. L. Su, "Bimetallic Ru-(Cr, $\mathrm{Ni}$, or $\mathrm{Cu}$ ) and $\mathrm{La}-(\mathrm{Co}$ or $\mathrm{Mn}$ ) incorporated MCM-41 molecular sieves as catalysts for oxidation of aromatic hydrocarbons," Journal of Molecular Catalysis A, vol. 211, pp. 143-148, 2004.

[67] S. Vetrivel and A. Pandurangan, "Co and Mn impregnated MCM-41: their applications to vapour phase oxidation of isopropylbenzene," Journal of Molecular Catalysis A, vol. 227, pp. 269-278, 2005.

[68] Y. Wan, D. Zhang, N. Hao, and D. Zhao, "Organic groups functionalised mesoporous silicates," International Journal of Nanotechnology, vol. 4, p. 66, 2007.

[69] V. Ayala, A. Corma, M. Iglesias, and F. Sanchez, "Mesoporous MCM41-heterogenised (salen)Mn and $\mathrm{Cu}$ complexes as effective catalysts for oxidation of sulfides to sulfoxides: isolation of a stable supported $\mathrm{Mn}(\mathrm{V})=\mathrm{O}$ complex, responsible of the catalytic activity," Journal of Molecular Catalysis A, vol. 221, pp. 201-208, 2004.

[70] Z. G. Hajos and D. R. Parrish, "Asymmetric synthesis of bicyclic intermediates of natural product chemistry," The Journal of Organic Chemistry, vol. 39, no. 12, pp. 1615-1621, 1974.

[71] L. Shu and Y. Shi, "An efficient ketone-catalyzed epoxidation using hydrogen peroxide as oxidant," The Journal of Organic Chemistry, vol. 65, pp. 8807-8810, 2000.

[72] E. J. Corey, F. Xu, and M. C. Noe, "A rational approach to catalytic enantioselective enolate alkylation using a structurally rigidified and defined chiral quaternary ammonium salt under phase transfer conditions," Journal of the American Chemical Society, vol. 119, pp. 12414-12415, 1997.

[73] B. Sellergren, R. N. Karmalkar, and K. J. Shea, "Enantioselective ester hydrolysis catalyzed by imprinted polymers. 2," Journal of Organic Chemistry, vol. 65, no. 13, pp. 4009-4027, 2000. 
[74] J. von Liebig, "Ueber die Bildung des Oxamids aus Cyan," Annalen der Chemie und Pharmacie, vol. 113, no. 2, pp. 246-247, 1860.

[75] H. D. Dakin, "The catalytic action of amino-acids, peptones and proteins in effecting certain syntheses," Journal of Biological Chemistry, vol. 7, p. 49, 1909.

[76] W. Langenbeck, "Über organische Katalysatoren. III. Die Bildung von Oxamid aus Dicyan bei Gegenwart von Aldehyden," Justus Liebigs Annalen der Chemie, vol. 469, p. 16, 1929.

[77] W. Langenbeck, Die Organische Katalysatoren und ihre Beziehungen zu den Fermenten, vol. 2, Springer, 1949.

[78] W. Langenbeck, Fortschritte Der Chemischen Forschung, vol. 6, Springer, Berlin, Germany, 1966.

[79] M. M. Vavon and P. Peignier, "Lapplication des alcaloïdes dans la synthèse organique," Bulletin de la Société Chimique de France, vol. 45, p. 293, 1929.

[80] R. Wegler, "Über die mit verschiedener Reaktionsgeschwindigkeit erfolgende Veresterung der optischen Antipoden eines Racemates durch opt. akt. Katalysatoren," Justus Liebigs Annalen der Chemie, vol. 498, pp. 62-73, 1932.

[81] S. Pizzarello and A. L. Weber, "Prebiotic amino acids as asymmetric catalysts," Science, vol. 303, no. 5661, p. 1151, 2004.

[82] G. Bredig and P. S. Fiske, Biochemische Zeitschrift, vol. 46, p. 7, 1912.

[83] H. Pracejus, “Organische Katalysatoren, LXI. Asymmetrische Synthesen mit Ketenen, I. Alkaloid-katalysierte asymmetrische Synthesen von $\alpha$-Phenyl-propionsäureestern," Justus Liebigs Annalen der Chemie, vol. 634, pp. 9-22, 1960.

[84] H. Pracejus, "Asymmetrische Synthesen mit Ketenen, II. Stereospezifische Addition von $\alpha$-Phenyl-äthylamin an Phenylmethyl-keten," Justus Liebigs Annalen der Chemie, vol. 634, pp. 23-29, 1960.

[85] S.-I. Yamada and G. Otani, "Asymmetric synthesis with amino acid II asymmetric synthesis of optically active 4,4-disubstituted-cyclohexenone," Tetrahedron Letters, vol. 10, no. 48, pp. 4237-4240, 1969.

[86] Z. G. Hajos and D. R. Parrish, German Patent DE, 21026231971.

[87] Z. G. Hajos and D. R. Parrish, United States Patent US, 3975442, 1971.

[88] U. Eder, G. Sauer, and R. Wiechert, "New type of asymmetric cyclization to optically active steroid CD partial structures," Angewandte Chemie International Edition, vol. 10, pp. 496-497, 1971.

[89] C. Allemann, R. Gordillo, F. R. Clemente, P. H.-Y. Cheong, and K. N. Houk, "Theory of asymmetric organocatalysis of aldol and related reactions: rationalizations and predictions," Accounts of Chemical Research, vol. 37, no. 8, pp. 568-569, 2004.

[90] H. Wynberg, "Asymmetric catalysis by alkaloids," Topics in Stereochemistry, vol. 16, pp. 87-129, 1986.

[91] H. Wynberg, "Catalytic asymmetric synthesis of chiral 4substituted 2-oxetanones," The Journal of Organic Chemistry, vol. 50, pp. 1977-1979, 1985.

[92] H. Wynberg, "Asymmetric synthesis of (S)- and (R)-malic acid from ketene and chloral," Journal of the American Chemical Society, vol. 104, pp. 166-168, 1982.

[93] B. List, R. A. Lerner, and C. F. Barbas III, "Proline-catalyzed direct asymmetric aldol reactions," Journal of the American Chemical Society, vol. 122, pp. 2395-2396, 2000.

[94] T. Bui and C. F. Barbas III, "A proline-catalyzed asymmetric Robinson annulation reaction," Tetrahedron Letters, vol. 41, no. 36, pp. 6951-6954, 2000.
[95] R. B. Woodward, E. Logusch, K. P. Nambiar et al., "Asymmetric total synthesis of erythromcin. 1. Synthesis of an erythronolide A secoacid derivative via asymmetric induction," Journal of the American Chemical Society, vol. 103, no. 11, pp. 3210-3213, 1981.

[96] K. A. Ahrendt, C. J. Borths, and D. W. C. MacMillan, "New strategies for organic catalysis: the first highly enantioselective organocatalytic diels-Alder reaction," Journal of the American Chemical Society, vol. 122, no. 17, pp. 4243-4244, 2000.

[97] B. List, R. A. Lerner, and C. F. Barbas III, "Proline-catalyzed direct asymmetric aldol reactions," Journal of the American Chemical Society, vol. 122, no. 10, pp. 2395-2396, 2000.

[98] N. Vignola and B. List, "Catalytic asymmetric intramolecular $\alpha$-alkylation of aldehydes," Journal of the American Chemical Society, vol. 126, no. 2, pp. 450-451, 2004.

[99] A. B. Northrup and D. W. C. MacMillan, "Two-step synthesis of carbohydrates by selective aldol reactions," Science, vol. 305, no. 5691, pp. 1752-1755, 2004.

[100] A. B. Northrup, I. K. Mangion, F. Hettche, and D. W. C. MacMillan, "Enantioselective organocatalytic direct aldol reactions of $\alpha$-oxyaldehydes: step one in a two-step synthesis of carbohydrates," Angewandte Chemie International Edition, vol. 43, no. 16, pp. 2152-2154, 2004.

[101] L. C. Dias, L. J. Steil, and V. D. A. Vasconcelos, "A short and efficient synthesis of (+)-prelactone B," Tetrahedron Asymmetry, vol. 15, no. 1, pp. 147-150, 2004.

[102] P. M. Pihko and A. Erkkilä, "Enantioselective synthesis of prelactone B using a proline-catalyzed crossed-aldol reaction," Tetrahedron Letters, vol. 44, no. 41, pp. 7607-7609, 2003.

[103] A. B. Northrup and D. W. C. MacMillan, "The first direct and enantioselective cross-aldol reaction of aldehydes," Journal of the American Chemical Society, vol. 124, no. 24, pp. 6798-6799, 2002.

[104] K. Sakthivel, W. Notz, T. Bui, and C. F. Barbas III, "Amino acid catalyzed direct asymmetric aldol reactions: a bioorganic approach to catalytic asymmetric carbon-carbon bond-forming reactions," Journal of the American Chemical Society, vol. 123, no. 22, pp. 5260-5267, 2001.

[105] B. List, P. Pojarliev, and C. Castello, "Proline-catalyzed asymmetric aldol reactions between ketones and $\alpha$-unsubstituted aldehydes," Organic Letters, vol. 3, no. 4, pp. 573-575, 2001.

[106] B. List, R. A. Lerner, and C. F. Barbas III, "Proline-catalyzed direct asymmetric aldol reactions," Journal of the American Chemical Society, vol. 122, no. 10, pp. 2395-2396, 2000.

[107] B. List, R. A. Lerner, and C. F. Barbas III, "Enantioselective aldol cyclodehydrations catalyzed by antibody 38C2," Organic Letters, vol. 1, no. 1, pp. 59-61, 1999.

[108] J. M. Betancort and C. F. Barbas III, "Direct asymmetric organocatalytic michael reactions of $\alpha, \alpha$-disubstituted aldehydes with $\beta$-nitrostyrenes for the synthesis of quaternary carboncontaining products," Organic Letters, vol. 6, pp. 2527-2530, 2004.

[109] A. Alexakis and O. Andrey, "Diamine-catalyzed asymmetric Michael additions of aldehydes and ketones to nitrostyrene," Organic Letters, vol. 4, no. 21, pp. 3611-3614, 2002.

[110] B. List, P. Pojarliev, and H. J. Martin, "Efficient proline-catalyzed Michael additions of unmodified ketones to nitro olefins," Organic Letters, vol. 3, no. 16, pp. 2423-2425, 2001.

[111] D. Enders and A. Seki, "Proline-catalyzed enantioselective Michael additions of ketones to nitrostyrene," Synlett, no. 1, pp. 26-28, 2002. 
[112] J. M. Betancort and C. F. Barbas III, "Catalytic direct asymmetric Michael reactions: taming naked aldehyde donors," Organic Letters, vol. 3, no. 23, pp. 3737-3740, 2001.

[113] J. M. Betancort, K. Sakthivel, R. Thayumanavan, and C. F. Barbas III, "Catalytic enantioselective direct Michael additions of ketones to alkylidene malonates," Tetrahedron Letters, vol. 42, no. 27, pp. 4441-4444, 2001.

[114] S. Hanessian and V. Pham, "Catalytic asymmetric conjugate addition of nitroalkanes to cycloalkenones," Organic Letters, vol. 2, no. 19, pp. 2975-2978, 2000.

[115] M. Yamaguchi, Y. Igarashi, R. S. Reddy, T. Shiraishi, and M. Hirama, "Asymmetric Michael addition of nitroalkanes to prochiral acceptors catalyzed by proline rubidium salts," Tetrahedron, vol. 53, no. 32, pp. 11223-11236, 1997.

[116] N. S. Chowdari, J. T. Suri, and C. F. Barbas III, "Asymmetric synthesis of quaternary $\alpha$-and $\beta$-amino acids and $\beta$-lactams via proline-catalyzed Mannich reactions with branched aldehyde donors," Organic Letters, vol. 6, no. 15, pp. 2507-2510, 2004.

[117] N. S. Chowdari, D. B. Ramachary, and C. F. Barbas III, "Organocatalysis in ionic liquids: highly efficient L-prolinecatalyzed direct asymmetric Mannich reactions involving ketone and aldehyde nucleophiles," Synlett, no. 12, pp. 19061909, 2003.

[118] B. List, P. Pojarliev, W. T. Biller, and H. J. Martin, "The proline-catalyzed direct asymmetric three-component Mannich reaction: scope, optimization, and application to the highly enantioselective synthesis of 1,2-amino alcohols," Journal of the American Chemical Society, vol. 124, no. 5, pp. 827-833, 2002.

[119] A. Córdova, W. Notz, G. Zhong, J. M. Betancort, and C. F. Barbas III, "A highly enantioselective amino acid-catalyzed route to functionalized $\alpha$-amino acids," Journal of the American Chemical Society, vol. 124, no. 9, pp. 1842-1843, 2002.

[120] A. Córdova, S.-I. Watanabe, F. Tanaka, W. Notz, and C. F. Barbas III, "A highly enantioselective route to either enantiomer of both $\alpha$ - and $\beta$-amino acid derivatives," Journal of the American Chemical Society, vol. 124, no. 9, pp. 1866-1867, 2002.

[121] A. Corodova and C. F. Barbas III, "anti-Selective SMP-catalyzed direct asymmetric Mannich-type reactions: synthesis of functionalized amino acid derivatives," Tetrahedron Letters, vol. 43, pp. 7749-7752, 2002.

[122] B. List, "The direct catalytic asymmetric three-component Mannich reaction," Journal of the American Chemical Society, vol. 122, no. 38, pp. 9336-9337, 2000.

[123] F. Shi, W. Tan, R.-Y. Zhu, G.-J. Xing, and S.-J. Tu, "catalytic asymmetric five-component tandem reaction: diastereo- and enantioselective synthesis of densely functionalized tetrahydropyridines with biological importance," Advanced Synthesis \& Catalysis, vol. 355, no. 8, pp. 1605-1622, 2013.

[124] J. W. Yang, M. T. Hechavarria Fonseca, and B. List, "Catalytic asymmetric reductive Michael cyclization," Journal of the American Chemical Society, vol. 127, no. 43, pp. 15036-15037, 2005.

[125] B. List, "Direct catalytic asymmetric $\alpha$-amination of aldehydes," Journal of the American Chemical Society, vol. 124, pp. 56565657, 2002.

[126] G. Zhong, "A facile and rapid route to highly enantiopure 1,2-diols by novel catalytic asymmetric $\alpha$-aminoxylation of aldehydes," Angewandte Chemie International Edition, vol. 42, no. 35, pp. 4247-4250, 2003.

[127] S. P. Brown, M. P. Brochu, C. J. Sinz, and D. W. C. MacMillan, "The direct and enantioselective organocatalytic $\alpha$-oxidation of aldehydes," Journal of the American Chemical Society, vol. 125, no. 36, pp. 10808-10809, 2003.
[128] A. Bøgevig, H. Sunden, and A. Córdova, "Direct catalytic enantioselective alpha-aminoxylation of ketones: a stereoselective synthesis of alpha-hydroxy and alpha,alpha'-dihydroxy ketones," Angewandte Chemie International Edition, vol. 43, pp. 1109-1112, 2004.

[129] J. Seayad and B. List, "Asymmetric organocatalysis," Organic \& Biomolecular Chemistry, vol. 3, pp. 719-724, 2005.

[130] R. R. Shaikh, A. Mazzanti, M. Petrini, G. Bartoli, and P. Melchiorre, "Proline-catalyzed asymmetric formal $\alpha$-alkylation of aldehydes via vinylogous iminium ion intermediates generated from arylsulfonyl indoles," Angewandte Chemie International Edition, vol. 47, no. 45, pp. 8707-8710, 2008.

[131] R. K. Kunz and D. W. C. MacMillan, "Enantioselective organocatalytic cyclopropanations. The identification of a new class of iminium catalyst based upon directed electrostatic activation," Journal of the American Chemical Society, vol. 127, no. 10, pp. 3240-3241, 2005.

[132] J. Franzén, M. Marigo, D. Fielenbach, T. C. Wabnitz, A. Kjærsgaard, and K. A. Jørgensen, "A general organocatalyst for direct $\alpha$-functionalization of aldehydes: stereoselective $\mathrm{C}-\mathrm{C}$, $\mathrm{C}-\mathrm{N}, \mathrm{C}-\mathrm{F}, \mathrm{C}-\mathrm{Br}$, and $\mathrm{C}-\mathrm{S}$ bond-forming reactions. Scope and mechanistic insights," Journal of the American Chemical Society, vol. 127, p. 18296, 2005.

[133] A. Bøgevig, K. Juhl, N. Kumaragurubaran, W. Zhuang, and K. A. Jørgensen, "Direct organo-catalytic asymmetric $\alpha$-amination of aldehydes-a simple approach to optically active $\alpha$-amino aldehydes, $\alpha$-amino alcohols, and $\alpha$-amino acids," Angewandte Chemie International Edition, vol. 41, pp. 1790-1793, 2002.

[134] M. Marigo and K. A. Jørgensen, " $\alpha$-Heteroatom functionalization," in Enantioselective Organocatalysis, P. I. Dalko, Ed., Chapter 2.2, Wiley-VCH, Weinheim, Germany, 2007.

[135] M. Marigo, T. Schulte, J. Franzén, and K. A. Jørgensen, “Asymmetric multicomponent domino reactions and highly enantioselective conjugated addition of thiols to $\alpha, \beta$-unsaturated aldehydes," Journal of the American Chemical Society, vol. 127, pp. 15710-15711, 2005.

[136] M. Marigo, J. Franzén, T. B. Poulsen, W. Zhuang, and K. A. Jørgensen, "Asymmetric organocatalytic epoxidation of $\alpha, \beta$ unsaturated aldehydes with hydrogen peroxide," Journal of the American Chemical Society, vol. 127, pp. 6964-6965, 2005.

[137] A. Carlone, G. Bartoli, M. Bosco, L. Sambri, and P. Melchiorre, "Organocatalytic asymmetric hydrophosphination of $\alpha, \beta$-unsaturated aldehydes," Angewandte Chemie International Edition, vol. 46, no. 24, pp. 4504-4506, 2007.

[138] I. Ibrahem, R. Rios, J. Vesely et al., "Enantioselective organocatalytic hydrophosphination of $\alpha, \beta$-unsaturated aldehydes," Angewandte Chemie International Edition, vol. 46, no. 24, pp. 4507-4510, 2007.

[139] X. Yu and W. Wang, "Organocatalysis: asymmetric cascade reactions catalysed by chiral secondary amines," Organic \& Biomolecular Chemistry, vol. 6, pp. 2037-2046, 2008.

[140] D. Enders, M. R. M. Hüttl, C. Grondal, and G. Raabe, "Control of four stereocentres in a triple cascade organocatalytic reaction," Nature, vol. 441, pp. 861-863, 2006.

[141] A. E. Allen and D. W. C. MacMillan, "Enantioselective $\alpha$ arylation of aldehydes via the productive merger of iodonium salts and organocatalysis," Journal of the American Chemical Society, vol. 133, no. 12, pp. 4260-4263, 2011.

[142] A. E. Allen and D. W. C. MacMillan, "The productive merger of iodonium salts and organocatalysis: a non-photolytic approach to the enantioselective $\alpha$-trifluoromethylation of aldehydes," 
Journal of the American Chemical Society, vol. 132, no. 14, pp. 4986-4987, 2010.

[143] H.-W. Shih, M. N. Vander Wal, R. L. Grange, and D. W. C. MacMillan, "Enantioselective $\alpha$-benzylation of aldehydes via photoredox organocatalysis," Journal of the American Chemical Society, vol. 132, no. 39, pp. 13600-13603, 2010.

[144] D. W. C. MacMillan, "The advent and development of organocatalysis," Nature, vol. 455, no. 7211, pp. 304-308, 2008.

[145] T. D. Beeson, A. Mastracchio, J.-B. Hong, K. Ashton, and D. W. C. MacMillan, "Enantioselective organocatalysis using SOMO activation," Science, vol. 316, no. 5824, pp. 582-585, 2007.

[146] S. G. Ouellet, A. Walji, and D. W. C. MacMillan, "Enantioselective organocatalytic transfer hydrogenation reactions using Hantzsch esters," Accounts of Chemical Research, vol. 40, pp. 1327-1339, 2007.

[147] Y. Huang, A. M. Walji, C. H. Larsen, and D. W. C. MacMillan, "Enantioselective organo-cascade catalysis," Journal of the American Chemical Society, vol. 127, no. 43, pp. 15051-15053, 2005.

[148] S. P. Brown, M. P. Brochu, C. J. Sinz, and D. W. C. MacMillan, "The direct and enantioselective organocatalytic $\alpha$-oxidation of aldehydes," Journal of the American Chemical Society, vol. 125, no. 36, pp. 10808-10809, 2003.

[149] N. A. Para and D. W. C. MacMillan, "New strategies in organic catalysis: the first enantioselective organocatalytic FriedelCrafts alkylation," Journal of the American Chemical Society, vol. 123, no. 18, pp. 4370-4371, 2001.

[150] W. S. Jen, J. J. M. Wiener, and D. W. C. MacMillan, "New strategies for organic catalysis: the first enantioselective organocatalytic 1,3-dipolar cycloaddition," Journal of the American Chemical Society, vol. 122, no. 40, pp. 9874-9875, 2000.

[151] F. Calderón, R. Fernández, F. Sánchez, and A. FernándezMayoralas, "Asymmetric aldol reaction using immobilized proline on mesoporous support," Advanced Synthesis \& Catalysis, vol. 347, no. 10, pp. 1395-1403, 2005.

[152] Z. An, W. Zhang, H. Shi, and J. He, "An effective heterogeneous 1-proline catalyst for the asymmetric aldol reaction using anionic clays as intercalated support," Journal of Catalysis, vol. 241, no. 2, pp. 319-327, 2006.

[153] M. Gruttadauria, F. Giacalone, and R. Noto, "Supported proline and proline-derivatives as recyclable organocatalysts," Chemical Society Reviews, vol. 37, no. 8, pp. 1666-1688, 2008.

[154] O. Bortolini, A. Cavazzini, P. P. Giovannini et al., "A combined kinetic and thermodynamic approach for the interpretation of continuous-flow heterogeneous catalytic processes," Chemistry-A European Journal, vol. 19, no. 24, pp. 7802-7808, 2013.

[155] A. Berkessel and H. Groeger, Eds., Asymmetric Organocatalysis: From Biomimetic Concepts To Applications in Asymmetric SynthesisSpecial Issue: Asymmetric Organocatalysis, Wiley-VCH, Weinheim, Germany, 2005.

[156] A. Berkessel and H. Groeger, Metal-Free Organic Catalysts in Asymmetric Synthesis, Wiley-VCH, Weinheim, Germany, 2004.

[157] K. N. Houk and B. List, "Special issue: asymmetric organocatalysis," Accounts of Chemical Research, vol. 37, no. 8, p. 487, 2004.

[158] F. Xu, M. Zacuto, N. Yoshikawa et al., "Asymmetric synthesis of telcagepant, a CGRP receptor antagonist for the treatment of migraine," Journal of Organic Chemistry, vol. 75, no. 22, pp. 7829-7841, 2010.

[159] H. U. Blaser and E. Schmidt, "Introduction," in Asymmetric Catalysis on Industrial Scale, H. U. Blaser and E. Schmidt, Eds., pp. 1-19, Wiley-VCH, Weinheim, Germany, 2004.
[160] H. U. Blaser, B. Pugin, and F. Spindler, "Progress in enantioselective catalysis assessed from an industrial point of view," Journal of Molecular Catalysis A, vol. 231, pp. 1-20, 2005.

[161] H. U. Blaser, "Enantioselective catalysis in fine chemicals production," Chemical Communications, pp. 293-296, 2003.

[162] S. S. V. Ramasastry, H. Zhang, F. Tanaka, and C. F. Barbas III, "Direct catalytic asymmetric synthesis of anti-1,2-amino alcohols and syn-1,2-diols through organocatalytic anti-Mannich and syn-aldol reactions," Journal of the American Chemical Society, vol. 129, pp. 288-289, 2007.

[163] Y. Zhao, J. Rodrigo, A. H. Hoveyda, and M. L. Snapper, "Enantioselective silyl protection of alcohols catalysed by an amino-acid-based small molecule," Nature, vol. 443, no. 7107, pp. 67-70, 2006.

[164] S. Saha and J. N. Moorthy, "Enantioselective organocatalytic Biginelli reaction: dependence of the catalyst on sterics, hydrogen bonding, and reinforced chirality," The Journal of Organic Chemistry, vol. 76, pp. 396-402, 2011.

[165] S. Gore, S. Baskaran, and B. Koenig, "Efficient synthesis of 3,4-dihydropyrimidin-2-ones in low melting tartaric acid-urea mixtures," Green Chemistry, vol. 13, no. 4, pp. 1009-1013, 2011.

[166] N. Li, X. H. Chen, J. Song, S. W. Luo, W. Fan, and L. Z. Gong, "Highly enantioselective organocatalytic Biginelli and Biginelli-like condensations: reversal of the stereochemistry by tuning the $3,3^{\prime}$-disubstituents of phosphoric acids," Journal of the American Chemical Society, vol. 132, p. 10953, 2010.

[167] N. Lu, D. Chen, G. Zhang, and Q. Liu, “Theoretical investigation on enantioselective Biginelli reaction catalyzed by natural tartaric acid," International Journal of Quantum Chemistry, vol. 111, pp. 2031-2038, 2010.

[168] M. Lei, "An efficient and environmentally friendly procedure for synthesis of pyrimidinone derivatives by use of a Biginelli-type reaction," Monatshefte für Chemie, vol. 141, pp. 1005-1008, 2010.

[169] Y. Y. Wu, Z. Chai, X. Y. Liu, G. Zhao, and S. W. Wang, "Synthesis of substituted 5-(Pyrrolidin-2-yl)tetrazoles and their application in the asymmetric Biginelli reaction," European Journal of Organic Chemistry, vol. 6, pp. 904-911, 2009.

[170] M. M. Savant, A. M. Pansuriya, C. V. Bhuva, N. P. Kapuriya, and Y. T. Naliapara, "Etidronic acid: a new and efficient catalyst for the synthesis of novel 5-nitro-3,4-dihydropyrimidin-2(1H)ones," Catalysis Letters, vol. 132, no. 1-2, pp. 281-284, 2009.

[171] J. N. Sangshetti, N. D. Kokare, and D. B. Shinde, "Oxalic acid as a versatile catalyst for one pot facile synthesis of 3,4-dihydropyrimidin-2-(1H)-ones and their thione analogues," Journal of Heterocyclic Chemistry, vol. 45, no. 4, pp. 1191-1194, 2008.

[172] E. Ramu, V. Kotra, N. Bansal, R. Varala, and S. R. Adapa, “Green approach for the efficient synthesis of Biginelli compounds promoted by citric acid under solvent-free conditions," Rasayan Journal of Chemistry, vol. 1, pp. 188-194, 2008.

[173] D. B. Ramachary, N. S. Chowdari, and C. F. Barbas III, "Aminecatalyzed direct self Diels-Alder reactions of $\alpha, \beta$-unsaturated ketones in water: synthesis of pro-chiral cyclohexanones," Tetrahedron Letters, vol. 43, no. 38, pp. 6743-6746, 2002.

[174] D. B. Ramachary, K. Anebouselvy, N. S. Chowdari, and C. F. Barbas III, "Direct organocatalytic asymmetric heterodomino reactions: the Knoevenagel/Diels-Alder/epimerization sequence for the highly diastereoselective synthesis of symmetrical and nonsymmetrical synthons of benzoannelated centropolyquinanes," Journal of Organic Chemistry, vol. 69, no. 18, pp. 58385849, 2004. 
[175] R. Martín-Rapún, X. Fan, S. Sayalero, M. Bahramnejad, F. Cuevas, and M. A. Pericàs, "Highly active organocatalysts for asymmetric anti-mannich reactions," Chemistry - A European Journal, vol. 17, no. 32, pp. 8780-8783, 2011.

[176] T. Ooi, M. Taniguchi, M. Kameda, and K. Maruoka, "Direct asymmetric aldol reactions of glycine schiff base with aldehydes catalyzed by chiral quaternary ammonium salts," Angewandte Chemie International Edition, vol. 41, pp. 4542-4544, 2002.

[177] D. R. Burri, I. R. Shaikh, S.-C. Han, and S.-E. Park, "Facile heterogenization of homogeneous ferrocene catalyst on SBA16," Studies in Surface Science and Catalysis, vol. 165, pp. 647650, 2007.

[178] I. R. Shaikh, "Heterogenization of a basic ionic liquid bearing $\mathrm{NTf}_{2}{ }^{-}$anion on mesoporous SBA-16 and its use as catalyst in knoevenagel reaction," in Proceedings of the National Conference on Drug Designing and Discovery, pp. 81-85, Devchand College, Arjun Nagar, Ta. Kagal, District Kolhapur, India, September 2013, http://devchandcollege.org/e\%20proceeding\%203D13.html.

[179] I. R. Shaikh and A. A. Shaikh, "Heterogenization of ionic liquid containing Hünig base on mesoporous SBA-16 and its use as catalyst in knovenagel condensation," in Proceedings of the National Conference on Frontiers of Physical, Chemical and Biological Sciences (FPCBS '13), University of Pune, Ganeshkhind, Pune, India, October 2013, published as special issue in: Environment Observer, vol. 13, pp. 35-36, 2013, http://www.seeram.org/.

[180] D. Petruzziello, M. Stenta, A. Mazzanti, and P. G. Cozzi, "A rational approach towards a new ferrocenyl pyrrolidine for stereoselective enamine catalysis," Chemistry - A European Journal, vol. 19, no. 24, pp. 7696-7700, 2013.

[181] S. Sulzer-Mossé and A. Alexakis, "Chiral amines as organocatalysts for asymmetric conjugate addition to nitroolefins and vinyl sulfonesviaenamine activation," Chemical Communications, no. 30, pp. 3123-3135, 2007.

[182] Z. An, W. Zhang, H. Shi, and J. He, "An effective heterogeneous 1-proline catalyst for the asymmetric aldol reaction using anionic clays as intercalated support," Journal of Catalysis, vol. 241, no. 2, pp. 319-327, 2006.

[183] L. Albrecht, G. Dickmeiss, C. F. Weise, C. Rodríguez-Escrich, and K. A. Jørgensen, "Dienamine-mediated inverse-electrondemand hetero-diels-alder reaction by using an enantioselective H-bond-directing strategy," Angewandte Chemie International Edition, vol. 51, no. 52, pp. 13109-13113, 2012.

[184] Q. Ren and J. Wang, "Recent developments in amine-catalyzed non-asymmetric transformations," Asian Journal of Organic Chemistry, vol. 2, no. 7, pp. 542-557, 2013.

[185] T. Li, J. Zhu, D. Wu et al., "A strategy enabling enantioselective direct conjugate addition of inert aryl methane nucleophiles to enals with a chiral amine catalyst under mild conditions," Chemistry-A European Journal, vol. 19, no. 28, pp. 9147-9150, 2013.

[186] G. Talavera, E. Reyes, J. L. Vicario, and L. Carrillo, “Cooperative dienamine/hydrogen-bonding catalysis: enantioselective formal [2+2] cycloaddition of enals with nitroalkenes," Angewandte Chemie International Edition, vol. 51, no. 17, pp. 41044107, 2012.

[187] D. B. Ramachary and Y. V. Reddy, "Dienamine catalysis: an emerging technology in organic synthesis," European Journal of Organic Chemistry, no. 5, pp. 868-887, 2012.

[188] J. Chin, F. Mancin, N. Thavarajah, D. Lee, A. Lough, and D. S. Chung, "Controlling diaza-Cope rearrangement reactions with resonance-assisted hydrogen bonds," Journal of the American Chemical Society, vol. 125, pp. 15276-15277, 2003.

[189] H. J. Kim, H. Kim, G. Alhakimi et al., "Preorganization in highly enantioselective diaza-Cope rearrangement reaction," Journal of the American Chemical Society, vol. 127, pp. 16370-16371, 2005.

[190] H. J. Kim, W. Kim, A. J. Lough, B. M. Kim, and J. Chin, "A cobalt(III)-salen complex with an axial substituent in the diamine backbone: stereoselective recognition of amino alcohols," Journal of the American Chemical Society, vol. 127, pp. 16776-16777, 2005.

[191] L. Cui, Y. Zhu, S. Luo, and J.-P. Cheng, "Primary-tertiary diamine/brønsted acid catalyzed C-C coupling between paravinylanilines and aldehydes," Chemistry - A European Journal , vol. 19, no. 29, pp. 9481-9484, 2013.

[192] M. Orlandi, M. Benaglia, L. Raimondi, and G. Celentano, “2Aminoimidazolyl and 2-aminopyridyl (S)-prolinamides as versatile multifunctional organic catalysts for aldol, Michael and Diels Alder reactions," European Journal of Organic Chemistry, vol. 12, pp. 2346-2354, 2013.

[193] H. Wang, Y. Wang, H. Song, Z. Zhou, and C. Tang, "Bifunctional squaramide-catalyzed one-pot sequential Michael addition/dearomative bromination: convenient access to optically active brominated pyrazol-5(4H)-ones with adjacent quaternary and tertiary stereocenters," European Journal of Organic Chemistry, vol. 2013, no. 22, pp. 4844-4851, 2013.

[194] B. Tan, G. Hernández-Torres, and C. F. Barbas III, "Rationally designed amide donors for organocatalytic asymmetric Michael reactions," Angewandte Chemie International Edition, vol. 51, no. 22, pp. 5381-5385, 2012.

[195] D. Nguyen, R. K. Akhani, C. I. Sheppard, and S. L. Wiskur, "Structure-activity relationship of formamides as organocatalysts: the significance of formamide structure and conformation," European Journal of Organic Chemistry, vol. 12, pp. 22792283, 2013.

[196] G. Lelais and D. W. C. MacMillan, "Modern strategies in organic catalysis: the advent and development of iminium activation," Aldrichimica Acta, vol. 39, no. 3, pp. 79-87, 2006.

[197] S. Lee and D. W. C. MacMillan, "Organocatalytic vinyl and Friedel-Crafts alkylations with trifluoroborate salts," Journal of the American Chemical Society, vol. 129, no. 50, pp. 15438-15439, 2007.

[198] N. A. Paras and D. W. C. MacMillan, "New strategies in organocatalysis:The first enantioselective organocatalytic Friedel-Crafts alkylation," Journal of the American Chemical Society, vol. 123, pp. 4370-4371, 2001.

[199] M. P. Brochu, S. P. Brown, and D. W. C. MacMillan, "Direct and enantioselective organocatalytic $\alpha$-chlorination of aldehydes," Journal of the American Chemical Society, vol. 126, no. 13, pp. 4108-4109, 2004.

[200] T. D. Beeson and D. W. C. MacMillan, "Enantioselective organocatalytic $\alpha$-fluorination of aldehydes," Journal of the American Chemical Society, vol. 127, no. 24, pp. 8826-8828, 2005.

[201] M. T. H. Fonseca and B. List, "Catalytic asymmetric intramolecular Michael reaction of aldehydes," Angewandte Chemie International Edition, vol. 43, no. 30, pp. 3958-3960, 2004.

[202] S. G. Ouellet, J. B. Tuttle, and D. W. MacMillan, "Enantioselective organocatalytic hydride reduction," Journal of the American Chemical Society, vol. 127, pp. 32-33, 2005.

[203] MacMillan Imidazolidinone OrganoCatalysts are a trademark of Materia, Inc., https://www.princeton.edu/chemistry/ macmillan/publications/aldrichimica.pdf. 
[204] M. C. Holland, S. Paul, W. B. Schweizer et al., "Noncovalent interactions in organocatalysis: modulating conformational diversity and reactivity in the MacMillan catalyst," Angewandte Chemie International Edition, vol. 52, no. 31, pp. 7967-7971, 2013.

[205] G. Chollet, F. Rodriguez, and E. Schulz, "A new method for recycling asymmetric catalysts via formation of charge transfer complexes," Organic Letters, vol. 8, pp. 539-542, 2006.

[206] L. Xing, J. H. Xie, Y. S. Chen, L. X. Wang, and Q. L. Zhou, "Simply modified chiral diphosphine: catalyst recycling via noncovalent absorption on carbon nanotubes," Advanced Synthesis \& Catalysis, vol. 350, pp. 1013-1016, 2008.

[207] R. Akiyama and S. Kobayashi, "Microencapsulated and related catalysts for organic chemistry and organic synthesis," Chemical Reviews, vol. 109, no. 2, pp. 594-642, 2009.

[208] C. A. Wang, Y. Zhang, J. Y. Shi, and W. Wang, "A selfsupported polymeric MacMillan catalyst for homogeneous organocatalysis and heterogeneous recycling," Chemistry-A European Journal, vol. 8, no. 6, pp. 1110-1114, 2013.

[209] J. Seayad, A. M. Seayad, and B. List, "Catalytic asymmetric Pictet-Spengler reaction," Journal of the American Chemical Society, vol. 128, no. 4, pp. 1086-1087, 2006.

[210] S. Hoffmann, A. M. Seayad, and B. List, "A powerful Brønsted acid catalyst for the organocatalytic asymmetric transfer hydrogenation of imines," Angewandte Chemie International Edition, vol. 44, no. 45, pp. 7424-7427, 2005.

[211] M. Rueping, E. Sugiono, C. Azap, T. Theissmann, and M. Bolte, "Enantioselective Brønsted acid catalyzed transfer hydrogenation: organocatalytic reduction of imines," Organic Letters, vol. 7, no. 17, pp. 3781-3783, 2005.

[212] R. I. Storer, D. E. Carrera, Y. Ni, and D. W. C. MacMillan, "Enantioselective organocatalytic reductive amination," Journal of the American Chemical Society, vol. 128, no. 1, pp. 84-86, 2006.

[213] J. Zhou and B. List, "Organocatalytic asymmetric reaction cascade to substituted cyclohexylamines," Journal of the American Chemical Society, vol. 129, no. 24, pp. 7498-7499, 2007.

[214] G. B. Rowland, H. Zhang, E. B. Rowland, S. Chennamadhavuni, Y. Wang, and J. C. Antilla, "Brønsted acid-catalyzed imine amidation," Journal of the American Chemical Society, vol. 127, no. 45, pp. 15696-15697, 2005.

[215] T. Akiyama, Y. Tamura, J. Itoh, H. Morita, and K. Fuchibe, "Enantioselective aza-Diels-Alder reaction catalyzed by a chiral Brønsted acid: effect of the additive on the enantioselectivity," Synlett, no. 1, Article ID Y07205ST, pp. 141-143, 2006.

[216] Y. Su, M. J. Bouma, L. Alcaraz et al., "Organocatalytic enantioselective one-pot four-component ugi-type multicomponent reaction for the synthesis of epoxy-tetrahydropyrrolo[3,4b]pyridin-5-ones," Chemistry-A European Journal, vol. 18, no. 40, pp. 12624-12627, 2012.

[217] D. J. Bayston, J. L. Fraser, M. R. Ashton, A. D. Baxter, M. E. C. Polywka, and E. Moses, "Preparation and use of a polymer supported BINAP hydrogenation catalyst," The Journal of Organic Chemistry, vol. 63, p. 3137, 1998.

[218] D. S. Kundu, J. Schmidt, C. Bleschke, A. Thomas, and S. Blechert, "A microporous binol-derived phosphoric acid," Angewandte Chemie International Edition, vol. 51, no. 22, pp. 54565459, 2012.

[219] Y. Huang, A. K. Unni, A. N. Thadani, and V. H. Rawal, "Single enantiomers from a chiral-alcohol catalyst," Nature, vol. 424, no. 6945, p. 146, 2003.

[220] H. M. Guo, L. Cheng, L. F. Cun, L. Z. Gong, A. Q. Mi, and Y. Z. Jiang, "L-Prolinamide-catalyzed direct nitroso aldol reactions of $\alpha$-branched aldehydes: a distinct regioselectivity from that with L-proline," Chemical Communications, no. 4, pp. 429-431, 2006.

[221] N. T. McDougal and S. E. Schaus, "Asymmetric Morita-BaylisHillman reactions catalyzed by chiral Brønsted acids," Journal of the American Chemical Society, vol. 125, no. 40, pp. 1209412095, 2003.

[222] P. Vachal and E. N. Jacobsen, "Structure-based analysis and optimization of a highly enantioselective catalyst for the strecker reaction," Journal of the American Chemical Society, vol. 124, no. 34, pp. 10012-10014, 2002.

[223] G. D. Joly and E. N. Jacobsen, "Thiourea-catalyzed enantioselective hydrophosphonylation of imines: practical access to enantiomerically enriched $\alpha$-amino phosphonic acids," Journal of the American Chemical Society, vol. 126, p. 4102, 2004.

[224] A. G. Wenzel and E. N. Jacobsen, "Asymmetric catalytic Mannich reactions catalyzed by urea derivatives: enantioselective synthesis of $\beta$-aryl- $\beta$-amino acids," Journal of the American Chemical Society, vol. 124, pp. 12964-12965, 2002.

[225] D. E. Fuerst and E. N. Jacobsen, "Thiourea-catalyzed enantioselective cyanosilylation of ketones," Journal of the American Chemical Society, vol. 127, no. 25, pp. 8964-8965, 2005.

[226] M. S. Taylor and E. N. Jacobsen, "Highly enantioselective catalytic acyl-Pictet-Spengler reactions," Journal of the American Chemical Society, vol. 126, no. 34, pp. 10558-10559, 2004.

[227] M. S. Talyor, N. Tokunaga, and E. N. Jacobsen, "Enantioselective thiourea-catalyzed acyl-mannich reactions of isoquinolines," Angewandte Chemie International Edition, vol. 44, pp. 67006704, 2005.

[228] X. Li, C. Yang, J.-L. Jin, X.-S. Xue, and J.-P. Cheng, "Synthesis of optically enriched spirocyclic benzofuran-2-ones by bifunctional thiourea-base catalyzed double-Michael addition of benzofuran-2-ones to dienones," Chemistry-An Asian Journal, vol. 8, no. 05, pp. 997-1003, 2013.

[229] S.-R. Ban, X.-X. Zhu, Z.-P. Zhang, H.-Y. Xie, and Q.-S. Li, "Benzoylthiourea-pyrrolidine as another bifunctional organocatalyst: highly enantioselective michael addition of cyclohexanone to nitroolefins," European Journal of Organic Chemistry, vol. 15, pp. 2977-2980, 2013.

[230] M. Tsakos, C. G. Kokotos, and G. Kokotos, "Primary aminethioureas with improved catalytic properties for "difficult" Michael reactions: efficient organocatalytic syntheses of (S)baclofen, (R)-baclofen and (S)-phenibut," Advanced Synthesis and Catalysis, vol. 354, no. 4, pp. 740-746, 2012.

[231] M. J. O'Donnell, "The enantioselective synthesis of $\alpha$-amino acids by phase-transfer catalysis with achiral Schiff base esters," Accounts of Chemical Research, vol. 37, pp. 506-517, 2004.

[232] B. Lygo and B. J. Andrews, “The enantioselective synthesis of $\alpha$ amino acids by phase-transfer catalysis with achiral Schiff base esters," Accounts of Chemical Research, vol. 37, pp. 518-525, 2004.

[233] S.-K. Tian, R. Hong, and L. Deng, "Catalytic asymmetric cyanosilylation of ketones with chiral Lewis base," Journal of the American Chemical Society, vol. 125, no. 33, pp. 9900-9901, 2003.

[234] T. B. Poulsen, C. Alemparte, and K. A. Jørgensen, "Enantioselective organocatalytic allylic amination," Journal of the American Chemical Society, vol. 127, pp. 11614-11615, 2005.

[235] M. Bella and K. A. Jørgensen, "Organocatalytic enantioselective conjugate addition to alkynones," Journal of the American Chemical Society, vol. 126, pp. 5672-5673, 2004. 
[236] P. Melchiorre, "Cinchona-based primary amine catalysis in the asymmetric functionalization of carbonyl compounds," Angewandte Chemie International Edition, vol. 51, no. 39, pp. 9748-9770, 2012.

[237] E. Arceo and P. Melchiorre, "Extending the aminocatalytic HOMO-raising activation strategy: where is the limit?" Angewandte Chemie International Edition, vol. 51, no. 22, pp. 52905292, 2012.

[238] C.-K. Pei and M. Shi, "Asymmetric cyclization reactions of allenoates with imines or $\alpha, \beta$-unsaturated ketones catalyzed by organocatalysts derived from cinchona alkaloids," ChemistryA European Journal, vol. 18, no. 22, pp. 6712-6716, 2012.

[239] A. Russo, G. Galdi, G. Croce, and A. Lattanzi, "Highly enantioselective epoxidation catalyzed by cinchona thioureas: synthesis of functionalized terminal epoxides bearing a quaternary stereogenic center," Chemistry-A European Journal, vol. 18, no. 20, pp. 6152-6157, 2012.

[240] A. Kumar and S. S. Chimni, "Organocatalytic asymmetric direct aldol reaction of pyruvic aldehyde dimethyl acetal with isatin derivatives," European Journal of Organic Chemistry, vol. 2013, no. 22, pp. 4780-4876, 2013.

[241] M.-X. Zhao, H. Zhou, W.-H. Tang, W.-S. Qu, and M. Shi, "Cinchona alkaloid-derived thiourea-catalyzed diastereo- and enantioselective $[3+2]$ cycloaddition reaction of isocyanoacetates to isatins: a facile access to optically active spirooxindole oxazolines," Advanced Synthesis \& Catalysis, vol. 355, no. 7, pp. 1277-1283, 2013.

[242] F. Xu, M. Zacuto, N. Yoshikawa et al., "Asymmetric synthesis of telcagepant, a CGRP receptor antagonist for the treatment of migraine," Journal of Organic Chemistry, vol. 75, no. 22, pp. 7829-7841, 2010.

[243] G. Rassu, V. Zambrano, L. Pinna et al., "Direct regio-, diastereo, and enantioselective vinylogous Michael addition of prochiral 3-alkylideneoxindoles to nitroolefins," Advanced Synthesis \& Catalysis, vol. 355, no. 9, pp. 1881-1886, 2013.

[244] S. Brandau, A. Landa, J. Franzén, M. Marigo, and K. A. Jørgensen, "Organocatalytic conjugate addition of malonates to alpha,beta-unsaturated aldehydes: asymmetric formal synthesis of (-)-paroxetine, chiral lactams, and lactones," Angewandte Chemie International Edition, vol. 45, no. 26, pp. 4305-4309, 2006.

[245] L. J. Hounjet, C. Bannwarth, C. N. Garon, C. B. Caputo, S. Grimme, and D. W. Stephan, "Combinations of ethers and $\mathrm{B}\left(\mathrm{C}_{6} \mathrm{~F}_{5}\right)_{3}$ function as hydrogenation catalysts," Angewandte Chemie International Edition, vol. 52, no. 29, pp. 7492-7495, 2013.

[246] X.-F. Cai, M.-W. Chen, Z.-S. Ye et al., "Asymmetric transfer hydrogenation of 3-nitroquinolines: facile access to cyclic nitro compounds with two contiguous stereocenters," ChemistryAn Asian Journal, vol. 8, no. 7, pp. 1381-1385, 2013.

[247] M. Kitamura, S. Shirakawa, and K. Maruoka, "Powerful chiral phase-transfer catalysts for the asymmetric synthesis of alphaalkyl- and alpha,alpha-dialkyl-alpha-amino acids," Angewandte Chemie International Edition, vol. 44, pp. 1549-1551, 2005.

[248] T. Ooi, Y. Arimura, Y. Hiraiwa et al., "Highly enantioselective monoalkylation of p-chlorobenzaldehyde imine of glycine tertbutyl ester under mild phase-transfer conditions," Tetrahedron: Asymmetry, vol. 17, pp. 603-606, 2006.

[249] T. Ooi and K. Maruoka, "Development and applications of C2symmetric, chiral, phase-transfer catalysts," Aldrichimica Acta, vol. 40, no. 3, pp. 77-86, 2007.
[250] E. J. Corey, R. K. Bakshi, and S. Shibata, "Highly enantioselective borane reduction of ketones catalyzed by chiral oxazaborolidines. Mechanism and synthetic implications," Journal of the American Chemical Society, vol. 109, pp. 5551-5553, 1987.

[251] E. J. Corey, R. K. Bakshi, S. Shibata, C. P. Chen, and V. K. Singh, "A stable and easily prepared catalyst for the enantioselective reduction of ketones. Applications to multistep syntheses," Journal of the American Chemical Society, vol. 109, pp. 79257926, 1987.

[252] E. H. M. Kirton, G. Tughan, R. E. Morris, and R. A. Field, "Rationalising the effect of reducing agent on the oxazaborolidinemediated asymmetric reduction of $\mathrm{N}$-substituted imines," Tetrahedron Letters, vol. 45, pp. 853-855, 2004.

[253] B. T. Cho and Y. S. Chun, "Enantioselective synthesis of optically active metolachlor via asymmetric reduction," Tetrahedron Asymmetry, vol. 3, no. 3, pp. 337-340, 1992.

[254] B. T. Cho and Y. S. Chun, "Asymmetric reduction of Nsubstituted ketimines with the reagent prepared from borane and (S)-(-)-2-amino-3-methyl-1,1-diphenylbutan-1-ol (itsuno's reagent): enantioselective synthesis of optically active secondary amines," Journal of the Chemical Society, Perkin Transactions, vol. 1, pp. 3200-3201, 1990.

[255] R. D. Tillyer, C. Boudreau, D. Tschaen, U.-H. Dolling, and P. J. Reider, "Asymmetric reduction of keto oxime ethers using oxazaborolidine reagents. The enantioselective synthesis of cyclic amino alcohols," Tetrahedron Letters, vol. 36, no. 25, pp. 4337-4340, 1995.

[256] D. H. Ryu and E. J. Corey, "Triflimide activation of a chiral oxazaborolidine leads to a more general catalytic system for enantioselective Diels-Alder addition," Journal of the American Chemical Society, vol. 125, pp. 6388-6390, 2003.

[257] Y. Tu, Z.-X. Wang, and Y. Shi, "An efficient asymmetric epoxidation method for trans-olefins mediated by a fructose-derived ketone," Journal of the American Chemical Society, vol. 118, no. 40, pp. 9806-9807, 1996.

[258] Z.-X. Wang, Y. Tu, M. Frohn, J.-R. Zhang, and Y. Shi, "An efficient catalytic asymmetric epoxidation method," Journal of the American Chemical Society, vol. 119, no. 46, pp. 11224-11235, 1997.

[259] Z.-X. Wang, Y. Tu, M. Frohn, J.-R. Zhang, and Y. Shi, "An efficient catalytic asymmetric epoxidation method," Journal of the American Chemical Society, vol. 119, no. 46, pp. 11224-11235, 1997.

[260] M. Marigo, J. Franzén, T. B. Poulsen, W. Zhuang, and K. A. Jørgensen, "Asymmetric organocatalytic epoxidation of $\alpha, \beta$ unsaturated aldehydes with hydrogen peroxide," Journal of the American Chemical Society, vol. 127, no. 19, pp. 6964-6965, 2005.

[261] N. Marion, S. Díez-González, and S. P. Nolan, "Inside cover: a molecular solomon link (Angew. Chem. Int. Ed. 1-2/2007)," Angewandte Chemie International Edition, vol. 46, p. 2, 2007.

[262] M. S. Kerr and T. Rovis, "Enantioselective synthesis of quaternary stereocenters via a catalytic asymmetric stetter reaction," Journal of the American Chemical Society, vol. 126, no. 29, pp. 8876-8877, 2004.

[263] M. He, J. R. Struble, and J. W. Bode, "Highly enantioselective azadiene diels-alder reactions catalyzed by chiral Nheterocyclic carbenes," Journal of the American Chemical Society, vol. 128, pp. 8418-8420, 2006.

[264] M. He, G. J. Uc, and J. W. Bode, "Chiral N-heterocyclic carbene catalyzed, enantioselective oxodiene Diels-Alder reactions with low catalyst loadings," Journal of the American Chemical Society, vol. 128, pp. 15088-15089, 2006. 
[265] P.-C. Chiang, J. Kaeobamrung, and J. W. Bode, "Enantioselective, cyclopentene-forming annulations via NHC-catalyzed benzoin-oxy-Cope reactions," Journal of the American Chemical Society, vol. 129, no. 12, pp. 3520-3521, 2007.

[266] S. S. Sohn and J. W. Bode, "N-heterocyclic carbene catalyzed $\mathrm{C}-\mathrm{C}$ bond cleavage in redox esterifications of chiral formylcyclopropanes," Angewandte Chemie International Edition, vol. 45, pp. 6021-6024, 2006.

[267] A. Grossmann and D. Enders, "N-heterocyclic carbene catalyzed domino reactions," Angewandte Chemie International Edition, vol. 51, no. 2, pp. 314-325, 2012.

[268] D. Enders, R. Hahn, and I. Atodiresei, "Asymmetric synthesis of functionalized tetrahydronaphthalenes via an organocatalytic nitroalkane-michael/henry domino reaction," Advanced Synthesis \& Catalysis, vol. 355, no. 6, pp. 1126-1136, 2013.

[269] H. Pellissier, "Recent developments in asymmetric organocatalytic domino reactions," Advanced Synthesis \& Catalysis, vol. 354, no. 2-3, pp. 237-294, 2012.

[270] L. Wu, Y. Wang, H. Song, L. Tang, Z. Zhou, and C. Tang, "Enantioselective organocatalytic domino Michael/aldol reactions: an efficient procedure for the stereocontrolled construction of 2H-thiopyrano[2,3-b]quinoline scaffolds," Chemistry-An Asian Journal, vol. 8, pp. 2204-2210, 2013.

[271] J. Zhao, C. Mück-Lichtenfeld, and A. Studer, "Cooperative Nheterocyclic carbene (NHC) and ruthenium redox catalysis: oxidative esterification of aldehydes with air as the terminal oxidant," Advanced Synthesis \& Catalysis, vol. 355, no. 6, pp. 1098-1106, 2013.

[272] R. Blanc, P. Nava, M. Rajzman, L. Commeiras, and J.-L. Parrain, "N-Heterocyclic carbene mediated organocatalytic transfer of tin onto aldehydes: an easy access to syn-diols and mechanistic studies," Advanced Synthesis \& Catalysis, vol. 354, no. 10, pp. 2038-2048, 2012.

[273] S. De Sarkar, A. Biswas, R. C. Samanta, and A. Studer, "Catalysis with N-heterocyclic carbenes under oxidative conditions," Chemistry - A European Journal, vol. 19, no. 15, pp. 4664-4678, 2013.

[274] H. U. Vora, P. Wheeler, and T. Rovis, "Exploiting acyl and enol azolium intermediates via N-hetero-cyclic carbene-catalyzed reactions of $\alpha$-reducible aldehydes," Advanced Synthesis \& Catalysis, vol. 354, no. 9, pp. 1617-1639, 2012.

[275] J. Mo, L. Shen, and Y. R. Chi, “Direct $\beta$-activation of saturated aldehydes to formal Michael acceptors through oxidative NHC catalysis," Angewandte Chemie International Edition, vol. 52, no. 33, pp. 8588-8591, 2013.

[276] M. Hans, J. Wouters, A. Demonceau, and L. Delaude, "Mechanistic insight into the staudinger reaction catalyzed by $\mathrm{N}$ heterocyclic carbenes," Chemistry - A European Journal, vol. 19, no. 29, pp. 9668-9676, 2013.

[277] W. Raimondi, D. Bonne, and J. Rodriguez, "1,2-dicarbonyl compounds as pronucleophiles in organocatalytic asymmetric transformations," Angewandte Chemie International Edition, vol. 51, no. 1, pp. 40-42, 2012.

[278] A. Rai and L. D. S. Yadav, "Cyclopropenone-catalyzed direct conversion of aldoximes and primary amides into nitriles," European Journal of Organic Chemistry, vol. 10, pp. 1889-1893, 2013.

[279] J. Marco-Martínez, V. Marcos, S. Reboredo, S. Filippone, and N. Martín, "Asymmetric organocatalysis in fullerenes chemistry: enantioselective phosphine-catalyzed cycloaddition of allenoates onto $\mathrm{C}_{60}$," Angewandte Chemie International Edition, vol. 52, no. 19, pp. 5115-5119, 2013.
[280] A.-L. Lee, “Organocatalyzed carbonyl-olefin metathesis," Angewandte Chemie International Edition, vol. 52, no. 17, pp. 45244525, 2013.

[281] F. Kniep, S. H. Jungbauer, Q. Zhang et al., "Organocatalysis by neutral multidentate halogen-bond donors," Angewandte Chemie International Edition, vol. 52, no. 27, pp. 7028-7032, 2013.

[282] J. H. Kim, I. Coric, S. Vellalath, and B. List, "The catalytic asymmetric acetalization," Angewandte Chemie International Edition, vol. 52, no. 16, pp. 4474-4477, 2013.

[283] P. Chauhan and S. S. Chimni, "Organocatalytic enantioselective Morita-Baylis-Hillman reaction of maleimides with isatins," Asian Journal of Organic Chemistry, vol. 2, no. 7, pp. 586-592, 2013.

[284] P. Chauhan, J. Kaur, and S. S. Chimni, "Asymmetric organocatalytic addition reactions of maleimides: a promising approach towards the synthesis of chiral succinimide derivatives," Chemistry-An Asian Journal, vol. 8, no. 2, pp. 328-346, 2013.

[285] C. C. J. Loh and D. Enders, "Exploiting the electrophilic properties of indole intermediates: new options in designing asymmetric reactions," Angewandte Chemie International Edition, vol. 51, no. 1, pp. 46-48, 2012.

[286] A. Martínez, M. J. Webber, S. Müller, and B. List, "Versatile access to chiral indolines by catalytic asymmetric fischer indolization," Angewandte Chemie International Edition, vol. 52, no. 36, pp. 948-9490, 2013.

[287] Z. Shi and T.-P. Loh, "Organocatalytic synthesis of highly functionalized pyridines at room temperature," Angewandte Chemie International Edition, vol. 52, no. 33, pp. 8584-8587, 2013.

[288] A. V. Malkov, S. Stoncius, M. Bell et al., "Mechanistic dichotomy in the asymmetric allylation of aldehydes with allyltrichlorosilanes catalyzed by chiral pyridine N-oxides," Chemistry-A European Journal, vol. 19, no. 28, pp. 9167-9185, 2013.

[289] K. Shibatomi and A. Narayama, "Catalytic enantioselective $\alpha$ chlorination of carbonyl compounds," Asian Journal of Organic Chemistry, vol. 2, no. 10, pp. 812-823, 2013.

[290] C. C. J. Loh and D. Enders, "Merging organocatalysis and gold catalysis - a critical evaluation of the underlying concepts," Chemistry-A European Journal, vol. 18, no. 33, pp. 10212-10225, 2012.

[291] H.-N. Yuan, S. Wang, J. Nie, W. Meng, Q. Yao, and J.-A. $\mathrm{Ma}$, "Hydrogen-bond-directed enantioselective decarboxylative Mannich reaction of $\beta$-ketoacids with ketimines: application to the synthesis of anti-HIV drug DPC 083," Angewandte Chemie International Edition, vol. 52, no. 14, pp. 3869-3873, 2013.

[292] Y. Hayashi, D. Sakamoto, H. Shomura, and D. Hashizume, "Asymmetric Mannich reaction of $\alpha$-keto imines catalyzed by diarylprolinol silyl ether," Chemistry-A European Journal, vol. 19, no. 24, pp. 7678-7681, 2013.

[293] W.-Q. Zhang, L.-F. Cheng, J. Yu, and L.-Z. Gong, "A chiral bis(betaine) catalyst for the mannich reaction of azlactones and aliphatic imines," Angewandte Chemie International Edition, vol. 51, no. 17, pp. 4085-4088, 2012.

[294] L. Hong and R. Wang, "Recent advances in asymmetric organocatalytic construction of $3,3^{\prime}$-spirocyclic oxindoles," Advanced Synthesis \& Catalysis, vol. 355, no. 6, pp. 1023-1052, 2013.

[295] M.-X. Wei, C.-T. Wang, J.-Y. Du et al., "Enantioselective synthesis of Amaryllidaceae alkaloids (+)-vittatine, (+)-epi-vittatine, and (+)-buphanisine," Chemistry-An Asian Journal, vol. 8, no. 9, pp. 1966-1971, 2013. 
[296] H.-J. Yang, F.-J. Xiong, X.-F. Chen, and F.-E. Chen, "Highly enantioselective thiolysis of prochiral cyclic anhydrides catalyzed by amino alcohol bifunctional organocatalysts and its application to the synthesis of pregabalin," European Journal of Organic Chemistry, vol. 2013, no. 21, pp. 4495-4489, 2013.

[297] R. Selke and M. Capka, "Carbohydrate phosphinites as chiral ligands for asymmetric syntheses catalyzed by complexes: part VIII: immobilization of cationic rhodium(I) chelates of phenyl 4,6-O-(R)-benzylidene-2,3-bis(O-diphenylphosphino)$\beta$-D-glucopyranoside on silica," Journal of Molecular Catalysis, vol. 63, pp. 319-334, 1990.

[298] M. Ichikawa, “'Ship-in-Bottle’ catalyst technology. Novel templating fabrication of platinum group metals nanoparticles and wires in micro/mesopores," Platinum Metals Review, vol. 44, no. 1, pp. 3-14, 2000.

[299] V. Trevisan, M. Signoretto, S. Colonna, V. Pironti, and G. Strukul, "Microencapsulated chloroperoxidase as a recyclable catalyst for the enantioselective oxidation of sulfides with hydrogen peroxide," Angewandte Chemie International Edition, vol. 43, no. 31, pp. 4097-4099, 2004.

[300] Á. Zsigmond, F. Notheisz, G. Csjernyik, and J.-E. Bäckvall, "Ruthenium-catalyzed aerobic oxidation of alcohols on zeoliteencapsulated cobalt salophen catalyst," Topics in Catalysis, vol. 19, no. 1, pp. 119-124, 2002.

[301] N. Legagneux, E. Jeanneau, A. Thomas et al., "Grafting reaction of platinum organometallic complexes on silica-supported or unsupported heteropolyacids," Organometallics, vol. 30, no. 7, pp. 1783-1793, 2011.

[302] Y. Wan, F. Zhang, Y. Lu, and H. Li, "Immobilization of Ru(II) complex on functionalized SBA-15 and its catalytic performance in aqueous homoallylic alcohol isomerization," Journal of Molecular Catalysis A, vol. 267, pp. 165-172, 2007.

[303] D. R. Burri, I. R. Shaikh, K.-M. Choi, and S.-E. Park, "Facile heterogenization of homogeneous ferrocene catalyst on SBA-15 and its hydroxylation activity," Catalysis Communications, vol. 8, no. 4, pp. 731-735, 2007.

[304] M. Kuroki, T. Asefa, W. Whitnal et al., "Synthesis and properties of 1,3,5-benzene periodic mesoporous organosilica (PMO): novel aromatic PMO with three point attachments and unique thermal transformations," Journal of the American Chemical Society, vol. 124, no. 46, pp. 13886-13895, 2002.

[305] T. Maschmeyer, F. Rey, G. Sankar, and J. M. Thomas, "Heterogeneous catalysts obtained by grafting metallocene complexes onto mesoporous silica," Nature, vol. 378, pp. 159-162, 1995.

[306] L. Hamidipour, Z. Ghasemzadeh, F. Farzaneh, and M. Ghandi, "Immobilization of $\mathrm{Cu}(\mathrm{II})$-histidine complex on Al-MCM-41 as catalyst for epoxidation of alkenes," Journal of Sciences, vol. 23, no. 1, pp. 29-36, 2012.

[307] J. G. Mesu, D. Baute, H. J. Tromp, E. E. Van Faassen, and B. M. Weckhuysen, "Synthesis and characterization of zeolite encaged enzyme-mimetic copper histidine complexes," Studies in Surface Science and Catalysis, vol. 143, pp. 287-293, 2002.

[308] B. M. Weckhuysen, A. A. Verberckmoes, L. Fu, and R. A. Schoonheydt, "Zeolite-encapsulated copper(II) amino acid complexes: synthesis, spectroscopy, and catalysis," Journal of Physical Chemistry, vol. 100, no. 22, pp. 9456-9461, 1996.

[309] D. Xuereb, J. Dzierzak, and R. Raja, "Biomimetic single-site heterogeneous catalysts: design strategies and catalytic potential," in Heterogenized Homogeneous Catalysts For Fine Chemicals Production, vol. 33 of Catalysis by Metal Complexes, pp. 37-63, 2010.
[310] P. Barbaro and F. Liguori, Eds., Heterogenized Homogeneous Catalysts for Fine Chemicals Production, vol. 33 of Materials and Processes Series: Catalysis by Metal Complexes, Springer, 2010.

[311] Z. An, W. Zhang, H. Shi, and J. He, "An effective heterogeneous 1-proline catalyst for the asymmetric aldol reaction using anionic clays as intercalated support," Journal of Catalysis, vol. 241, pp. 319-327, 2006.

[312] J. W. Wiench, Y. S. Avadhut, N. Maity et al., "Characterization of covalent linkages in organically functionalized MCM-41 mesoporous materials by solid-state NMR and theoretical calculations," Journal of Physical Chemistry B, vol. 111, no. 15, pp. 3877-3885, 2007.

[313] Q. Gao, W. Xu, Y. Xu et al., "Amino acid adsorption on mesoporous materials: influence of types of amino acids, modification of mesoporous materials, and solution conditions," The Journal of Physical Chemistry B, vol. 112, no. 7, pp. 2261-2267, 2008.

[314] S. Luo, J. Li, L. Zhang, H. Xu, and J. P. Cheng, "Noncovalently supported heterogeneous chiral amine catalysts for asymmetric direct aldol and Michael addition reactions," Chemistry $-A$ European Journal, vol. 14, no. 4, pp. 1273-1281, 2008.

[315] C. Aprile, F. Giacalone, M. Gruttadauria et al., "New ionic liquid-modified silica gels as recyclable materials for 1-prolineor H-Pro-Pro-Asp-NH2-catalyzed aldol reaction," Green Chemistry, vol. 9, no. 12, pp. 1328-1334, 2007.

[316] I. Hermans, J. Van Deun, K. Houthoofd, J. Peeters, and P. A. Jacobs, "Silica-immobilized N-hydroxyphthalimide: an efficient heterogeneous autoxidation catalyst," Journal of Catalysis, vol. 251, no. 1, pp. 204-212, 2007.

[317] K. Yamaguchi, T. Imago, Y. Ogasawara, J. Kasai, M. Kotani, and N. Mizuno, "An immobilized organocatalyst for cyanosilylation and epoxidation," Advanced Synthesis and Catalysis, vol. 348, no. 12-13, pp. 1516-1520, 2006.

[318] H. Hagiwara, S. Inotsume, M. Fukushima, T. Hoshi, and T. Suzuki, "Heterogeneous amine catalyst grafted on amorphous silica: an effective organocatalyst for microwave-promoted Michael reaction of 1,3-dicarbonyl compounds in water," Chemistry Letters, vol. 35, no. 8, pp. 926-927, 2006.

[319] A. Corma and H. Garcia, "Silica-bound homogenous catalysts as recoverable and reusable catalysts in organic synthesis," Advanced Synthesis Catalysis, vol. 348, pp. 1391-1412, 2006.

[320] C. Ayats, A. H. Henseler, and M. A. Pericás, "A solid-supported organocatalyst for continuous-flow enantioselective aldol reactions," ChemSusChem, vol. 5, no. 2, pp. 320-325, 2012.

[321] D. Font, C. Jimeno, and M. A. Pericàs, "Polystyrene-supported hydroxyproline: an insoluble, recyclable organocatalyst for the asymmetric aldol reaction in water," Organic Letters, vol. 8, pp. 4653-4655, 2006.

[322] D. Font, S. Sayalero, C. Jimeno, and M. A. Pericàs, “Toward an artificial aldolase," Organic Letters, vol. 10, pp. 337-340, 2008.

[323] D. Font, S. Sayalero, A. Bastero, C. Jimeno, and M. A. Pericàs, “Toward an artificial aldolase," Organic Letters, vol. 12, p. 2678, 2010.

[324] M. Benaglia, M. Cinquini, F. Cozzi, A. Puglisi, and G. Celentano, "Poly(ethylene-glycol)-supported proline: a recyclable aminocatalyst for the enantioselective synthesis of $\gamma$ nitroketones by conjugate addition," Journal of Molecular Catalysis A, vol. 204-205, pp. 157-163, 2003.

[325] D. Q. Xu, S. P. Luo, Y. F. Wang et al., "Organocatalysts wrapped around by poly(ethylene glycol)s (PEGs): a unique host-guest system for asymmetric Michael addition reactions," Chemical Communications, no. 42, pp. 4393-4395, 2007. 
[326] A. M. Caminade, A. Ouali, M. Keller, and J. P. Majoral, "Organocatalysis with dendrimers," Chemical Society Reviews, vol. 41, pp. 4113-4125, 2012.

[327] L. Zhang, S. Luo, and J.-P. Cheng, "Non-covalent immobilization of asymmetric organocatalysts," Catalysis Science and Technology, vol. 1, no. 4, pp. 507-516, 2011.

[328] B.-C. Hong, H.-C. Tseng, and S.-H. Chen, "Synthesis of aromatic aldehydes by organocatalytic [4+2] and [3+3] cycloaddition of $\alpha, \beta$-unsaturated aldehydes," Tetrahedron, vol. 63, no. 13, pp. 2840-2850, 2007.

[329] M. J. Gaunt, C. C. C. Johansson, A. McNally, and N. T. Vo, "Enantioselective organocatalysis," Drug Discovery Today, vol. 12, no. 1-2, pp. 8-27, 2007.

[330] D. J. Xuereb and R. Raja, "Design strategies for engineering selectivity in bio-inspired heterogeneous catalysts," Catalysis Science and Technology, vol. 1, no. 4, pp. 517-534, 2011.

[331] D. J. Xuereb, Strategies for organocatalyst heterogenisation and performance in selective transformations [Ph.D. thesis], University of Southampton, 2012.

[332] D. E. De Vos, I. F. J. Vankelecom, and P. A. Jacobs, Eds., Chiral Catalyst Immobilization and Recycling, Wiley-VCH, Weinheim, Germany, 2000.

[333] J. Zhou, J. Wan, X. Ma, and W. Wang, "Copolymer-supported heterogeneous organocatalyst for asymmetric aldol addition in aqueous medium," Organic \& Biomolecular Chemistry, vol. 10, pp. 4179-4185, 2012.

[334] P. C. Bulman Page, A. Mace, D. Arquier et al., "Towards heterogeneous organocatalysis: chiral iminium cations supported on porous materials for enantioselective alkene epoxidation," Catalysis Science \& Technology, vol. 3, pp. 2330-2339, 2013.

[335] J. Franzén, M. Marigo, D. Fielenbach, T. C. Wabnitz, A. Kjaersgaard, and K. A. Jørgensen, "A general organocatalyst for direct $\alpha$-functionalization of aldehydes: stereoselective $\mathrm{C}-\mathrm{C}$, $\mathrm{C}-\mathrm{N}, \mathrm{C}-\mathrm{F}, \mathrm{C}-\mathrm{Br}$, and $\mathrm{C}-\mathrm{S}$ bond-forming reactions. Scope and mechanistic insights," Journal of the American Chemical Society, vol. 127, no. 51, pp. 18296-18304, 2005.

[336] M. Fochi, L. Gramigna, A. Mazzanti et al., "Solvent-free noncovalent organocatalysis: enantioselective addition of nitroalkanes to alkylideneindolenines as a flexible gateway to optically active tryptamine derivatives," Advanced Synthesis \& Catalysis, vol. 354, pp. 71373-71380, 2012.

[337] Y. Zhang, Y. Zhang, Y. L. Sun et al., "4-(N,N-dimethylamino)pyridine-embedded nanoporous conjugated polymer as a highly active heterogeneous organocatalyst," Chemistry - $A$ European Journal, vol. 18, no. 20, pp. 6328-6334, 2012.

[338] C. A. Wang, Y. Zhang, J. Y. Shi, and W. Wang, "A self-supported polymeric MacMillan catalyst for homogeneous organocatalysis and heterogeneous recycling," Chemistry-An Asian Journal, vol. 8, no. 6, pp. 1110-1114, 2013.

[339] V. Lucchini, M. Noè, M. Selva, M. Fabris, and A. Perosa, "Cooperative nucleophilic-electrophilic organocatalysis by ionic liquids," Chemical Communications, vol. 48, no. 42, pp. 5178-5180, 2012.

[340] D. Kühbeck, G. Saidulu, K. R. Reddy, and D. D. Díaz, “Critical assessment of the efficiency of chitosan biohydrogel beads as recyclable and heterogeneous organocatalyst for $\mathrm{C}-\mathrm{C}$ bond formation," Green Chemistry, vol. 14, pp. 378-392, 2012.

[341] S. Verma, S. L. Jain, and B. Sain, "An efficient biomaterial supported bifunctional organocatalyst $\left(\mathrm{ES}-\mathrm{SO}_{3}{ }^{-} \mathrm{C}_{5} \mathrm{H}_{5} \mathrm{NH}^{+}\right)$for the synthesis of $\beta$-amino carbonyls," Organic \& Biomolecular Chemistry, vol. 9, pp. 2314-2318, 2011.
[342] M. S. DeClue and J. S. Siegel, "Polysiloxane-bound ligand accelerated catalysis: a modular approach to heterogeneous and homogeneous macromolecular asymmetric dihydroxylation ligands," Organic \& Biomolecular Chemistry, vol. 2, pp. 22872298, 2004.

[343] G. Kardos and T. Soós, "Tether-free immobilized bifunctional squaramide organocatalysts for batch and flow reactions," European Journal of Organic Chemistry, vol. 2013, no. 21, pp. 4490-4494, 2013.

[344] P. Kasaplar, P. Riente, C. Hartmann, and M. A. Pericàs, "A polystyrene-supported, highly recyclable squaramide organocatalyst for the enantioselective Michael addition of 1,3-dicarbonyl compounds to $\beta$-nitrostyrenes," Advanced Synthesis \& Catalysis, vol. 354, no. 16, pp. 2905-2910, 2013.

[345] K. E. Alza, C. Rodríguez-Escrich, S. Sayalero, A. Bastero, and M. A. Pericàs, "A solid-supported organocatalyst for highly stereoselective, batch, and continuous-flow mannich reactions," Chemistry - A European Journal, vol. 15, no. 39, pp. 10167-10172, 2009.

[346] P. Riente, J. Yadav, and M. A. Pericàs, "A solid-supported organocatalyst for continuous-flow enantioselective aldol reactions," ChemSusChem, vol. 5, no. 2, pp. 320-325, 2012.

[347] M. Kotke and P. Schreiner, "(Thio)Urea Organocatalysts," in Hydrogen Bonding in Organic Synthesis, P. M. Pihko, Ed., pp. 141-352, Wiley-VCH, 2009.

[348] Y. Takemoto, "Development of chiral thiourea catalysts and its application to asymmetric catalytic reactions," Chemical and Pharmaceutical Bulletin, vol. 58, pp. 593-601, 2010.

[349] M. Tsakos, C. G. Kokotos, and G. Kokotos, "Primary aminethioureas with improved catalytic properties for "difficult" Michael reactions: efficient organocatalytic syntheses of (S)baclofen, (R)-baclofen and (S)-phenibut," Advanced Synthesis and Catalysis, vol. 354, no. 4, pp. 740-746, 2012.

[350] M. Tsakos and C. G. Kokotos, "Organocatalytic "Difficult" Michael reaction of ketones with nitrodienes utilizing a primary amine-thiourea based on di-tert-butyl aspartate," European Journal of Organic Chemistry, vol. 2012, no. 3, pp. 576-580, 2012.

[351] J. Hine, S.-M. Linden, and V. M. Kanagasabapathy, "1,8Biphenylenediol is a double-hydrogen-bonding catalyst for reaction of an epoxide with a nucleophile," Journal of the American Chemical Society, vol. 107, no. 4, pp. 1082-1083, 1985.

[352] J. Hine, S. M. Linden, and V. M. Kanagasabapathy, "Doublehydrogen-bonding catalysis of the reaction of phenyl glycidyl ether with diethylamine by 1,8-biphenylenediol," The Journal of Organic Chemistry, vol. 50, pp. 5096-5099, 1985.

[353] C. K. De, E. G. Klauber, and D. Seidel, "Merging nucleophilic and hydrogen bonding catalysis: an anion binding approach to the kinetic resolution of amines," Journal of the American Chemical Society, vol. 131, pp. 17060-17061, 2009.

[354] R. P. Herrera, V. Sgarzani, L. Bernardi, and A. Ricci, "Catalytic enantioselective friedel-crafts alkylation of indoles with nitroalkenes by using a simple thiourea organocatalyst," Angewandte Chemie International Edition, vol. 44, pp. 6576-6579, 2005.

[355] "Special issue on "Organocatalysis"', Advanced Synthesis \& Catalysis, vol. 346, no. 9-10, 2004.

[356] F. Cozzi, "Immobilization of organic catalysts: when, why, and how," Advanced Synthesis \& Catalysis, vol. 348, pp. 1367-1390, 2006. 
[357] T. E. Kristensen and T. Hansen, "Polymer-supported chiral organocatalysts: synthetic strategies for the road towards affordable polymeric immobilization," European Journal of Organic Chemistry, no. 17, pp. 3179-3204, 2010.

[358] M. Benaglia, F. Cozzi, and A. Puglisi, "Polymer-supported organic catalysts," Chemical Reviews, vol. 103, no. 9, pp. 34013429, 2003.

[359] M. Benaglia, Ed., Recoverable and Recyclable Catalysts, John Wiley \& Sons, Chichester, UK, 2009.

[360] J. Lu and P. H. Toy, "Organic polymer supports for synthesis and for reagent and catalyst immobilization," Chemical Reviews, vol. 109, no. 2, pp. 815-838, 2009.

[361] M. Gruttadauria, F. Giacalone, and R. Noto, "Supported proline and proline-derivatives as recyclable organocatalysts," Chemical Society Reviews, vol. 37, no. 8, pp. 1666-1688, 2008.

[362] F. Calderón, R. Fernández, F. Sánchez, and A. FernándezMayoralas, "Asymmetric aldol reaction using immobilized proline on mesoporous support," Advanced Synthesis \& Catalysis, vol. 347, no. 10, pp. 1395-1403, 2005.

[363] L. Qin, L. Zhang, Q. Jin, J. Zhang, B. Han, and M. Liu, "Supramolecular assemblies of amphiphilic L-proline regulated by compressed $\mathrm{CO}_{2}$ as a recyclable organocatalyst for the asymmetric aldol reaction," Angewandte Chemie International Edition, vol. 52, no. 30, pp. 7761-7765.

[364] S. Luo, J. Li, L. Zhang, H. Xu, and J.-P. Cheng, "Noncovalently supported heterogeneous chiral amine catalysts for asymmetric direct aldol and Michael addition reactions," Chemistry-A European Journal, vol. 14, no. 4, pp. 1273-1281, 2008.

[365] H. Hagiwara, S. Inotsume, M. Fukushima, T. Hoshi, and T. Suzuki, "Heterogeneous amine catalyst grafted on amorphous silica: an effective organocatalyst for microwave-promoted Michael reaction of 1,3-dicarbonyl compounds in water," Chemistry Letters, vol. 35, no. 8, pp. 926-927, 2006.

[366] I. Hermans, J. Van Deun, K. Houthoofd, J. Peeters, and P. A. Jacobs, "Silica-immobilized N-hydroxyphthalimide: an efficient heterogeneous autoxidation catalyst," Journal of Catalysis, vol. 251, no. 1, pp. 204-212, 2007.

[367] A. Corma and H. Garcia, "Silica-bound homogenous catalysts as recoverable and reusable catalysts in organic synthesis," Advanced Synthesis \& Catalysis, vol. 348, pp. 1391-1412, 2006.

[368] K. Yamaguchi, T. Imago, Y. Ogasawara, J. Kasai, M. Kotani, and N. Mizuno, "An immobilized organocatalyst for cyanosilylation and epoxidation," Advanced Synthesis and Catalysis, vol. 348, no. 12-13, pp. 1516-1520, 2006.

[369] A. Córdova and J. Hafrén, "Direct Homogeneous and Heterogeneous Organic Acid and Amino Acid-Catalyzed Modification of Amines and Alcohols," International Patent WO 2006068611 A1 20060629.

[370] R. S. Verma and V. Polshettiwar, "Magnetic nanoparticlesupported glutathione as a sustainable organocatalyst," Patent no.: US, 8324125 B2, December 2012.

[371] R. C. Garrett and H. Yang, "Sulfonamide-Based Organocatalysis and Method for their Use," Patent no.: US 8, 399, 684 B2, March 2013.

[372] A. M. Caminade, C. O. Turrin, R. Laurent, A. Ouali, and B. Delavaux-Nicot, Eds., Dendrimers Towards Catalytic Material and Biomedical Uses, John Wiley \& Sons, Chichester, UK, 2011.

[373] P. Servin, R. Laurent, L. Gonsalvi et al., "Grafting of watersoluble phosphines to dendrimers and their use in catalysis: positive dendritic effects in aqueous media," Dalton Transactions, no. 23, pp. 4432-4434, 2009.
[374] M. Keller, A. Perrier, R. Linhardt et al., "Dendrimers or nanoparticles as supports for the design of efficient and recoverable organocatalysts?" Advanced Synthesis \& Catalysis, vol. 355, no. 9, pp. 1748-1754, 2013.

[375] Thematic Series "Organocatalysis" (Guest Editor: Benjamin List) Beilstein Journal of Organic Chemistry, 2012, http://www .beilstein-journals.org/bjoc/browse/singleSeries.htm?sn=27.

[376] Y. S. Lee, M. M. Alam, and R. S. Keri, "Enantioselective reactions of $\mathrm{N}$-acyliminium ions using chiral organocatalysts," Chemistry-An Asian Journal, vol. 8, no. 12, pp. 2906-2919, 2013.

[377] F. Lv, S. Liu, and W. Hu, "Recent advances in the use of chiral brønsted acids as cooperative catalysts in cascade and multicomponent reactions," Asian Journal of Organic Chemistry, vol. 2, no. 10, pp. 824-836, 2013.

[378] W. Yan, X. Shi, and C. Zhong, "Secondary amines as lewis bases in nitroalkene activation," Asian Journal of Organic Chemistry, vol. 2, no. 11, pp. 904-914, 2013.

[379] S. Ulf and M. Rainer, "Recent advances in organocatalytic methods for asymmetric C-C bond formation," Chemistry- $A$ European Journal, vol. 19, no. 43, pp. 14346-14396, 2013.

[380] S. Narayanaperumal, D. G. Rivera, R. C. Silva, and M. W. Paixão, "Terpene-derived bifunctional thioureas in asymmetric organocatalysis," ChemCatChem, vol. 5, no. 10, pp. 2756-2773, 2013.

[381] L.-W. Xu, "Powerful amino acid derived bifunctional phosphine catalysts bearing a hydrogen bond donor in asymmetric synthesis," ChemCatChem, vol. 5, no. 10, pp. 2775-2784, 2013.

[382] N. Kielland, C. J. Whiteoak, and A. W. Kleij, "Stereoselective synthesis with carbon dioxide," Advanced Synthesis \& Catalysis, vol. 355, no. 11-12, pp. 2115-2138, 2013.

[383] S. Mohammadi, R. Heiran, R. P. Herrera, and E. MarquésLópez, "Isatin as a strategic motif for asymmetric catalysis," ChemCatChem, vol. 5, no. 8, pp. 2131-2148, 2013. 

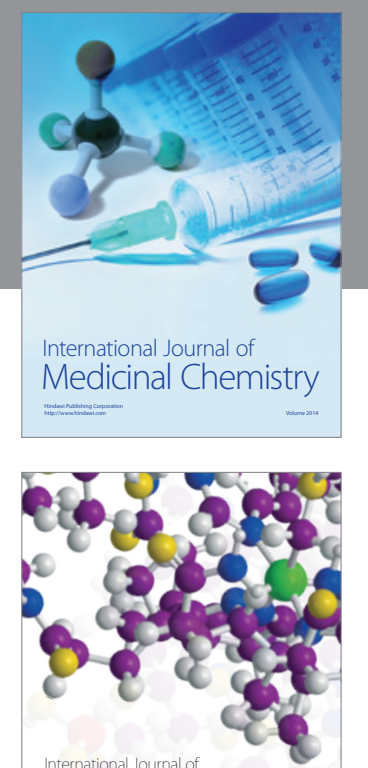

\section{Carbohydrate} Chemistry

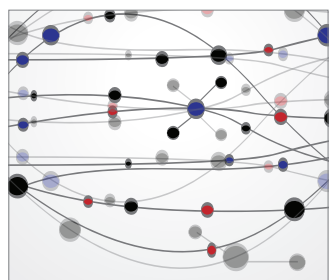

The Scientific World Journal
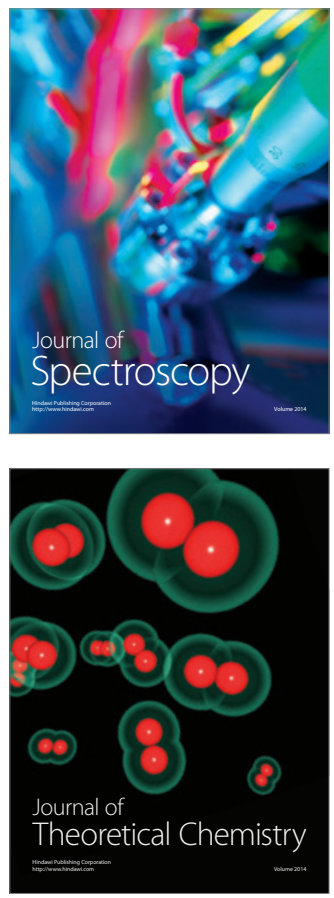
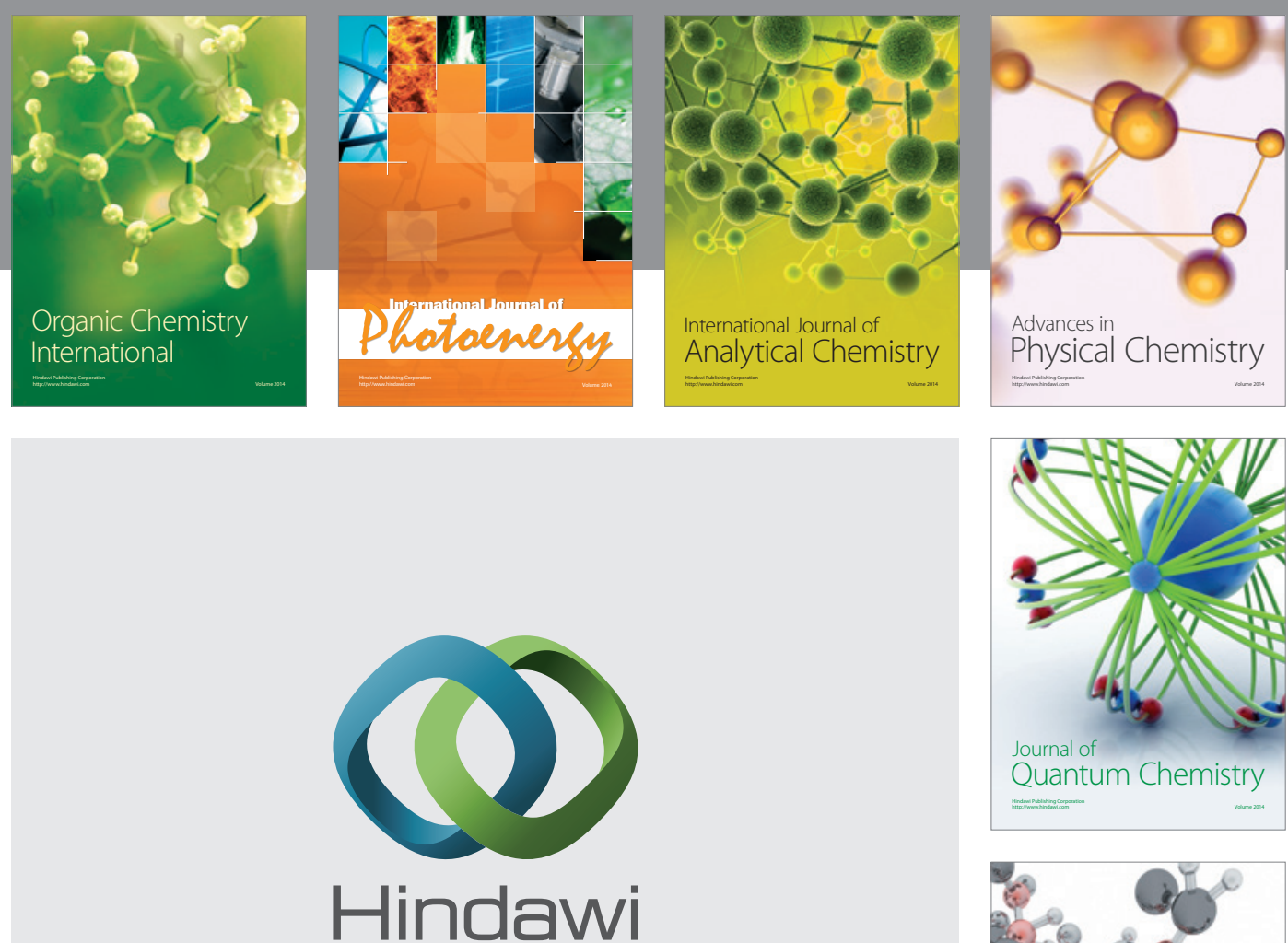

Submit your manuscripts at

http://www.hindawi.com

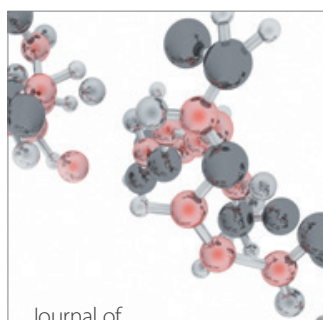

Analytical Methods

in Chemistry

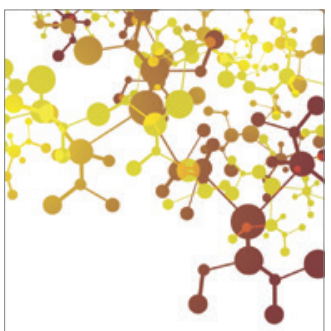

Journal of

Applied Chemistry

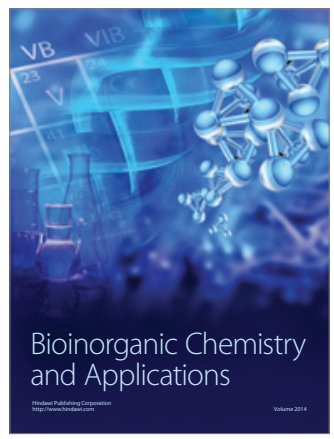

Inorganic Chemistry
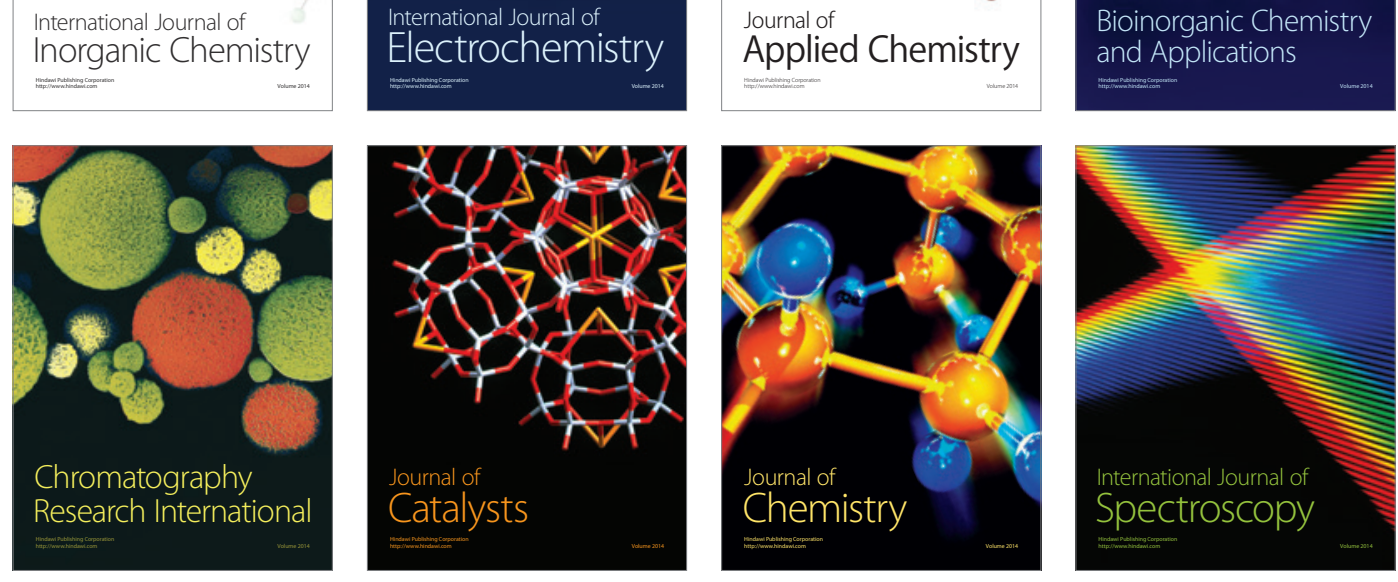